\title{
Carotid baroreflex activation : a novel method to treat resistant hypertension
}

Citation for published version (APA):

Scheffers, I. (2010). Carotid baroreflex activation : a novel method to treat resistant hypertension. [Doctoral Thesis, Maastricht University]. Datawyse / Universitaire Pers Maastricht. https://doi.org/10.26481/dis.20100312is

Document status and date:

Published: 01/01/2010

DOI:

$10.26481 /$ dis.20100312is

Document Version:

Publisher's PDF, also known as Version of record

\section{Please check the document version of this publication:}

- A submitted manuscript is the version of the article upon submission and before peer-review. There can be important differences between the submitted version and the official published version of record.

People interested in the research are advised to contact the author for the final version of the publication, or visit the DOI to the publisher's website.

- The final author version and the galley proof are versions of the publication after peer review.

- The final published version features the final layout of the paper including the volume, issue and page numbers.

Link to publication

\footnotetext{
General rights rights.

- You may freely distribute the URL identifying the publication in the public portal. please follow below link for the End User Agreement:

www.umlib.nl/taverne-license

Take down policy

If you believe that this document breaches copyright please contact us at:

repository@maastrichtuniversity.nl

providing details and we will investigate your claim.
}

Copyright and moral rights for the publications made accessible in the public portal are retained by the authors and/or other copyright owners and it is a condition of accessing publications that users recognise and abide by the legal requirements associated with these

- Users may download and print one copy of any publication from the public portal for the purpose of private study or research.

- You may not further distribute the material or use it for any profit-making activity or commercial gain

If the publication is distributed under the terms of Article $25 \mathrm{fa}$ of the Dutch Copyright Act, indicated by the "Taverne" license above, 


\section{Carotid baroreflex activation}

a novel method to treat resistant hypertension 
Soms is er zo veel wat we voelen

maar zo weinig wat we kunnen zeggen

(C) 2010 Ingrid Scheffers, Maastricht

Cover design: Ron Ras

Layout: Tiny Wouters

Production: Datawyse | Universitaire Pers Maastricht

ISBN: 978-90-5278-916-3

The study described in this thesis was financially supported by CVRx. Inc., Minneapolis, MN, USA. 


\title{
Carotid baroreflex activation
}

\author{
a novel method to treat resistant hypertension
}

\begin{abstract}
PROEFSCHRIFT
ter verkrijging van de graad van doctor aan de Universiteit Maastricht, op gezag van de Rector Magnificus, Prof. mr. G.P.M.F. Mols, volgens het besluit van het College van Decanen, in het openbaar te verdedigen op vrijdag 12 maart 2010 om 16.00 uur

door
\end{abstract}

Ingrid Scheffers

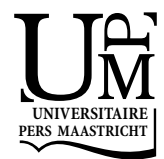


Promotor

Prof. dr. P.W. de Leeuw

\section{Copromotores}

Dr. A.A. Kroon

Dr. J.H.M. Tordoir

Beoordelingscommissie

Prof. dr. H.J. Crijns (voorzitter)

Prof. dr. R.S. Reneman

Prof. dr. J. Schmidli, University Hospital Bern, Switzerland

Prof. dr. P. Sleight, John Radcliff Hospital, Oxford, United Kingdom

Prof. dr. H.A. Struiker-Boudier 


\section{Contents}

$\begin{array}{lll}\text { Chapter } 1 \text { General introduction } & 7\end{array}$

Chapter 2 Carotid baroreflex activation: Past, present and future 13

Chapter 3 Device profile: Rheos ${ }^{\circledR}$ Baroreflex Hypertension Therapy ${ }^{\mathrm{TM}} \quad 29$ System to treat resistant hypertension

Chapter 4 An implantable carotid sinus baroreflex activating system:

Surgical technique and short-term outcome from a multi-center feasibility study for the treatment of resistant hypertension

Chapter 5 Novel carotid baroreflex activation therapy in resistant hypertension: 57 Results of a European multi-center feasibility and proof-of-principle study

Chapter 6 Effects of chronic baroreceptor stimulation on the autonomic cardiovascular regulation in humans with drug-resistant arterial hypertension

Chapter 7 Chronic carotid baroreceptor stimulation in humans does not induce orthostatic hypotension during head-up tilt

Chapter 8 Renal hemodynamics and neurohormonal profile during chronic carotid baroreceptor stimulation in humans with drug-resistant hypertension

Chapter 9 General discussion

Summary

Samenvatting

Dankwoord

Curriculum vitae 



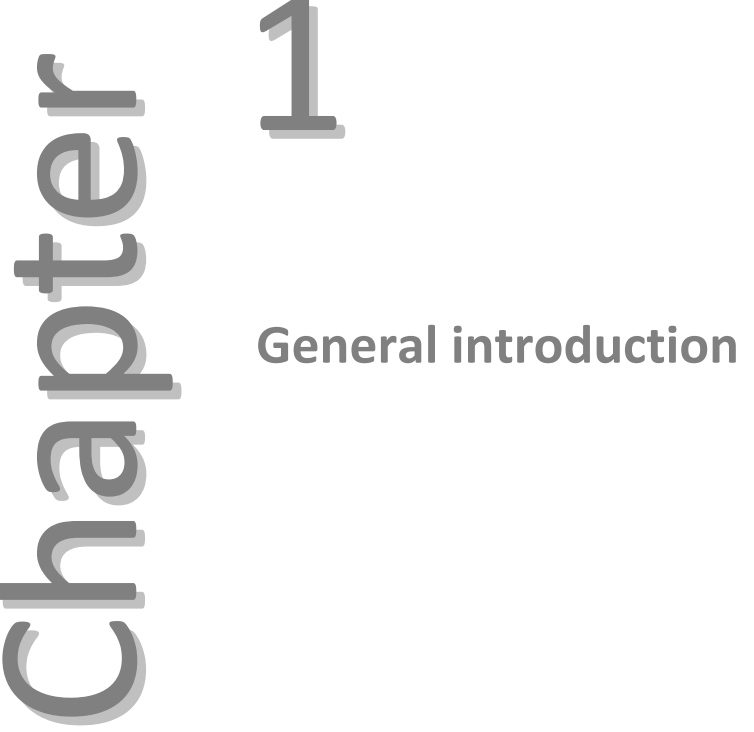





\section{Introduction}

Hypertension is a major clinical problem and is associated with target organ damage and a high added cardiovascular risk ${ }^{1}$. In the majority of cases the underlying cause is unknown and is therefore defined as primary hypertension. The guidelines for hypertension ${ }^{2}$ classify blood pressure based upon the average of two or more readings at each of two or more visits after an initial screen and are defined in Table 1.1. Subjects with hypertension are at increased risk of developing cardiovascular disease. Furthermore, blood pressure is strongly associated with the age-specific mortality rates for stroke, ischemic heart disease, and all vascular diseases ${ }^{3}$. Given the associated morbidity and mortality, the usual treatment goals are aggressive in terms of 'normalizing' blood pressure to levels associated with low cardiovascular risks. Blood pressure should be reduced to at least below 140/90 $\mathrm{mmHg}$, and to lower values in some hypertensive patients ${ }^{4}$. In high risk patients, such as those with diabetes or associated clinical conditions, blood pressure goal should be at least below $130 / 80 \mathrm{mmHg}^{4}$.

Table 1.1 Definition and classification of blood pressure levels.

\begin{tabular}{lcc}
\hline Category & \multicolumn{2}{c}{ Blood pressure $(\mathrm{mmHg})$} \\
& Systolic & Diastolic \\
\hline Normal & $<120$ & $<80$ \\
Pre Hypertension & $120-139$ & $80-89$ \\
Stage 1 Hypertension & $140-159$ & $90-99$ \\
Stage 2 Hypertension & $160-179$ & $100-109$ \\
Stage 3 Hypertension & $\geq 180$ & $\geq 110$ \\
\hline
\end{tabular}

An adequate therapeutic plan should pay attention to lifestyle changes, i.e. smoking cessation, moderation of alcohol consumption, sodium restriction and other dietary changes, weight reduction, and physical exercise. In addition, pharmacological therapy can be prescribed in optimal doses, specified on the individual patient. Initially this may be monotherapy and when required it can be switched to another agent of a different class or extended to combination therapy. When a therapeutic plan that has included attention to lifestyle measures and the prescription of at least three drugs, including a diuretic, in adequate doses has failed to lower blood pressure toward the treatment goal, hypertension is defined as resistant ${ }^{4}$. Despite the availability of different classes of antihypertensive drugs, recent clinical trials have shown that $35 \%$ or more of treated patients did not reach the goal for systolic blood pressure $^{2,5}$. The Antihypertensive and Lipid-Lowering treatment to prevent Heart Attack Trial (ALLHAT), a large clinical trial among patients with hypertension and at least one other risk factor for coronary artery disease, showed that $8 \%$ of the patients were treated with four or more drugs. It has been calculated that a minimum of $15 \%$ would have been classified as having resistant hypertension ${ }^{5}$. In general practice, with 
little selection of patients, the prevalence of resistant hypertension is around $5 \%$. With this prevalence and the high associated risk, a therapy that successfully treats resistant hypertension is urgently needed. A novel method with chronic electrical carotid baroreflex activation is under investigation. This thesis describes the novel method and the first clinical results in drug-resistant hypertensive patients.

\section{Outline of the thesis}

Chapter 2 gives a historical overview of all techniques applied and data collected on electrical activation of the carotid baroreflex system since 1964. Furthermore, it describes recent experience with a new developed device and it describes the future perspectives for carotid baroreceptor stimulation in human. The new developed device (Rheos ${ }^{\circledR}$ Baroreflex Hypertension Therapy ${ }^{\mathrm{TM}}$ System; CVRx. Inc., Minneapolis, MN, USA) is profiled in Chapter 3. Surgical technique with short-term outcome are presented in Chapter 4. Chapter 5 describes the results from a European multi-center feasibility study. In total, 45 participants were included and this chapter shows the safety and efficacy analysis after three months of carotid baroreceptor stimulation and up to two years for the cohort that already completed two years of follow-up. Chapter 6 investigates the effects of chronic electrical carotid baroreflex activation on heart rate variability as measured by 24-hour electrocardiogram registration. We analysed changes in sympathetic and parasympathetic activity in drug-resistant hypertensive patients. In Chapter 7, we investigated the effects on autonomic cardiovascular regulation during supine rest and head-up tilt, in order to measure the effect of one year chronic carotid baroreceptor stimulation on orthostatic blood pressure. The effects on renal hemodynamics are investigated in Chapter 8, to measure whether the decrease in blood pressure affects renal function or the level of activity of the renin-angiotensin-system. Finally, Chapter 9 discusses the main findings presented in this thesis. 


\section{References}

1 Cuspidi C, Macca G, Sampieri L, Michev I, Salerno M, Fusi V, Severgnini B, Meani S, Magrini F, Zanchetti A. High prevalence of cardiac and extracardiac target organ damage in refractory hypertension. J Hypertens 2001;19:2063-2070.

2 Chobanian AV, Bakris GL, Black HR, Cushman WC, Green LA, Izzo JL, Jr., Jones DW, Materson BJ, Oparil S, Wright JT, Jr., Roccella EJ. The Seventh Report of the Joint National Committee on Prevention, Detection, Evaluation, and Treatment of High Blood Pressure: the JNC 7 report. JAMA 2003;289: 2560-2572.

3 Lewington S, Clarke R, Qizilbash N, Peto R, Collins R. Age-specific relevance of usual blood pressure to vascular mortality: a meta-analysis of individual data for one million adults in 61 prospective studies. Lancet 2002;360:1903-1913.

4 Mancia G, De Backer G, Dominiczak A, Cifkova R, Fagard R, Germano G, Grassi G, Heagerty AM, Kjeldsen SE, Laurent S, Narkiewicz K, Ruilope L, Rynkiewicz A, Schmieder RE, Boudier HA, Zanchetti A, Vahanian A, Camm J, De Caterina R, Dean V, Dickstein K, Filippatos G, Funck-Brentano C, Hellemans I, Kristensen SD, McGregor K, Sechtem U, Silber S, Tendera M, Widimsky P, Zamorano JL, Erdine S, Kiowski W, Agabiti-Rosei E, Ambrosioni E, Lindholm LH, Viigimaa M, Adamopoulos S, Agabiti-Rosei E, Ambrosioni E, Bertomeu V, Clement D, Erdine S, Farsang C, Gaita D, Lip G, Mallion JM, Manolis AJ, Nilsson PM, O'Brien E, Ponikowski P, Redon J, Ruschitzka F, Tamargo J, van Zwieten P, Waeber B, Williams B. 2007 Guidelines for the Management of Arterial Hypertension: The Task Force for the Management of Arterial Hypertension of the European Society of Hypertension (ESH) and of the European Society of Cardiology (ESC). J Hypertens 2007;25:1105-1187.

5 Major outcomes in high-risk hypertensive patients randomized to angiotensin-converting enzyme inhibitor or calcium channel blocker vs diuretic: The Antihypertensive and Lipid-Lowering Treatment to Prevent Heart Attack Trial (ALLHAT). JAMA 2002;288:2981-2997.

6 Kaplan NM. Resistant hypertension. J Hypertens 2005;23:1441-1444. 



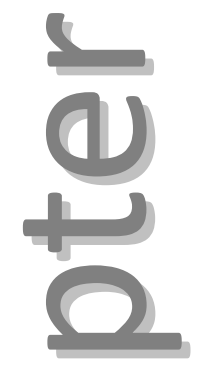

\section{Carotid baroreflex activation:} Past, present and future

IJM Scheffers, AA Kroon, PW de Leeuw 


\section{Abstract}

Electrical activation of the carotid baroreflex system can be an attractive therapy for the treatment of drugresistant hypertension. In the past, several attempts were made to directly activate the carotid baroreceptor system in humans, but the method had to be restricted to only few, selected patients. Side effects, the demand for better electrical devices and better surgical techniques, and the lack of knowledge about the long-term effects has greatly hampered developments in this area for many years. Recently, a new and promising device has been evaluated in a multi-center feasibility study. It shows a clinically and statistically significant reduction in office blood pressure of over $20 \mathrm{mmHg}$ systolic that could be sustained for at least two years with an acceptable safety profile. In the future, this new device may stimulate further application of electrical activation of the carotid baroreflex in drug-resistant hypertension. 


\section{Introduction}

Lowering blood pressure to values below $140 / 90 \mathrm{mmHg}$ is of great value for patients with essential hypertension and in those with co-morbidities, such as diabetes mellitus or renal impairment, the target should even be lower ${ }^{1}$. However, available antihypertensive drugs have limitations and several patients either cannot be controlled by full medical therapy or do not tolerate the side effects. Drug-resistant hypertension, therefore, remains a significant clinical problem in a number of patients. These patients, in particular, could benefit from alternative ways of treatment such as electrical activation of the carotid baroreflex.

The aim of the present review is to summarize early observations on the baroreceptor system and experiments on electrical activation of the carotid baroreflex system that have been performed in the past. These observations and experiments have contributed to our current understanding of the baroreceptor system in the regulation of blood pressure. Furthermore, the recent experiences with a newly developed device, which is still under investigation, are presented. Finally, the future role of carotid baroreflex activation therapy in the treatment of hypertension is discussed.

A comprehensive search strategy was performed of databases (PubMed, MEDLINE and OLDMEDLINE) from 1950 till 2009. The keywords carotid sinus, baroreflex, electrical activation, hypertension and angina pectoris were used in the literature search. Reference lists of found articles were also reviewed for other relevant articles. Articles in another language than English, France, German and Dutch were excluded from this review.

\section{Early observations on the baroreceptor system}

In 1836, Cooper was among the first to describe the role of the baroreceptor system in the regulation of blood pressure ${ }^{2}$. More than 85 years later, Hering demonstrated in dogs, that electrical stimulation of the carotid sinus nerve induced both bradycardia and hypotension, and that transaction of the nerve reversed these changes ${ }^{3}$. He was also able to show that bilateral transection of the carotid sinus nerve resulted in systemic hypertension. Later on, similar results were reported by Korner, who observed in rabbits an increase in blood pressure as well as in cardiac output and heart rate after bilateral transection of the carotid nerves ${ }^{4}$. In addition, several investigators noted that blood pressure became very unstable after denervation of the baroreceptors ${ }^{5-8}$. Taken together, their data suggested that the primary function of the baroreceptor system is to stabilize blood pressure and to prevent large short-term fluctuations in pressure. Accordingly, Guyton and colleagues proposed that the baroreflex system is not important for the long-term regulation of blood pressure and that previous data on the development of hypertension after carotid sinus nerve 
denervation in animals had been highly exaggerated, presumably as a result of methodological errors ${ }^{5,6}$.

Nonetheless, interest in the role of the baroreceptor system in hypertension has continued and a variety of methods have been developed to challenge the system ${ }^{9-19}$. These methods include blocking the carotid sinus area using procaine ${ }^{11}$ or lidocaine ${ }^{13}$ and stimulating it using epinephrine ${ }^{11}$. Other researchers have stimulated the carotid sinus area using the neck cuff technique ${ }^{10,14-19}$. With this device, it was possible to create a negative pressure around the neck which resulted in an increased transmural pressure in the carotid arteries. Such stimulation of the baroreceptor elicited significant decreases in blood pressure, heart rate and cardiac output in both hypertensive and normotensive subjects ${ }^{19}$.

Kubicek and colleagues wondered why the baroreceptor system fails to restore blood pressure to normal levels in hypertensive patients ${ }^{20}$. Using chronic splanchnic nerve stimulation, they discovered the mechanism of resetting of the baroreceptor system. Their data indicated that it is possible for the baroreceptors and/or the central nervous system pathways to adapt to a chronically elevated arterial blood pressure. Subsequently, electro-neurographic studies showed fewer impulses along the carotid sinus nerve in renal hypertensive dogs than in normotensive dogs ${ }^{21}$. These results implied that, once the reflex was reset, the baroreceptor system would act to maintain the blood pressure at the elevated level.

Bristow and colleagues showed that the baroreceptor system in patients with hypertension is not only reset, but also less sensitive ${ }^{22}$. They assessed baroreceptor sensitivity from the relationship between changes in systolic blood pressure and those in R-R intervals after intravenous bolus injections of angiotensin II. Subsequently, several research groups confirmed that the baroreceptor system is less sensitive under conditions of an elevated pressure ${ }^{22-25}$. Angell-James concluded that, at least in rabbits, the reduction in baroreceptor sensitivity is more closely related to the duration of hypertension than to its severity ${ }^{7}$. All these data support the notion that the baroreflex system more or less passively follows the development of hypertension and that activation of the system is unlikely to produce sustained reductions in blood pressure.

\section{Electrical activation of the baroreflex}

\section{Early experiments in animals}

Despite the foregoing, there has been an ongoing interest in devices with which the baroreceptor system could be stimulated. In this respect pioneering work has been done by Bilgutay and colleagues who designed a compact implantable unit with two flat, discoid, stainless steel electrodes that were attached directly to the baroreceptor area and sutured in the wall of the carotid arteries. The unit was triggered 
intermittently by R-waves picked up by an electrode from the heart. In 1964 and 1965 , the investigators reported on the results of their experiments in four different groups of dogs: normotensive, acute neurogenic hypertensive, renal hypertensive and arteriosclerotic ones ${ }^{26,27}$. Bilateral electrical stimulation of the baroreceptor for two hours caused a drop in blood pressure in all dogs, but the best results were seen in hypertensive dogs with decreases in blood pressure ranging from 28 to $100 \mathrm{mmHg}$ systolic and from 12 to $75 \mathrm{mmHg}$ diastolic. Griffith \& Schwartz also designed an implantable device with a bipolar electrode that was attached directly to the carotid sinus nerve ${ }^{28}$. They showed that unilateral electrical stimulation in normotensive and renal hypertensive dogs with or without a sectioned contralateral carotid sinus nerve resulted in a reduction in blood pressure in all animals. After the stimulation had been discontinued, blood pressure quickly returned to baseline levels. A few years later, Neistadt \& Schwartz reported similar results in 14 adult dogs with experimentally induced hypertension ${ }^{29}$. The applied stimulator consisted of an implantable carotid sinus nerve stimulator with two electrodes and an external rechargeable transmitter. On the day of implantation, a decrease of mean arterial pressure by $36 \%$ was measured. During the first month, three dogs died and five extracted their stimulator. Only six dogs were therefore evaluated after one month of carotid nerve stimulation and the average decrease in mean arterial pressure was $30 \%$. After two months, three dogs could be evaluated and at that time the average decrease in pressure was still $23 \%$.

In 1969, Agishi and colleagues reported on their experiments with carotid sinus nerve stimulation in mongrel dogs ${ }^{30}$. Direct stimulation caused a drop in blood pressure in all normotensive and hypertensive dogs. Chronic stimulation was applied in eight hypertensive dogs and all of these responded well. Others have also shown blood pressure reductions in animals subjected to carotid sinus nerve stimulation ${ }^{31-34}$. From these experiments one can conclude that stimulation of the carotid baroreceptor or carotid sinus nerve can, indeed, lower blood pressure, at least in experimental animals.

\section{Early experiments in humans}

Carlsten and colleagues were the first to report on the effects of brief episodes of direct carotid sinus stimulation in humans ${ }^{35}$. They studied five patients with neck cancer, in whom the cancer process made a dissection of the carotid sinus region necessary. Their findings were identical to those obtained in animal experiments. Electrical stimulation of the carotid sinus nerve caused a typical response with a prompt fall in mean blood pressure, pulse amplitude and heart rate. In 1966, Bilgutay \& Lillehei reported on the results of the first two patients who were treated with an electronic implantable device for a period of up to 12 months ${ }^{36}$. Both patients experienced an immediate and significant reduction in blood pressure of 70/35 and $100 / 40 \mathrm{mmHg}$, respectively. In the first patient, blood pressure remained at the lower 
level, but in the second one pressure showed a tendency to return toward baseline levels. At about the same time, Schwartz and colleagues published their results on chronic electrical stimulation of the carotid sinus nerve in eleven humans ${ }^{37}$ : Eight patients, who had been subjected to carotid sinus nerve stimulation for periods varying between five months and two and a half years, were treated successfully with a sustained reduction in blood pressure between 30 and $100 \mathrm{mmHg}$ systolic and between 24 and $80 \mathrm{mmHg}$ diastolic. Two patients responded only minimally to carotid sinus nerve stimulation and one died of renal failure two months postoperatively.

Since these initial observations several investigators have applied electrical activation of the baroreflex system in patients with resistant hypertension and also in those with severe angina pectoris.

\section{Hypertension}

Altogether, 64 cases of chronic electrical activation of the baroreflex system in the treatment of hypertension have been reported (Table 2.1) ${ }^{36-57}$. In 44 of these a significant reduction in blood pressure, ranging from 15 to $130 \mathrm{mmHg}$ systolic and from 10 to $80 \mathrm{mmHg}$ diastolic, was shown after electrical stimulation with follow-up periods ranging from one to 37 months. In one study with three patients the follow-up period was not specified ${ }^{42}$. Eight of these 44 well-responsive patients did not receive any antihypertensive drugs anymore ${ }^{37,50}$. Two patients had a minimal response ${ }^{37}$ and two patients had no response at all to electrical stimulation ${ }^{53}$. Most of the remaining 16 patients had a favorable response initially, but they died, stopped or were lost to follow-up within three months after implantation. Two patients died because of stroke, three because of renal failure, two patients because of pulmonary embolism and another patient died because of hyperkalemia and ventricular arrhythmia ${ }^{36,37,49-}$ 51,57 . In two patients the cause of death was not identified ${ }^{46,51}$. Three patients stopped because of serious side effects, one patient required removal of the stimulator and two patients were lost to follow-up $37,51,54$.

\section{Angina Pectoris}

In 1967, Braunwald and colleagues presented the first report on the relief of angina pectoris by electrical activation of the baroreflex system in humans ${ }^{58}$. Since oxygen requirements of the heart are directly related to heart rate, the inotropic state of the myocardium and intraventricular pressure, these authors felt that if these factors could be reduced, the oxygen demands of the heart would also be diminished, resulting in a decrease in the incapacitating symptoms of angina. 
Table 2.1 Publications on electrical activation of the carotid baroreflex system in treatment of hypertension.

\begin{tabular}{|c|c|c|c|c|c|}
\hline Year & Author(s) & $\begin{array}{l}\text { Earlier publication } \\
\text { on same subjects }\end{array}$ & $\begin{array}{l}\text { Total } \\
\text { cases }\end{array}$ & $\begin{array}{l}\text { Follow-up } \\
\text { (months) }\end{array}$ & Results on BP \\
\hline 1966 & Bilgutay \& Lillehei $^{36}$ & & 2 & 12 & $\begin{array}{l}\text { 1: significant } \downarrow \\
1 \text { : lost to follow-up }\end{array}$ \\
\hline 1967 & Schwartz et al. ${ }^{37}$ & & 11 & $\begin{array}{l}5-30 \\
5-30\end{array}$ & $\begin{array}{l}\text { 6: significant } \downarrow \\
\text { 2: minimal response } \\
\text { 3: lost to follow-up }\end{array}$ \\
\hline 1968 & Khatri \& Cohn ${ }^{42}$ & & 3 & unk & 3: significant $\downarrow$ \\
\hline 1969 & Parsonnet ${ }^{43}$ & Rothfeld et al. ${ }^{43}$ & 1 & 3 & 1: significant $\downarrow$ \\
\hline 1969 & Warembourg et al. ${ }^{46}$ & & 3 & $5-8$ & $\begin{array}{l}\text { 2: significant } \downarrow \\
\text { 1: lost to follow-up }\end{array}$ \\
\hline 1970 & Kaufmann et al. ${ }^{48}$ & & 1 & 1 & 1: significant $\downarrow$ \\
\hline 1970 & Torresani et al. ${ }^{49}$ & $\begin{array}{l}\text { Jouve }^{41} \\
\text { Torresani et al. }^{39} \\
\text { Torresani et al. }^{40}\end{array}$ & 3 & $12-15$ & $\begin{array}{l}\text { 2: significant } \downarrow \\
1 \text { : lost to follow-up }\end{array}$ \\
\hline 1972 & Brest et al. $^{50}$ & Brest $^{47}$ & 8 & $7-16$ & $\begin{array}{l}\text { 6: significant } \downarrow \\
\text { 2: lost to follow-up }\end{array}$ \\
\hline 1972 & Tuckman et al. $^{51}$ & $\begin{array}{l}\text { Reich }^{44} \\
\text { Tuckman et al. }^{38}\end{array}$ & 12 & $4-37$ & $\begin{array}{l}\text { 7: significant } \downarrow \\
\text { 5: lost to follow-up }\end{array}$ \\
\hline 1973 & Both et al. ${ }^{52}$ & & 1 & 6 & 1: significant $\downarrow$ \\
\hline 1973 & Ernst et al. $^{53}$ & & 5 & $5-10$ & $\begin{array}{l}\text { 3: significant } \downarrow \\
\text { 2: no response }\end{array}$ \\
\hline 1973 & Wagner et al. ${ }^{54}$ & & 5 & $2-18$ & $\begin{array}{l}\text { 4: significant } \downarrow \\
1 \text { : lost to follow-up }\end{array}$ \\
\hline 1975 & Solti et al. ${ }^{55}$ & & 1 & 13 & 1: significant $\downarrow$ \\
\hline 1977 & Myers $^{56}$ & & 1 & 96 & 1: significant $\downarrow$ \\
\hline 1980 & Saadjian et al. ${ }^{57}$ & & 7 & $10-36$ & $\begin{array}{l}\text { 5: significant } \downarrow \\
\text { 2: lost to follow-up }\end{array}$ \\
\hline
\end{tabular}

In total, 135 cases of chronic electrical stimulation in the treatment of angina pectoris

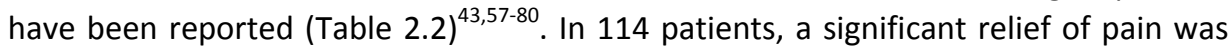
shown, with follow-up periods ranging from one to 132 months. Four patients experienced only a minimal response and three patient had no sustained relief of pain after electrical activation of the baroreflex system ${ }^{57,67,68}$. The remaining 14 patients died within one month after implantation ${ }^{43,57,67,68,78,79}$. In nine cases the cause of death was related to the procedure, for instance bradycardia, ventricular fibrillation, heart failure, myocardial infarction and pulmonary infarction. 
Table 2.2 Publications on electrical activation of the carotid baroreflex system in treatment of angina pectoris.

\begin{tabular}{|c|c|c|c|c|c|}
\hline Year & Author(s) & $\begin{array}{l}\text { Earlier publication } \\
\text { on same subjects }\end{array}$ & $\begin{array}{l}\text { Total } \\
\text { cases }\end{array}$ & $\begin{array}{l}\text { Follow-up } \\
\text { (months) }\end{array}$ & Results on AP \\
\hline \multirow[t]{2}{*}{1968} & Hyman et al. $^{60}$ & & 1 & 3 & 1: significant $\downarrow$ \\
\hline & Elliott et al. ${ }^{61}$ & & 2 & $4-5$ & 2: significant $\downarrow$ \\
\hline 1969 & Parsonnet. $^{43}$ & & 1 & & 1: lost to follow-up \\
\hline 1969 & Zeft $^{66}$ & & 1 & 3 & 1: significant $\downarrow$ \\
\hline 1970 & Braunwald et al. ${ }^{67}$ & $\begin{array}{l}\text { Epstein et al. }{ }^{62} \\
\text { Epstein et al. }^{63} \\
\text { Braunwald et al. }^{58}\end{array}$ & 21 & $2-24$ & $\begin{array}{l}\text { 16: significant } \downarrow \\
\text { 1: no response } \\
\text { 4: lost to follow-up }\end{array}$ \\
\hline 1970 & Farrehi $^{68}$ & & 4 & unk & $\begin{array}{l}\text { 2: } \text { significant } \downarrow \\
\text { 1: } \text { minimal response } \\
\text { 1: lost to follow-up }\end{array}$ \\
\hline 1971 & Dart et al. ${ }^{59}$ & & 13 & $1-8$ & 13: significant $\downarrow$ \\
\hline 1971 & Helmer $^{72}$ & & 3 & $3-17$ & 3: significant $\downarrow$ \\
\hline 1971 & Yatteau $^{73}$ & & 1 & 7 & 1: significant $\downarrow$ \\
\hline 1972 & Dennison \& Lulu $^{74}$ & & 1 & 9 & 1: significant $\downarrow$ \\
\hline 1972 & Dunning $^{75}$ & $\begin{array}{l}\text { Dunning et al. }{ }^{71} \\
\text { Keeman et al. }\end{array}$ & 12 & $6-36$ & 12: significant $\downarrow$ \\
\hline 1972 & Gach \& Fourny ${ }^{76}$ & & 1 & 6 & 1: significant $\downarrow$ \\
\hline 1973 & Wagner et al. ${ }^{78}$ & Schaede \& Wagner ${ }^{65}$ & 18 & $11-48$ & $\begin{array}{l}\text { 16: significant } \downarrow \\
\text { 2: lost to follow-up }\end{array}$ \\
\hline 1974 & Rotem $^{79}$ & Rotem \& Bernstein ${ }^{69}$ & 13 & $11-50$ & $\begin{array}{l}\text { 10: significant } \downarrow \\
\text { 2: no response } \\
\text { 1: lost to follow-up }\end{array}$ \\
\hline 1975 & Wallin et al. ${ }^{80}$ & Delius et al. ${ }^{77}$ & 4 & $3-6$ & 4: significant $\downarrow$ \\
\hline 1980 & Saadjian et al. ${ }^{57}$ & Courbier et al. $^{70}$ & 39 & $12-132$ & $\begin{array}{l}\text { 31: significant } \downarrow \\
\text { 3: minimal response } \\
\text { 5: lost to follow-up }\end{array}$ \\
\hline
\end{tabular}

\section{Problems and side effects}

Despite the initial positive and promising results, electrical activation of the baroreflex system remained restricted to a carefully selected group of patients in only a few institutions ${ }^{47,81}$. Probably, developments in this area have been hampered by the introduction of newer, more effective and better tolerated antihypertensive drugs at that same time ${ }^{82}$. But also several questions remained unanswered and several problems remained unresolved. One of these is where the electrodes should be placed $^{45}:$ In the majority of the treated humans the electrodes were placed on the carotid sinus nerves, even though experiments in animals with placement of the electrodes on the carotid arteries also showed good results. No advantages or disadvantages for a certain position of the electrodes were mentioned in the literature, but a nerve seems more fragile than an artery and risks for trauma and devascularization are greater with dissection of the nerve than with dissection of the artery $^{83}$. The surgical techniques were limited at that time and better techniques were necessary to limit the risks and to shorten the duration of the implant procedure. 
Another problem refers to the site of stimulation ${ }^{45}$ : Parsonnet and colleagues showed similar effects on blood pressure during bilateral nerve stimulation and unilateral stimulation of the most responsive nerve ${ }^{83}$. In contrast, Schwartz and colleagues demonstrated that bilateral stimulation was more effective than the summation of the pressure reduction resulting from unilateral stimulation of the two nerves ${ }^{37}$. It is difficult to determine preoperatively which is the most responsive nerve and differences in responsiveness could also occur as a result of surgical trauma ${ }^{44,83}$. Another problem is the system of stimulation. In an open-loop system the duration, frequency and amplitude of the impulses have to be fixed after testing to find out the most optimal adjustments. Possible changes in the sensitivity of the baroreceptors or the effect of the stimulation are not taken into consideration because there is no feedback of the actual cardiovascular status to the stimulator. From this point of view, the introduction of a feedback-loop can improve the possibilities of electrical activation of the baroreflex system ${ }^{84,85}$. In experimental studies, where closed-loop stimulation has been compared to open-loop stimulation, all patients achieved similar hemodynamic results, but with lower intensity of stimulation in the closed-loop stimulation system ${ }^{84}$.

Finally, a problem to consider is the long-term effects of the procedure. There is still a lot uncertainty about damage and degeneration of the sinus nerve fibers and nerve fatigue and resetting of the baroreceptor mechanism after a long period of electrical stimulation $^{29,37,51}$. Besides, little is known about long-term effects on the function of the heart and other organs ${ }^{43,45}$. Proper investigation of chronic stimulation is important to evaluate the long-term effects of baroreflex activation.

Beside these problems, the reported side effects could have played a role in hampering the developments in this area ${ }^{44,51,84,86}$. The most obvious side effect associated with the use of electrical stimulators is the occurrence of pain in the mandible, teeth, external auditory canals, throat and chest and in the postauricular, posterior neck and suboccipital regions ${ }^{30,37,50-52,74}$. Also side effects like dysphonia, dysphagia, hyperpnea, tachypnea, laryngospasm, gagging, coughing, oedema around the electrodes and hypotension have been reported $37,44,51,66,73$. These side effects were caused by non-optimal settings of the stimulator, leakage or spread of the electrical signal from the electrodes and improper positioning of the electrodes. Improper positioning of the electrodes can weaken or disturb the electrical signals ${ }^{37,86}$. It can also lead to stimulation of muscle fibers or motor nerves with subsequent contraction of adjacent muscles ${ }^{30,74}$.

\section{Recent developments}

Nowadays, the sympathetic nervous system has moved toward the center of cardiovascular medicine, since it seems to be a key factor in the genesis of essential hypertension $^{87}$. More and more results become available that strongly suggest that 
the baroreceptors play a role in the long-term control of arterial pressure ${ }^{88}$. As a result, there is a growing interest in antihypertensive therapies with beneficial effects on hypertension-related sympathetic activation ${ }^{89,90}$. A few years ago, Lohmeier et al. published the results on prolonged activation of the baroreflex. He showed sustained hypotension in six dogs that were subjected to continuous carotid baroreceptor stimulation for seven days ${ }^{91}$. These results and the fact that improved surgical techniques and modern microelectronics are at hand, it is time to reevaluate the possible role of electrical carotid baroreflex activation in the treatment of patients with resistant hypertension.

Recently, the Rheos $^{\circledR}$ Baroreflex Hypertension Therapy ${ }^{\mathrm{TM}}$ System (CVRx. Inc., Minneapolis, MN, USA) became available. This device has been described in detail previously $^{92}$ and also the surgical technique is described before ${ }^{93}$. In general, the Rheos ${ }^{\circledR}$ System uses bilateral carotid artery stimulation with an open-loop system. The device is totally implantable, consisting of a pulse generator and two leads. It utilizes modern microelectronics and a special lead design for chronic electrical activation of the carotid sinus baroreflex to reduce blood pressure. The two leads conduct the activation energy from the pulse generator to the baroreceptors located on the left and right carotid artery. With a programmer an interface can be made to the pulse generator, which makes it possible to non-invasively control the delivery of the activation energy. The device is multiple programmable with independent output circuits for the left and right lead and with four independent therapies, to optimize the performance. Each therapy has independent control of start and stop times, ramp function, dose settings, burst settings, pulse amplitude, pulse width, pulse frequency and therapy pathway.

Lohmeier and colleagues ${ }^{89,90}$ used the same techniques and electrodes in dogs, but with an externally adjustable pulse generator in stead of an implantable pulse generator. A reduction of mean arterial pressure from 93 to $75 \mathrm{~mm} \mathrm{Hg}$ was seen on the first day of bilateral electrical stimulation. This response was sustained throughout the entire seven days of baroreflex activation. In 2003 the Baroreflex Activation System Study (BRASS) was conducted, in which 11 normotensive participants undergoing carotid endarterectomy were enrolled ${ }^{94}$. The carotid sinus baroreceptors were briefly stimulated under local or general anesthesia through 1-minute incremental intervals. This study demonstrated an average decrease in systolic blood pressure from $144 \mathrm{mmHg}$ to $131 \mathrm{mmHg}$, directly related to the intensity of stimulation.

A case report recently described a patient with malignant hypertension who was successfully treated with the chronic implantable Rheos ${ }^{\circledR}$ System ${ }^{95}$. Now, results from a multi-center feasibility study are available in participants with treatment-resistant hypertension who underwent implantation of the Rheos ${ }^{\circledR}$ System. It shows an acceptable safety profile and a clinically and statistically significant reduction in office blood pressure of over $20 \mathrm{mmHg}$ systolic after three months of stimulation in 
37 participants. A cohort of 17 participants were followed for up to two years and the blood pressure reduction could be sustained.

\section{Future perspectives}

This new device may stimulate further research into the applicability of electrical activation of the carotid baroreflex, not only in treatment-resistant hypertension but also in related cardiovascular disorders. Presently, studies are being undertaken to evaluate carotid baroreflex activation in patients with congestive heart failure. Angina pectoris would be another area where the device could be useful. Of course, there are still many problems that need to be addressed. Apart from technical issues, these relate to the optimal use of the system. For instance, we do not know which settings will give the best results. Currently, frequency and voltage are set empirically but there may be more dynamic ways to stimulate the baroreceptor system. We need to find out how we can best modify the settings in relation to the circadian pattern of blood pressure and heart rate. Also, it is unknown whether both carotid arteries need to be stimulated or that we can do with unilateral stimulation only. Once we know all the preferred settings, there is one more challenge lying ahead of us and that is the closed-loop feedback system. If we are able to build a device that can monitor blood pressure and stimulate the baroreceptor system on demand, as it were, this would be a major breakthrough for patients with hitherto refractory hypertension. 


\section{References}

1 Mancia G, De Backer G, Dominiczak A, Cifkova R, Fagard R, Germano G, Grassi G, Heagerty AM, Kjeldsen SE, Laurent S, Narkiewicz K, Ruilope L, Rynkiewicz A, Schmieder RE, Boudier HA, Zanchetti A, Vahanian A, Camm J, De Caterina R, Dean V, Dickstein K, Filippatos G, Funck-Brentano C, Hellemans I, Kristensen SD, McGregor K, Sechtem U, Silber S, Tendera M, Widimsky P, Zamorano JL, Erdine S, Kiowski W, Agabiti-Rosei E, Ambrosioni E, Lindholm LH, Viigimaa M, Adamopoulos S, Agabiti-Rosei E, Ambrosioni E, Bertomeu V, Clement D, Erdine S, Farsang C, Gaita D, Lip G, Mallion JM, Manolis AJ, Nilsson PM, O'Brien E, Ponikowski P, Redon J, Ruschitzka F, Tamargo J, van Zwieten P, Waeber B, Williams B. 2007 Guidelines for the Management of Arterial Hypertension: The Task Force for the Management of Arterial Hypertension of the European Society of Hypertension (ESH) and of the European Society of Cardiology (ESC). J Hypertens 2007;25:1105-1187.

2 Cooper A. Guy's Hospital Report. In: Heymans C, Neil E, eds. Reflexogenic areas of the cardiovascular system. London: J\&A Churchill; 1858:457.

3 Hering H. Der Karotisdruckversuch. Münch Med Wochenschr 1923;70:1278-1290.

4 Korner PI. The effect of section of the carotid sinus and aortic nerves on the cardiac output of the rabbit. J Physiol 1965;180:266-278.

5 Guyton AC, Coleman TG, Fourcade JC, Navar LG. Physiologic control of arterial pressure. Bull N Y Acad Med 1969;45:811-830.

6 Cowley AW Jr, Liard JF, Guyton AC. Role of baroreceptor reflex in daily control of arterial blood pressure and other variables in dogs. Circ Res 1973;32:564-576.

7 Angell-James JE, George MJ. Time-course of the reduction of baroreceptor sensitivity in experimental hypertensive rabbits. Clin Sci Mol Med Suppl 1976;3:369s-372s.

8 Coleman TG, Guyton AC, Cowley AW, Jr., Bower JD, Norman RA, Jr., Manning RD, Jr. Feedback mechanisms of arterial pressure control. Contrib Nephrol 1977;8:5-12.

$9 \quad$ Koch E. Die Irradiation der pressoreceptorischen Kreislaufreflexe. Klin Wochenschr 1932;11:225-227.

10 Möller F. Der Karotisdruckversuch beim Normalen, bei der Hypertonie und anderen Veranderten Kreislaufeinstellungen im Zusammenhang mit der reflektorischen Selbststeuerung. Arch Kreislaufforsch 1942;10:185-209.

11 Kezdi P. Sinoaortic regulatory system; role in pathogenesis of essential and malignant hypertension. Arch Intern Med 1953;91:26-34.

12 Warner HR. The frequency-dependent nature of blood pressure regulation by the carotid sinus studied with an electric analog. Circ Res 1958;6:35-40.

13 Tuckman J, Slater Sr SR, Mendlowitz M. The carotid sinus reflexes. Am Heart J 1965;70:119-135.

14 Bevegard BS, Shepherd JT. Circulatory effects of stimulating the carotid arterial stretch receptors in man at rest and during exercise. J Clin Invest 1966;45:132-142.

15 Thron HL, Brechmann W, Wagner J, Keller K. Quantitative Untersuchungen über die Bedeutung der Gefassdehungsreceptoren im Rahmen der Kreislauf Homoistase beim wachen Menschen. Pflügers Arch Gesamte Physiol Menschen Tiere 1967;293:68-99.

16 Wagner J, Wachenbauer J, Hilger H. Arterielles Blutdruck- und Herzfrequenzverhalten bei Hypertoniekern unter Anderung des transmuralen Druckes im Karotissinusberiech. Z Kreislaufforsch 1968;57:701-712.

17 Kober G, Arndt JO. Die druck-durchmesser-Beziehung der A. carotis communis des wachen Menschen. Pflügers Arch 1970;314:27-39.

18 Stegemann J, Busert A, Brock D. Influence of fitness on the blood pressure control system in man. Aerosp Med 1974;45:45-48.

19 Bevegard S, Castenfors J, Danielson M. Carotid baroreceptor function in hypertensive patients. Scand J Clin Lab Invest 1977;37:495-501.

20 Kubicek WG, Kottke FJ, Laker DJ, Visscher MB. Adaptation in the pressor-receptor reflex mechanisms in experimental neurogenic hypertension. Am J Physiol 1953;175:380-382.

21 McCubbin JW, Green JH, Page IH. Baroceptor function in chronic renal hypertension. Circ Res 1956;4:205-210.

22 Bristow JD, Honour AJ, Pickering GW, Sleight P, Smyth HS. Diminished baroreflex sensitivity in high blood pressure. Circulation 1969;39:48-54. 
23 Korner PI, Shaw J, West MJ, Oliver JR. Central nervous system control of baroreceptor reflexes in the rabbit. Circ Res 1972;31:637-652.

24 Korner PI, West MJ, Shaw J. Central nervous resetting of baroreceptor reflexes. Aust J Exp Biol Med Sci 1973;51:53-64.

25 Mancia G, Ludbrook J, Ferrari A, Gregorini L, Valentini R, Zanchetti A. Carotid baroreceptor reflex in normotensive and hypertensive subjects. Clin Sci Mol Med Suppl 1976;3:343s-345s.

26 Bilgutay AM, Wingrove RC, Simmons RL, Dahlstrom IJ, Lillehei CW. A new concept in the treatment of hypertension utilizing an implantable electronic device: "Baropacer". Trans Am Soc Artif Intern Organs 1964;10:387-395.

27 Bilgutay AM, Lillehei CW. Treatment of Hypertension with an Implantable Electronic Device. JAMA 1965;191:649-653.

28 Griffith LS, Schwartz SI. Reversal of renal hypertension by electrical stimulation of the carotid sinus nerve. Surgery 1964;56:232-239.

29 Neistadt A, Schwartz SI. Effects of electrical stimulation of the carotid sinus nerve in reversal of experimentally induced hypertension. Surgery 1967;61:923-931.

30 Agishi T, Temples J, Peirce EC, 2nd. Electrical stimulation of the carotid sinus nerve as an experimental treatment of hypertension. J Surg Res 1969;9:305-309.

31 Neufeld HN, Goor D, Nathan D, Fischler H, Yerushalmi S. Stimulation of the carotid baroreceptors using a radio-frequency method. Israel J Med Sci 1965;1:630-632.

32 Myers GH. An experimental radio-frequency carotid-sinus pacemaker. Med Res Eng 1968;7:13-16.

33 Michaelis LL, Gilmore JP. Renal effects of electrical stimulation of the carotid sinus nerve. Surgery 1969;65:797-801.

34 Resnicoff SA, Harris JP, Hampsey JP, Schwartz SI. Effects of sinus nerve stimulation on arterial resistance and flow patterns of specific vascular beds. Surgery 1969;66:755-761.

35 Carlsten A, Folkow B, Grimby G, Hamberger CA, Thulesius O. Cardiovascular effects of direct stimulation of the carotid sinus nerve in man. Acta Physiol Scand 1958;44:138-145.

36 Bilgutay AM, Lillehei CW. Surgical treatment of hypertension with reference to baropacing. Am J Cardiol 1966;17:663-667.

37 Schwartz SI, Griffith LS, Neistadt A, Hagfors N. Chronic carotid sinus nerve stimulation in the treatment of essential hypertension. Am J Surg 1967;114:5-15.

38 Tuckman J, Reich T, Goodman B, Freidman E, Jacobson JH. Effects of radio frequency carotid sinus nerve stimulators in patients with severe hypertension. Circulation Suppl III 1966;33:III-231.

39 Torresani J, Heuillet G, Monties JR, Baille Y, Jouve A, Garcia M. Hypertension artérielle grave. Traitement par stimulation du nerf du sinus carotidien. Arch Mal Coeur Vaiss 1967;60:1032-1040.

40 Torresani J, Heuillet G, Rouvier M, Monties JR, Jouve A, Garcia M. Stimulation électrique du sinus carotidien et régulation de la tension artérielle. Mars Med 1967;104:303-307.

41 Jouve A. La stimulation permanente des sinus carotidiens en pathologie cardio-vasculaire. Rev Med Liege 1969;24:593-597.

42 Khatri IM, Cohn JN. Cardiac and peripheral vascular effects of carotid sinus nerve stimulation in hypertension in man. Clin Res 1968;16:235.

43 Parsonnet V, Rothfeld EL, Raman KV, Myers GH. Electrical stimulation of the carotid sinus nerve. Surg Clin North Am 1969;49:589-596.

44 Reich T. Implantation of carotid sinus nerve stimulator. Aorn J 1969;10:53-56.

45 Rothfeld EL, Parsonnet V, Raman KV, Zucker IR, Tiu R. The effect of carotid sinus nerve stimulation on cardiovascular dynamics in man. Angiology 1969;20:213-218.

46 Warembourg H, Soots G, Pauchant M, Bertrand M, Ducloux G, Delomez M, Carré A, Prez M. Le traitement de l'hypertension artérielle grave par la stimulation bilatérale du nerf du sinus carotidien. A propos de trois observations. Lille Med 1969;14:383-392.

47 Brest AN. Carotid sinus nerve stimulation. Am J Cardiol 1970;26:328-329.

48 Kaufmann H, Piwnica A, Larens P, Virag R, Chetochine F. Traitement d'un cas d'hypertension artérielle par implantation d'un stimulateur sinu-carotidien. Presse Med 1970;78:35-36.

49 Torresani J, Chevalier-Cholat AM, Heuillet G, Jouve A, Henry E. Stimulation du nerf du dinus carotidien et hypertension artérielle. Acta Chir Belg 1970;69:33-41.

50 Brest AN, Wiener L, Bachrach B. Bilateral carotid sinus nerve stimulation in the treatment of hypertension. Am J Cardiol 1972;29:821-825. 
51 Tuckman J, Lyon AF, Reich T, Jacobson JH, 2nd. Evaluation of carotid sinus nerve stimulation in the treatment of hypertension. Ther Umsch 1972;29:382-391.

52 Both A, Reidemeister JC, Hofer I, Kreuzer H, Kuhn H. Die Behandlung der malignen Hypertension mit permanenter Carotissinusnervstimulation. Verh Dtsch Ges Inn Med 1973;79:776-777.

53 Ernst CB, Hansson L, Hunyor SN, Julius S. Stimulering av sinusnerverna med implanterad baropacer vid terapiresistent hypertension. Lakartidningen 1973;70:1166-1168.

54 Wagner J, Wilbrandt R, Kreutzberg B, Olnhoff U. Carotis-Sinusnervenstimulation zur Beeinflussung maligner Hypertonien. Verh Dtsch Ges Inn Med 1973;79:777-781.

55 Solti F, Szabo Z, Kerkovits G, Budai G, Bodor E, Kalmar I. Baropacing of the carotid sinus nerve for treatment of "Intractable" hypertension. Z Kardiol 1975;64:368-374.

56 Myers MG. Clonidine-induced facilitation of baroreceptor reflex. Brith Med J 1977;2:802-803.

57 Saadjian A, Torresani J, Pudddu PE. Clinical interest of carotid sinus nerve stimulation in man. G Ital Cardiol 1980;10:1578-1582.

58 Braunwald E, Epstein SE, Glick G, Wechsler AS, Braunwald NS. Relief of angina pectoris by electrical stimulation of the carotid-sinus nerves. N Engl J Med 1967;277:1278-1283.

59 Dart CH, Scott SM, Nelson WM, Fish RG, Takaro T. Carotid sinus nerve stimulation treatment of angina refractory to other surgical procedures. Ann Thorac Surg 1971;11:348-359.

60 Hyman AL, Pearce CW, Barnes GE. Implantation of an intermittent electrical carotid sinus stimulator for treatment of angina pectoris. J La State Med Soc 1968;120:386-390.

61 Elliott WC, King RD, Ross E, McHenry PL. Carotid sinus nerve stimulation in the treatment of angina pectoris. J Indiana State Med Assoc 1969;62:176-180.

62 Epstein SE, Beiser GD, Goldstein RE, Redwood D, Rosing DR, Glick G, Wechsler AS, Stampfer M, Cohen LS, Reis RL, Braunwald NS, Braunwald E. Treatment of angina pectoris by electrical stimulation of the carotid-sinus nerves. N Engl J Med 1969;280:971-978.

63 Epstein SE, Beiser GD, Goldstein RE, Stampfer M, Wechsler AS, Glick G, Braunwald E. Circulatory effects of electrical stimulation of the carotid sinus nerves in man. Circulation 1969;40:269-276.

64 Keeman JN, Dunning AJ. [Stimulation of the carotid sinus nerve]. Ned Tijdschr Geneeskd 1969;113:1909-1910.

65 Schaede A, Wagner J. Beeinflussung der Angina pectoris durch Carotissinusnerven-Reizung. Erfahrungen mit einem elektronisch gesteuerten Carotissinusnerven-Stimulator. Dtsch Med Wochenschr 1969;94:1717-1720 passim.

66 Zeft HJ, Ruskin J, McGowan RL, Roman L. Hypotension and carotid-sinus-nerve stimulation. New Eng J Med 1969;281:103-104.

67 Braunwald NS, Epstein SE, Braunwald E. Carotid sinus nerve stimulation for the treatment of intractable angina pectoris: surgical technic. Ann Surg 1970;172:870-876.

68 Farrehi C. Stimulation of the carotid sinus nerve in treatment of angina pectoris. Am Heart J 1970;80:759-765.

69 Rotem CE, Bernstein V. Management of intractable angina pectoris by implantation of a carotid sinus nerve stimulator. Can Med Assoc J 1970;103:1263-1265 passim.

70 Courbier R, Torresani J, Houze J, Jouve A, Henry E. Carotid sinus nerve stimulation in angina pectoris. J Cardiovasc Surg 1971;12:231-234.

71 Dunning AJ, Roos JC, Keeman JN. Carotid sinus nerve stimulation in angina pectoris. Folia Med Neerl 1971;14:253-262.

72 Helmer F, Kaindl F, Kohn P, Künhn P, Navrátil J. Karotissinusnerv-Stimulation bei Angina pectoris. Wien Klin Wochenschr 1971;83:753-758.

73 Yatteau RF, Hartman CW, Soule TI, Wagner GS. Laryngospasm induced by a carotid-sinus-nerve stimulator. New Eng J Med 1971;284:709-710.

74 Dennison AD, Jr., Lulu DJ. Carotid sinus nerve stimulation, clinical applications and case report. J lowa Med Soc 1972;62:478-484.

75 Dunning AJ. Electrical stimulation of the carotid sinus nerves. Med Prog Technol 1972;1:75-81.

76 Gach J, Fourny M. Traitement de l'angine de poitrine par stimulation électrique des nerfs sinocarotidiens premiers résultats personnels. Rev Med Liege 1972;27:324-332.

77 Delius W, Wallin G, Hallén A, Sundlöf G. Registrierung sympathischer Nervenaktivität beim Menschen während elektrischer Stimulation der Carotissinusnerven. Verh Dtsch Ges Kreislaufforsch 1973;39: 240-243. 
78 Wagner J, Korsukewitz J, Meyer W, Dittberner KH, Zerbst E, Schaede A. CarotissinusnervenStimulation. Dtsch Med Wochenschr 1973;98:37-43.

79 Rotem CE. Carotid sinus nerve stimulation in the management of intractable angina pectoris: fouryear follow-up. Can Med Assoc J 1974;110:285-288.

80 Wallin BG, Sundlof G, Delius W. The effect of carotid sinus nerve stimulation on muscle and skin nerve sympathetic activity in man. Pflugers Arch 1975;358:101-110.

81 Weidmann P, Keusch G. Behandlung des therapieresistenten Hochdrucks. Verh Dtsch Ges Kreislaufforsch 1977;43:120-131.

82 Barker WF. The surgical treatment of hypertension. Vasc Surg 1977;11:47-51.

83 Parsonnet V, Myers GH, Holcomb WG, Zucker IR. Radio-frequency stimulation of the carotid baroreceptors in the treatment of hypertension. Surg Forum 1966;17:125-127.

84 Korsukewitz J, Wagner J, Dittberner KH, Zerbst E. Methoden zur Verbesserung der elektrischen Carotissinusnerven-Reizung. Klin Wochenschr 1973;51:506-510.

85 Peters TK, Koralewski HE, Zerbst E. The principle of electrical carotid sinus nerve stimulation: a nerve pacemaker system for angina pectoris and hypertension therapy. Ann Biomed Eng 1980;8:445-458.

86 Testerman RL, Hagfors NR, Schwartz SI. Design and evaluation of nerve stimulating electrodes. Med Res Eng 1971;10:6-11.

87 Esler M, Kaye D. Sympathetic nervous system activation in essential hypertension, cardiac failure and phychosomatic heart disease. J Cardiovascular Pharmacol 2000;35:S1-S7.

88 Trasher TN. Baroreceptors and the long-term control of blood pressure. Exp Physiol 2004;89:331-335.

89 Mancia G, Grassi G. Antihypertensive treatment: past, present and future. J Hypertens Suppl 1998;16:S1-S7

90 Grassi G.Sympatehtic deactivation as a goal of nonpharmacologic antihypertensive treatment: rationale and options. Curr Hypertens Rep 2003;5:277-280.

91 Lohmeier TE, Irwin ED, Rossing MA, Serdar DJ, Kieval RS. Prolonged activation of the baroreflex produces sustained hypotension. Hypertension 2004;43:306-311.

92 Scheffers IJ, Kroon AA, Tordoir JH, de Leeuw PW. Rheos ${ }^{\circledR}$ Baroreflex Hypertension Therapy ${ }^{\mathrm{TM}}$ System $^{\mathrm{T}}$ to treat resistant hypertension. Expert Rev Med Devices 2008;5:33-39.

93 Tordoir JH, Scheffers I, Schmidli J, Savolainen H, Liebeskind U, Hansky B, Herold U, Irwin E, Kroon AA, de Leeuw P, Peters TK, Kieval R, Cody R. An implantable carotid sinus baroreflex activating system: surgical technique and short-term outcome from a multi-center feasibility trial for the treatment of resistant hypertension. Eur J Vasc Endovasc Surg 2007;33:414-421.

94 Schmidli J, Savolainen H, Eckstein F, Irwin E, Peters TK, Martin R, Kieval R, Cody R, Carrel T. Acute device-based blood pressure reduction: electrical activation of the carotid baroreflex in patients undergoing elective carotid surgery. Vascular 2007;15:63-69.

95 Mohaupt MG, Schmidli J, Luft FC. Management of uncontrollable hypertension with a carotid sinus stimulation device. Hypertension 2007;50:825-828. 



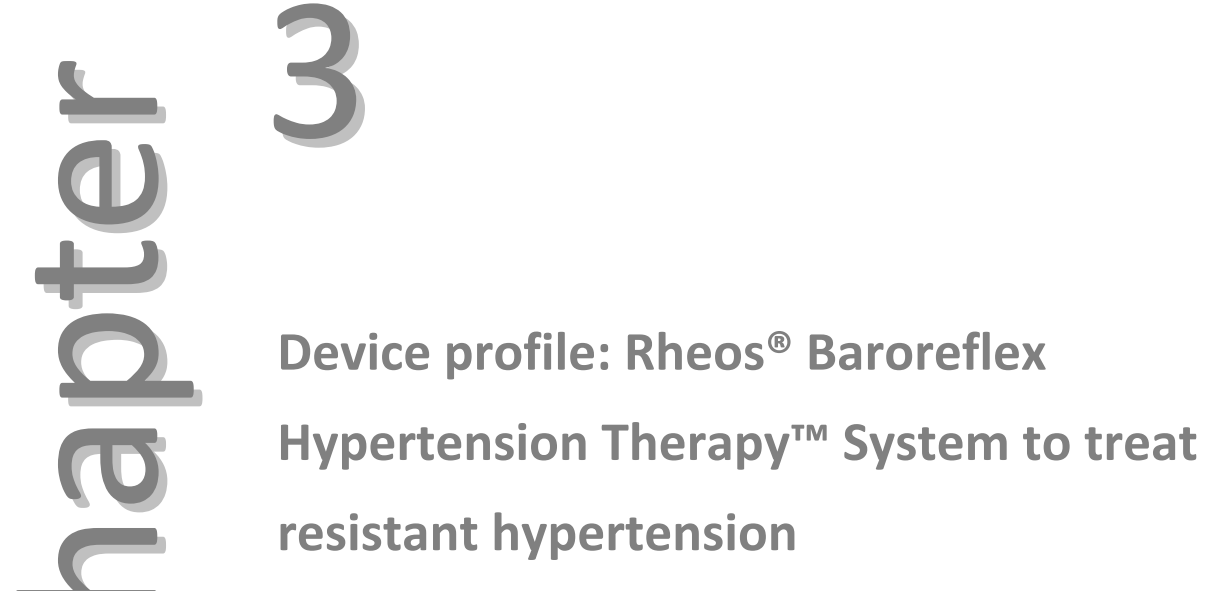

IJM Scheffers, AA Kroon, JHM Tordoir, PW de Leeuw Expert Rev Med Devices 2008;5:33-39 


\section{Abstract}

Resistant hypertension has a high prevalence and is associated with high morbidity and mortality. The Rheos $^{\circledR}$ Baroreflex Hypertension Therapy ${ }^{\mathrm{TM}}$ System is an implantable device which offers a completely new approach to treat patients with resistant hypertension by electrically activating the carotid baroreflex. Preliminary results from current feasibility clinical studies have shown sustained decreases in blood pressure after one year. The pivotal trial for US FDA approval and market release is currently ongoing. This article profiles the Rheos ${ }^{\circledR}$ System and evaluates the treatment of resistant hypertension in general. 


\section{Introduction}

Hypertension is a major clinical problem and is associated with target organ damage and a high added cardiovascular risk ${ }^{1}$. Despite the availability of different classes of antihypertensive drugs, recent clinical trials have shown that $35 \%$ or more of treated patients did not reach the goal for systolic blood pressure ${ }^{2,3}$. Blood pressure should be reduced to at least below 140/90 $\mathrm{mmHg}$, and to lower values in some hypertensive patients ${ }^{4}$. In high risk patients, such as those with diabetes or associated clinical conditions, the blood pressure goal should be below $130 / 80 \mathrm{mmHg}^{4}$. When a therapeutic plan that has included attention to lifestyle measures and the prescription of at least three drugs, including a diuretic, in adequate doses has failed to lower blood pressure toward the treatment goal, hypertension is defined as resistant ${ }^{4}$. The Antihypertensive and Lipid-Lowering treatment to prevent Heart Attack Trial (ALLHAT), a large clinical trial among patients with hypertension and at least one other risk factor for coronary artery disease, showed that $8 \%$ of the patients were treated with four or more drugs. It has been calculated that a minimum of $15 \%$ would have been classified as having resistant hypertension ${ }^{2}$. In general practice, with little selection of patients, the prevalence of resistant hypertension is around $5 \%{ }^{5}$. With this prevalence and the high associated risk, a therapy that successfully treats resistant hypertension is urgently needed.

The Rheos ${ }^{\circledR}$ Baroreflex Hypertension Therapy ${ }^{\text {TM }}$ System (CVRx. Inc., Minneapolis, MN, USA) is an implantable medical device with a novel approach to treat patients with resistant hypertension. This device lowers blood pressure with electrical activation of the carotid baroreflex. Clinical feasibility studies in Europe and the USA evaluate device safety and effectiveness ${ }^{6-8}$. Recently, a pivotal trial was started to further investigate the safety and effectiveness in a double-blind, randomized design. Information obtained in the feasibility studies supported CE-Mark approval of the Rheos $^{\circledR}$ System on 29 October 2007. Information obtained in the pivotal trial will support the pre-market approval application to the US FDA.

\section{Overview of the market}

Hypertension is often difficult to treat for various reasons. To combat these reasons, alternative interventions or additional therapies are available. If the cause of resistant hypertension is unknown, the only possibility at this time is to prescribe more antihypertensive drugs ${ }^{4}$. So far, the optimal choice of additional drugs has not been properly investigated and side effects, maladaptive responses and contraindications may limit the possible combinations.

Sympathetic hyperactivity has often been suggested to play an important role in essential hypertension ${ }^{9-11}$. Numerous studies that employed microneurography, to directly estimate muscle sympathetic nerve activity, have provided evidence for this 
hypothesis ${ }^{12-16}$. Studies with spectral analysis of heart rate and blood pressure, to indirectly yield information about the relative activity of sympathetic and parasympathetic systems ${ }^{17,18}$ and also studies with plasma catecholamine assays ${ }^{19}$, lend support for this view. Sympathetic hyperactivity has been detected in patients with various degrees of blood pressure elevation ${ }^{20,21}$ and the hyperactivity increases progressively from the normotensive to the moderately and more severe states ${ }^{13,15}$. Altogether, it is more than likely that sympathetic hyperactivity plays a role in both the initiation and the maintenance of hypertension ${ }^{16,20-22}$. As a result, there is a growing interest in the ability of antihypertensive therapies to exert beneficial effects on hypertension-related sympathetic activation ${ }^{23,24}$. This new approach is especially interesting in the treatment of resistant hypertension, since no alternative therapies are available at this moment.

The Rheos ${ }^{\circledR}$ System offers a novel therapy to treat resistant hypertension by activating the carotid baroreflex to reduce sympathetic tone. In fact, this therapy is based on an old therapeutic concept. In the past, several devices and techniques were described and tested. Despite initial success, investigation was limited to some case reports ${ }^{25-27}$ and only a few pilot studies ${ }^{28-30}$. Technical difficulties hampered further investigation, and introduction of more effective and better tolerated antihypertensive drugs at that same time hampered further development of the techniques. The current technology used in the Rheos ${ }^{\circledR}$ System is much more advanced and improved from earlier technology that was used in former investigations.

\section{How the device works}

The implantable components of the Rheos ${ }^{\circledR}$ System are shown in Figure 3.1. It consists of an implantable pulse generator (IPG) and a left and right carotid sinus lead (CSL). The IPG contains a battery and circuitry in a hermetic enclosure, that provides control and delivery of the activation energy. It measures a height, width and thickness of 90 , 48 and $12 \mathrm{~mm}$, respectively, with a weight of $95 \mathrm{~g}$. Two lead bores, at the upper right side of the IPG are used to connect both CSLs. The CSL measures a length of $50 \mathrm{~cm}$ to bridge the distance between the carotid sinus and the IPG and it contains an active area with a pseudo tripolar electrode, which is placed around the carotid sinus. A right and left configuration of the CSL are available and the electrode backer size and electrode coil dimensions distinguish a small and large model (distance between outer electrode coils is 10 and $14 \mathrm{~mm}$, respectively). In general, the small model provides an active area which covers the free wall of the carotid sinus. The large model of the CSL provides a larger active area and is used in large arteries or large anatomic variants of the carotid sinus.

During the surgical implant procedure, which has recently been described in detail by Tordoir et al. ${ }^{31}$ and also by Illig et al. ${ }^{32}$, both carotid sinuses are exposed and an appropriate lead model is chosen based on visual examination of the exposed sinus. 
The active area of the electrode is placed around the carotid sinus at the location with the highest density of baroreceptors. To keep the electrode in place, the suture pads of the electrode are affixed to the carotid adventitia with non-absorbable suture material. The optimal location for electrode placement (i.e. the location with the highest density of baroreceptors) is not visible and, therefore, is identified using a mapping procedure. During mapping, the electrode is placed at different locations on the carotid bifurcation in the area of the carotid sinus. Changes in blood pressure and heart rate due to activation of the Rheos ${ }^{\circledR}$ System are measured for every location, to identify the location with the largest hemodynamic response. That location is used for electrode placement and fixation.

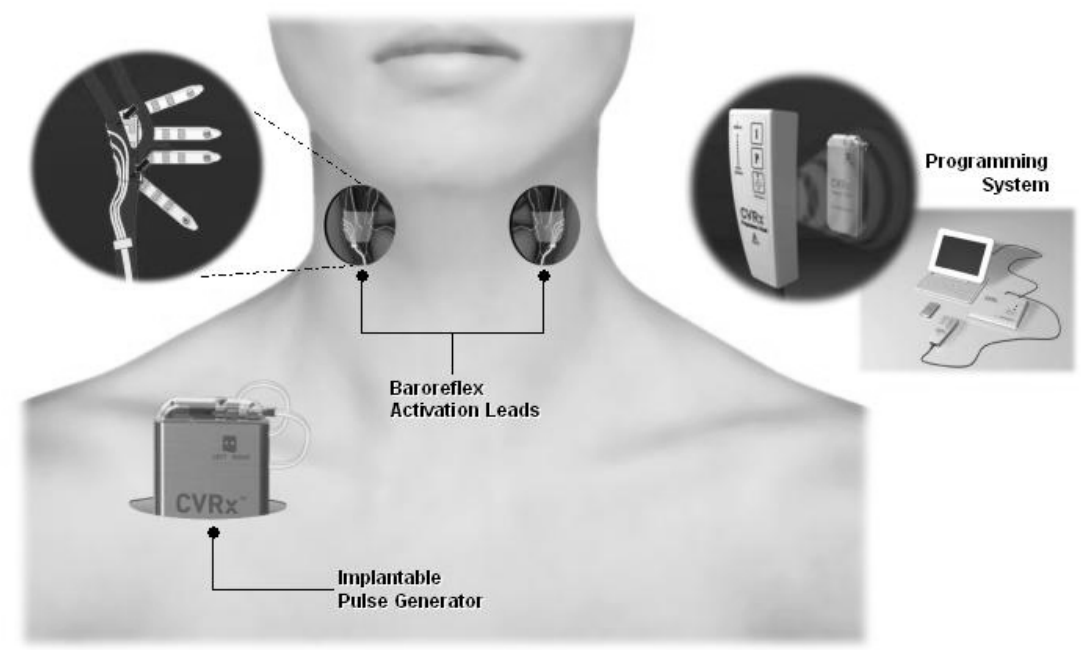

Figure 3.1 Rheos ${ }^{\circledR}$ System.

The implantable components of the Rheos ${ }^{\circledR}$ System consists of an implantable pulse generator and a left and right carotid sinus lead. The external programming system consists of a computer with specific software and a programmer unit with an interface head.

The leads are tunnelled subcutaneously toward the IPG, which is placed under the skin near the collarbone. The IPG delivers chronic activation energy through both CSLS to the left and right carotid sinuses. This energy stimulates the carotid baroreceptors and as a consequence the carotid baroreflex is activated. The baroreflex generates increased afferent nerve impulses that stimulates the cardio-inhibitory center and inhibits the vasomotor center. As a result, sympathetic outflow is inhibited and parasympathetic outflow is raised. This leads to modulation of the autonomic nervous system, neurohormonal activity and the function of key target organs, including the heart, kidneys and peripheral vasculature to decrease blood pressure. 
Via a bidirectional telemetry interface to the IPG, it is easy to non-invasively control the method in which the IPG delivers the activation energy and to retrieve information regarding the status of the IPG. This interface is possible using the Rheos ${ }^{\circledR}$ Programmer System, which is shown in Figure 3.1. It consists of an interface head connected to a computer with specific software. This software allows a 24-hour programming scheme, with up to four different therapies, adapted to the needs of each individual patient. Parameters for each therapy are set independently. Four parameters, that can affect the hemodynamic response, are actively used. These include pulse amplitude, pulse width, pulse frequency and pathway. The pathway can be programmed to left, right, bilateral or alternating stimulation. Preferably, the device is programmed to the pathway (left or right) that yields the greatest response. Bilateral therapy is only recommended for those patients, which require it to achieve the desired response. Increasing amplitude and/or decreasing pulse width is likely to result in a greater reduction in blood pressure. The pulse amplitude is most frequently adjusted to determine the desired reduction in blood pressure.

\section{Cost-effectiveness}

Uncontrolled high blood pressure directly leads to higher healthcare costs owing to more physician visits, more drug prescriptions and more diagnostic tests ${ }^{33}$. On a long term, it is related to cardiovascular morbidity and mortality. Cardiovascular morbidity further raises health care costs, due to more frequent hospitalizations with a longer duration and treatment of associated diseases ${ }^{34}$.

The Rheos $^{\circledR}$ System will increase health care costs for the device, initial surgical implantation and surgical battery replacements. The estimated longevity of the current IPG is 2-4 years. Managing of the program parameters can easily be incorporated in the standard treatment. However, when this Rheos ${ }^{\circledR}$ System is able to effectively treat uncontrolled high blood pressure in resistant hypertensive patients, it will reduce the need for more drug prescriptions, medical check-ups and diagnostic tests in this patient group. Besides, it is hoped that the number of antihypertensive drugs may be reduced in a sizable proportion of patients treated with the Rheos ${ }^{\circledR}$ System. Furthermore, long-term risks for cardiovascular morbidity and mortality will decrease, and costs associated with these co-morbidities will be reduced.

Overall, using the Rheos ${ }^{\circledR}$ System will initially increase costs for the treatment of resistant hypertensive patients, but is anticipated to reduce the long-term health care costs in many of treated patients. Exact information regarding cost-effectiveness of the Rheos ${ }^{\circledR}$ System is limited at this moment and should be part of future evaluations. 


\section{Pre-commercialization process}

A Quality System was established, documented and implemented in laboratory studies to ensure that the Rheos ${ }^{\circledR}$ System conforms to all specified requirements. Animal studies, a human activation study and feasibility studies have been completed and some continue to be implemented. A pivotal trial is currently in process. CVRx is currently certified to ISO 13485.

\section{Animal studies}

Safety evaluations using Good Laboratory Practice (GLP) were performed in normotensive canine and ovine models. It showed an acceptable safety profile in 12 canines being followed for one, three and six months. It also showed significant reductions in mean blood pressure at initial activation $(17.5 \mathrm{mmHg}, P<0.001)$ and during long-term activation for six months $(22.5 \mathrm{mmHg}, P=0.01)$. Additionally, an extended chronic ovine safety study was initiated to demonstrate safety of the electrodes after 36 months implant duration on an artery of similar diameter to the human carotid artery. Data are complete until one year. No infection nor any signs of erosion, thrombosis or stenosis were seen. Vessel integrity was maintained and inflammation of the vessel wall was not observed.

Additional studies were executed to further investigate the hemodynamic and neurohormonal responses to this therapy in normotensive and hypertensive dogs ${ }^{35-38}$. Overall, baroreflex activation resulted in sustained reductions in blood pressure, heart rate and plasma norepinephrine concentration, and plasma renin activity did not increase. This therapy creates a unique controlled animal model of autonomic cardiovascular regulation that is used to investigate the physiology of the baroreflex and more animal studies are underway.

\section{Human activation study}

In 2003, 11 patients undergoing a carotid endarterectomy procedure participated in an activation study to obtain physiological data and to register lead assessment. Following the exposure of the carotid artery and prior to initiating the endarterectomy, the Rheos ${ }^{\circledR}$ System was tested. The magnitude of the response on systolic blood pressure was variable $(5-80 \mathrm{mmHg})$, but the system was effective at acutely reducing blood pressure in all patients. Several identifiable factors contributed to the variability of blood pressure reduction in response to baroreflex activation. These factors were type of anesthesia, number of intraoperative medications and anatomic variability of the carotid sinus. No extraneous tissue stimulation or other adverse events were reported. 


\section{Feasibility studies}

A multi-center, chronic, prospective, nonrandomized feasibility study with a follow-up period of five years was started in March 2004 in Europe. Another feasibility study with a virtually identical protocol was started one year later in the USA. To be enrolled participants must be diagnosed with resistant hypertension, and all treatable causes for secondary hypertension must be excluded. Main exclusion criteria are baroreflex failure, cardiac arrhythmias, dialysis and carotid atherosclerosis or abnormal anatomy of the carotid bifurcation. Interim information obtained in these studies supported CE-Mark approval.

In total, approximately 60 subjects with resistant hypertension are to be enrolled at 14 centers. Interim results summarizing the European study showed significant decreases in systolic and diastolic blood pressure $(39 \mathrm{mmHg}, P<0.001$ and $26 \mathrm{mmHg}$, $P<0.001$, respectively) after one year of chronic therapy in 13 subjects $^{8}$. It also showed an acceptable safety profile with no failures of system components and no unexpected or unanticipated system- or procedure-related serious adverse events. No events of syncope were reported and first analysis in a subgroup of participants who received one year of chronic therapy with the Rheos ${ }^{\circledR}$ System showed neither change in baroreceptor sensitivity nor evidence of orthostatic hypotension ${ }^{39}$.

\section{Pivotal trial}

Recently, a pivotal trial with comparable exclusion criteria was initiated to support US FDA approval and market release. The trial is designed as a chronic, prospective, randomized double-blinded study. All participants have the device implanted, and at one month after implant they are randomized in a 2:1 ratio into device $\mathrm{ON}$ and device OFF groups, respectively. During the first 6-month period, participants in the OFF-group will not receive therapy, but after this time point, those participants will also have their device turned on. Endpoints will be measured at six and 12 months. This study has a long-term follow-up period on a quarterly basis (after the first year) until FDA approval. The purpose of this pivotal trial is to demonstrate a sustained and clinically significant reduction in blood pressure in the ON-group compared to the OFF-group, and to demonstrate acute and long-term safety of the Rheos ${ }^{\circledR}$ System in drug-resistant hypertensive participants. Up to 50 investigational centers in the USA and Europe will enrol approximately 300 subjects.

\section{Single-center experience at the University Hospital Maastricht}

Since November 2004, 18 participants with drug-resistant hypertension were enrolled in the feasibility study at the University Hospital of Maastricht in the Netherlands. The Rheos ${ }^{\circledR}$ System was successfully implanted in all participants (100\%). Each patient showed a reduction in systolic and diastolic blood pressure and also in heart rate during chronic stimulation with the Rheos ${ }^{\circledR}$ System, with variable magnitude of 
responses. For the 16 participants who have completed three month of stimulation, the average reduction in blood pressure is $25 \pm 17 \mathrm{mmHg}$ systolic and $9 \pm 9 \mathrm{mmHg}$ diastolic and the average reduction in heart rate is $3 \pm 11$ beats $/ \mathrm{min}$. At this time, ten participants have completed two years of follow-up and two participants have completed three years of follow-up with a sustained decrease in blood pressure.

Anesthetic regimen turned out to be very important during the mapping procedure. To identify the desired location for affixing the electrode, measurement of hemodynamic responses to electrical stimulation of the carotid sinus is necessary. Therefore, it is critical during this procedure that agents which blunt the baroreflex are avoided. The precision of electrode placement may be an important determinant in effectiveness of this therapy.

A total of two participants (11\%) developed an infection perioperatively and acute explantation of the complete system was necessary in one patient because of Staphylococcus aureus infection at one electrode. The other case was a sterile infection around the IPG. As a consequence, the IPG was explanted and electrodes were left in situ. Therapy using the Rheos ${ }^{\circledR}$ System is still an option in this patient after implanting a new IPG.

During device testing to determine optimal programming, acute extravascular tissue stimulation was reported in a majority of participants (92\%). It caused a broad spectrum of complaints (i.e. tickling in throat, coughing, pain in teeth and jaws, pain in ears and tears). In all cases, reprogramming of the device to lower parameter settings during chronic programming resolved the complaints. Different combinations of the various parameter settings were used to optimize blood pressure reduction and to avoid oversensitivity to electrical stimulation. Another practical issue was the size and weight of the IPG. It often caused uncomfortable placement (33\%) and/or movement of the IPG during arm and body movements. Only one event resulted in surgical repositioning of the IPG.

\section{Conclusion}

Given the disappointing results of drug treatment in a large proportion of hypertensive patients, interest in alternative therapies has expanded. The interest for new therapies with the ability to exert beneficial effects in hypertension-related sympathetic activation has grown. The Rheos ${ }^{\circledR}$ System reduces sympathetic outflow and increases parasympathetic outflow by activation of the carotid baroreflex. Although the manufacturer faces a lengthy market approval process, experience at our institution and in others indicates that the Rheos ${ }^{\circledR}$ System is promising for the treatment of patients with resistant hypertension. Future design changes of the IPG and the electrodes may resolve practical problems during implant procedure and also during chronic use in daily life. 


\section{Expert commentary}

Available data from the current clinical studies that investigate the effectiveness of the Rheos ${ }^{\circledR}$ System, have shown significant reductions in both systolic and diastolic blood pressure ${ }^{8,31}$. These preliminary results are promising and show the potential for future treatment of resistant hypertensive patients using an implantable device to electrically stimulate the carotid sinuses.

To make application of this Rheos ${ }^{\circledR}$ System possible on a large scale, some recommendations are to be made. The implant procedure time is relatively long, potentially increasing the risk for infection and the occurrence of other procedure-related events. Most time is used for the mapping procedure, to identify the desired location for electrode placement. Development of a new surgical technique for electrode placement or a new electrode design may ease the electrode placement and will shorten the procedure time and, consequently, decrease related risks.

Placement of the IPG in the chest often causes discomfort. Therefore, it is preferable to develop a new model with a smaller size and weight and a higher longevity. It will reduce discomfort, sensitivity and visibility of the IPG and also the number of surgical replacements. In addition, with a higher longevity, the way device programming effects battery longevity becomes less important and will not limit device programming and hence blood pressure reduction.

At last, it is recommended to focus future research on development of new techniques to further improve the device and implant techniques. Preliminary results from the current studies have shown that in some patients, unilateral stimulation of the carotid sinus effectively reduces blood pressure. Unilateral implantation will shorten the procedure time and will reduce the burden for the patient, and the follow-on effect on blood pressure reduction may be comparable with bilateral implantation. Also the design of a closed-loop therapy may improve the device. Currently, the programming scheme of the Rheos ${ }^{\circledR}$ System is fixed, based on the individual 24-hour blood pressure trend. A closed-loop system with feedback information on blood pressure and heart rate, that uses this information to automatically adjust the amount of stimulation, will reduce side effects of under or overstimulation during changes in the individual 24-hour trend.

\section{Five-year view}

In the next five years, experience with the Rheos ${ }^{\circledR}$ System to treat resistant hypertensive patients will be increased and more data will become available from the current feasibility studies and pivotal trial, which may lead to regulatory approvals and market release of the Rheos ${ }^{\circledast}$ System in Europe and the USA. Further advancements in technology will ease the implant procedure and especially electrode placement. Smaller IPG models with increased battery longevity will reduce discomfort and the number of surgical procedures for the patient. 


\section{References}

1 Cuspidi C, Macca G, Sampieri L, Michev I, Salerno M, Fusi V, Severgnini B, Meani S, Magrini F, Zanchetti A. High prevalence of cardiac and extracardiac target organ damage in refractory hypertension. J Hypertens 2001;19:2063-2070.

2 Major outcomes in high-risk hypertensive patients randomized to angiotensin-converting enzyme inhibitor or calcium channel blocker vs diuretic: The Antihypertensive and Lipid-Lowering Treatment to Prevent Heart Attack Trial (ALLHAT). JAMA 2002;288:2981-2997.

3 Black HR, Elliott WJ, Grandits G, Grambsch P, Lucente T, White WB, Neaton JD, Grimm RH, Jr., Hansson L, Lacourciere Y, Muller J, Sleight P, Weber MA, Williams G, Wittes J, Zanchetti A, Anders RJ. Principal results of the Controlled Onset Verapamil Investigation of Cardiovascular End Points (CONVINCE) trial. JAMA 2003;289:2073-2082.

4 Mancia G, De Backer G, Dominiczak A, Cifkova R, Fagard R, Germano G, Grassi G, Heagerty AM, Kjeldsen SE, Laurent S, Narkiewicz K, Ruilope L, Rynkiewicz A, Schmieder RE, Boudier HA, Zanchetti A. 2007 Guidelines for the Management of Arterial Hypertension: The Task Force for the Management of Arterial Hypertension of the European Society of Hypertension (ESH) and of the European Society of Cardiology (ESC). J Hypertens 2007;25:1105-1187.

5 Kaplan NM. Resistant hypertension. J Hypertens 2005;23:1441-1444.

6 Bisognano J, Sloand J, Papademetriou V, Rothstein M, Sica D, Flack J, Pertile T, Kieval R, Cody R. An implantable carotid sinus baroreflex activating system for drug-resistant hypertension: interim chronic efficacy results from the multi-center Rheos feasibilty trial (abstract). Circ 2006;Suppl II:, 575.

7 de Leeuw PW, Kroon AA, Scheffers I, Tordoir J, Schmidli J, Mohaupt M, Allemann Y, Jordan J, Engeli S, Liebeskind U, Luft F, Eckert S, Hansky B, Kieval R, Cody R, Rossing M, Irwin E, Peters T. Baroreflex hypertension therapy with a chronically implanted system: preliminary efficacy and safety results from the Rheos DEBuT-HT study in patients with resistant hypertension (abstract). J Hypertens 2006;24 (suppl 4):S300.

8 Scheffers I, Schmidli J, Kroon AA, Tordoir J, Mohaupt M, Allemann Y, Jordan J, Engeli S, Liebeskind U, Luft F, Eckert S, Hansky B, Cody R, Peters T, de Leeuw PW. Sustained blood pressure reduction by baroreflex hypertension therapy with a chronically implanted system: long-term data from the Rheos DEBuT-HT study in patients with resistant hypertension (abstract). J Hypertens 2007;25(S2): S141-S142

9 Folkow B. Physiological aspects of primary hypertension. Physiol Rev 1982;62:347-504.

10 Mark AL. Regulation of sympathetic nerve activity in mild human hypertension. J Hypertens Suppl 1990;8:S67-75.

11 Mancia G, Grassi G, Giannattasio C, Seravalle G. Sympathetic activation in the pathogenesis of hypertension and progression of organ damage. Hypertension 1999;34:724-728.

12 Grassi G. Role of the sympathetic nervous system in human hypertension. J Hypertens 1998;16: 1979-1987.

13 Grassi G, Cattaneo BM, Seravalle G, Lanfranchi A, Mancia G. Baroreflex control of sympathetic nerve activity in essential and secondary hypertension. Hypertension 1998;31:68-72.

14 Esler M. The sympathetic system and hypertension. Am J Hypertens 2000;13:99S-105S.

15 Schlaich MP, Kaye DM, Lambert E, Sommerville M, Socratous F, Esler MD. Relation between cardiac sympathetic activity and hypertensive left ventricular hypertrophy. Circulation 2003;108:560-565.

16 Smith PA, Graham LN, Mackintosh AF, Stoker JB, Mary DA. Relationship between central sympathetic activity and stages of human hypertension. Am J Hypertens 2004;17:217-222.

17 Mancia G, Ferrari A, Gregorini L, Parati G, Pomidossi G, Bertinieri G, Grassi G, di Rienzo M, Pedotti A, Zanchetti $A$. Blood pressure and heart rate variabilities in normotensive and hypertensive human beings. Circ Res 1983;53:96-104.

18 Parati G. Blood pressure variability: its measurement and significance in hypertension. J Hypertens Suppl 2005;23:S19-25.

19 Goldstein DS. Plasma catecholamines and essential hypertension. An analytical review. Hypertension 1983;5:86-99.

20 Julius S, Majahalme S. The changing face of sympathetic overactivity in hypertension. Ann Med 2000; 32:365-370. 
21 Grassi G, Mancia G. Neurogenic hypertension: is the enigma of its origin near the solution? Hypertension 2004;43:154-155.

22 Grassi G. Counteracting the sympathetic nervous system in essential hypertension. Curr Opin Nephrol Hypertens 2004;13:513-519.

23 Mancia G, Grassi G. Antihypertensive treatment: past, present and future. J Hypertens Suppl 1998; 16:S1-7.

24 Grassi G. Sympathetic deactivation as a goal of nonpharmacologic and pharmacologic antihypertensive treatment: rationale and options. Curr Hypertens Rep 2003;5:277-280.

25 Bilgutay AM, Lillehei CW. Surgical treatment of hypertension with reference to baropacing. Am J Cardiol 1966;17:663-667.

26 Parsonnet V, Rothfeld EL, Raman KV, Myers GH. Electrical stimulation of the carotid sinus nerve. Surg Clin North Am 1969;49:589-596.

27 Solti F, Szabo Z, Kerkovits G, Budai G, Bodor E, Kalmar I. Baropacing of the carotid sinus nerve for treatment of "Intractable" hypertension. Z Kardiol 1975;64:368-374.

28 Schwartz SI, Griffith LS, Neistadt A, Hagfors N. Chronic carotid sinus nerve stimulation in the treatment of essential hypertension. Am J Surg 1967;114:5-15.

29 Brest AN, Wiener L, Bachrach B. Bilateral carotid sinus nerve stimulation in the treatment of hypertension. Am J Cardiol 1972;29:821-825.

30 Tuckman J, Lyon AF, Reich T, Jacobson JH, 2nd. Evaluation of carotid sinus nerve stimulation in the treatment of hypertension. Ther Umsch 1972;29:382-391.

31 Tordoir JH, Scheffers I, Schmidli J, Savolainen H, Liebeskind U, Hansky B, Herold U, Irwin E, Kroon AA, de Leeuw P, Peters TK, Kieval R, Cody R. An implantable carotid sinus baroreflex activating system: surgical technique and short-term outcome from a multi-center feasibility trial for the treatment of resistant hypertension. Eur J Vasc Endovasc Surg 2007;33:414-421.

32 Illig KA, Levy M, Sanchez L, Trachiotis GD, Shanley C, Irwin E, Pertile T, Kieval R, Cody R. An implantable carotid sinus stimulator for drug-resistant hypertension: surgical technique and shortterm outcome from the multicenter phase II Rheos feasibility trial. J Vasc Surg 2006;44:1213-1218.

33 Paramore LC, Halpern MT, Lapuerta P, Hurley JS, Frost FJ, Fairchild DG, Bates D. Impact of poorly controlled hypertension on healthcare resource utilization and cost. Am J Manag Care 2001;7: 389-398.

34 Degli Esposti L, Valpiani G. Pharmacoeconomic burden of undertreating hypertension. Pharmacoeconomics 2004;22:907-928.

35 Lohmeier TE, Irwin ED, Rossing MA, Serdar DJ, Kieval RS. Prolonged activation of the baroreflex produces sustained hypotension. Hypertension 2004;43:306-311.

36 Lohmeier TE, Dwyer TM, Hildebrandt DA, Irwin ED, Rossing MA, Serdar DJ, Kieval RS. Influence of prolonged baroreflex activation on arterial pressure in angiotensin hypertension. Hypertension 2005;46:1194-1200.

37 Lohmeier TE, Hildebrandt DA, Dwyer TM, Barrett AM, Irwin ED, Rossing MA, Kieval RS. Renal denervation does not abolish sustained baroreflex-mediated reductions in arterial pressure. Hypertension 2007;49:373-379.

38 Lohmeier TE, Dwyer TM, Irwin ED, Rossing MA, Kieval RS. Prolonged activation of the baroreflex abolishes obesity-induced hypertension. Hypertension 2007;49:1307-1314.

39 Scheffers I, Kroon AA, Tordoir J, Cody R, De Leeuw PW. Baroreflex sensitivity during chronic therapy with electrical stimulation of the carotid sinus in human (abstract). J Hypertens 2007;25(S2):S288. 


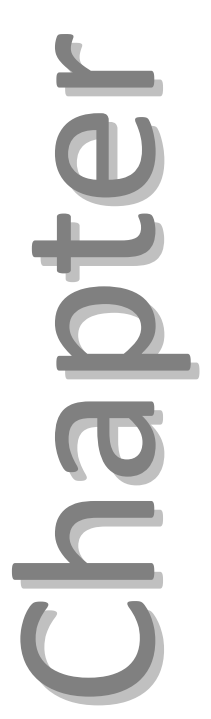

An implantable carotid sinus baroreflex activating system: Surgical technique and short-term outcome from a multi-center feasibility study for the treatment of resistant hypertension

JHM Tordoir, IJM Scheffers, J Schmidli, H Savolainen, U Liebeskind, B Hansky, U Herold, E Irwin, AA Kroon, PW de Leeuw, TK Peters, R Kieval, R Cody 


\section{Abstract}

The present study was intended to assess perioperative outcomes and blood pressure responses to an implantable carotid sinus baroreflex activating system being investigated for the treatment of resistant hypertension.

We report on the first 17 participants enrolled in a multi-center study. Bilateral perivascular carotid sinus leads and an implantable pulse generator are permanently implanted. Optimal placement of the leads is determined by intraoperative blood pressure responses to test activations. Acute blood pressure responses were tested postoperatively and during the first three months of carotid baroreceptor stimulation.

Prior to implant, blood pressure was $190 / 111 \mathrm{mmHg}$ despite stable therapy ( $5 \pm 2$ antihypertensive drugs). The mean procedure time was 202 minutes. No perioperative strokes or deaths occurred. System tests performed one or up to three days postoperatively resulted in significant (all $P \leq 0.001$ ) mean maximum reduction, with $95 \%$ confidence limits for systolic blood pressure, diastolic blood pressure and heart rate of $28(17,39) \mathrm{mmHg}, 16(10,22) \mathrm{mmHg}$ and $8(6,11)$ beats/min, respectively. Repeated testing before and after three months of electrical carotid baroreflex activation demonstrated a durable response.

These preliminary data suggest an acceptable safety of the procedure with a low rate of adverse events and support further clinical development of baroreflex activation as a new concept to treat drug-resistant hypertension. 


\section{Introduction}

The role of vascular surgeons in the treatment of arterial hypertension is usually restricted to the correction of secondary causes of hypertension, such as repair of renal artery stenosis, or resection of pheochromocytoma and aldosterone-producing adenomas. Many other vascular procedures treat the sequelae of atherosclerosis in patients with longstanding uncontrolled arterial hypertension. Even with advances in medical therapy, a significant proportion of hypertensive patients fail to reach their goal blood pressure (BP) due to refractoriness to multi-drug treatment or poor compliance $^{1-8}$. In such patients, new treatment options are needed to reduce hypertension induced cardiovascular morbidity ${ }^{9,10}$.

A key mechanism of BP control, recently re-evaluated as a potential therapeutic approach is the electrical activation of the carotid baroreflex. In the 1960s and 1970s the carotid baroreflex was modulated as part of the treatment of resistant hypertension and refractory angina pectoris. The carotid sinus nerves were chronically stimulated using implanted nerve electrodes and an implantable radiofrequency controlled receiver ${ }^{11-17}$. This technique never became established as a viable therapy for hypertension. This was partially due to the simultaneous development of new agents used in the treatment of hypertension (e.g. Minoxidil and ACE-Inhibitors) and technical limitations. These earlier and more recent observations from data in chronically instrumented animals, demonstrate that the carotid baroreflex can influence the long-term regulation of arterial $\mathrm{BP}^{18-23}$.

A new implantable device (Rheos ${ }^{\circledR}$ System; CVRx. Inc., Minneapolis, MN, USA) activates the carotid baroreflex through electrical stimulation of the carotid sinus wall. Electrodes implanted on the exterior surface of the carotid sinus wall are connected to a battery powered implantable pulse generator (IPG). This concept was initially validated in animal studies ${ }^{19-21}$, and subsequently in patients undergoing elective carotid surgery in which acute unilateral electrical stimulation of the carotid sinus wall reduced $B P$ and heart rate (HR). These hemodynamic effects increased gradually as the amplitude (voltage) of stimulation was increased in a stepwise manner ${ }^{24}$.

For an early assessment of perioperative outcomes and BP responses we now report the perioperative data from the first 17 participants with drug resistant hypertension enrolled in a European multi-center feasibility study ${ }^{25}$. The study protocol hypothesizes that chronic electrical stimulation of the carotid sinus wall added to stable maximal drug therapy will result in sustained reductions of systolic BP of at least $10 \mathrm{mmHg}$ with an acceptable risk benefit ratio.

This preliminary analysis focuses on our early experience and perioperative outcomes and details of the surgical procedure. As such it does not allow full statistical analysis of the prospectively defined primary and secondary outcome variables as planned for the complete study. 


\section{Methods}

The study is currently conducted in six clinical centers in Europe. It was approved by the institutional review board at each participating center, and all participants provided written informed consent before the start of the study. The main eligibility criteria are given in Table 4.1. Participants who fulfill these criteria are enrolled into a prospective, nonrandomized, self-controlled registry of safety and efficacy of BP reduction. To facilitate this assessment the participants antihypertensive regimen is held constant during the first four months of the study unless doing so would compromise patient safety. Per protocol, the first three participants are to be excluded from efficacy and safety analyses. The formal primary endpoints of the study are to be analysed at four month follow-up, i.e. after three months of continuous carotid baroreflex activation. For safety, all adverse events are evaluated and the device- and procedure-related adverse events rate is estimated. For efficacy, the study hypothesis calls for a reduction in office systolic BP of at least $10 \mathrm{mmHg}$ at that time point. A total of 50 participants are to be enrolled in order to yield at least 45 evaluable participants for the primary endpoints.

Table 4.1 Main inclusion and exclusion criteria.

Age: $\geq 20$ years

Bilateral carotid bifurcations located at or below C3-C4

No carotid artery stenosis $>50 \%$

No prior surgery or radiation in the carotid sinus region

Drug-resistant hypertension (not secondary to a treatable cause)

Systolic BP $\geq 160 \mathrm{mmHg}$ and/or diastolic BP $\geq 90 \mathrm{mmHg}$ despite adhering to two months of stable full therapy with at least three antihypertensive medications, of which at least one must be a diuretic

\section{The active implantable device}

The implantable Rheos $^{\circledR}$ System consists of bilateral carotid sinus leads (CSL) and a battery powered, programmable active IPG. Biocompatible materials are used on all surfaces. The CSL conducts the activation energy from the IPG to stimulate the baroreceptor fibers in the vessel walls of both carotid sinuses. These impulses are transmitted to the brainstem, where the increased nerve traffic originating from baroreceptor afferents is interpreted as an elevated BP and results in central nervous system modulation of sympathetic and vagal outflows which reduce BP and HR.

This device is fully programmable by an external system, linked telemetrically to the IPG and allows the physician to non-invasively adjust the stimulation parameters delivered to the CSL. The patient can temporarily disable or turn off the IPG, respectively by using a magnet or a patient wand. Stimulation impulses can be delivered to one or both CSLS. The range of the main programmable electrical parameters is given in Table 4.2 . 
Table 4.2 Stimulation parameters.

\begin{tabular}{lccc}
\hline Sequence of stimuli & Frequency $(\mathrm{Hz})$ & Amplitude $(\mathrm{V})$ & Impulse duration $(\mu \mathrm{s})$ \\
\hline $\begin{array}{l}\text { Continuous stimuli or bursts } \\
\text { of variable duration }\end{array}$ & $10-100$ & $1-7.5$ & $120-760$ \\
& & (in steps of 0.5 V) & \\
\hline
\end{tabular}

\section{Tests of hemodynamic responses to acute device activation}

Electrical parameters can be separately adjusted for each of the two CSLs (left and right) in order to adapt to potential differences in stimulation thresholds and hemodynamic responses.

The standard settings for testing the BP response at least once postoperatively at predischarge and at every follow-up visit are the following: continuous bilateral stimulation with a frequency of $100 \mathrm{~Hz}$ and an impulse width of $480 \mu \mathrm{s}$. Stimulus amplitude in volts $(\mathrm{V})$ is increased in steps of $1 \mathrm{~V}$ from 1-6 V, each for five minutes. Acute changes in office BP and HR are measured with an automated device.

During these acute dose response tests the patient is allowed to rest quietly. The postoperative and 1-month follow-up tests were performed prior to the initiation of chronic carotid baroreceptor stimulation. For subsequent tests, the stimulation was turned off for five to 30 minutes before testing. Acute tests at the follow-up visits are regularly done with other frequencies and impulse widths to further explore how each patient responds to the device. Therapy is programmed individually for each patient taking into account results of their office BP, 24-hour ambulatory BP, when available, and responses to the acute dose response tests.

\section{Preparation for surgery}

On the day of surgery morning doses of antihypertensive medications were held, except for beta-adrenergic blockers and aspirin was given unless otherwise contraindicated. An infusion of sodium nitroprusside, or nitroglycerine, was used to control BP preoperatively and all other antihypertensive medications were administered in the immediate postoperative period. All procedures were performed under general anesthesia. It is critical to the conduct of the procedure that agents which blunt the baroreflex be avoided, as has been briefly communicated previously $^{26}$, and thus will not be expanded upon at this time. The level of the carotid bifurcation was marked on each side using ultrasound guidance. A catheter was placed in the nondominant radial artery for continuous monitoring of the BP.

\section{Access to the carotid sinus}

The patient was positioned and the surgical field prepared which allowed access for three incisions, one over each carotid bifurcation and a third inferior to the clavicle for the IPG. A transverse or vertical incision was made at the level of the bifurcation, at 
the discretion of the attending surgeon. The incision was deepened and the common carotid artery was exposed according to the standard practice of the surgeon. The vagus nerve was identified and protected. The carotid dissection was extended cephalad exposing the bifurcation. In this process the Ansa cervicalis may be divided, however, all other nerves including the hypoglossal which was mobilized if needed, were preserved. The carotid artery bifurcation was then mobilized circumferentially, however, dissection within the bifurcation was avoided so as to minimize the risk of injury to the neurovascular bundle. If the geometry of the carotid bifurcation was such that the angle between the internal and external carotid arteries was great and the arteries separate rapidly, the internal carotid artery was dissected circumferentially two centimeters above the flow divider to facilitate fixation of the electrode around the sinus without directly dissecting near the flow divider of the carotid bifurcation where the carotid sinus nerve was most likely to be located.

\section{Carotid sinus lead application and testing}

At this time participants receiving inhalational agents, as part of their anesthetic regimen, had the agents reduced, or temporarily discontinued, and supplemental narcotics, barbiturates and/or benzodiazepines administered intravenously to maintain adequate anesthesia.

The electrode was positioned on the bifurcation in the area of the carotid sinus. If the carotid sinus was clearly seen the electrode is applied with the active area centered on the sinus. If the sinus was not a discrete structure the lead is positioned around the carotid bifurcation so that the active area was centered on the internal carotid artery at a point opposite the neurovascular bundle within the bifurcation. The electrode was positioned on the distal five millimeters of the common carotid artery extending cephalad onto the bifurcation. The electrode was then tested to assess the hemodynamic response. The electrode was repositioned in the cephalad-caudal orientation as well as being rotated around the long axis of the carotid artery until the location providing the optimal hemodynamic response was identified. Several locations were tested to assure that the position producing the optimal response was identified. During testing the CSL was connected to the IPG and briefly activated with impulses of $3 \mathrm{~V}, 100 \mathrm{~Hz}$ and a pulse width of $480 \mu$ s once BP and HR were stable and not influenced by mechanical manipulation. Within one minute, stimulation at a correct location should reduce systolic BP by at least $10-20 \mathrm{mmHg}$ and HR by 5-10 beats/minute. Once the optimal location was confirmed the electrode was sutured in place (6-O polyprophylene; Prolene ${ }^{\circledR}$ ). The design of the electrode allowed all suturing to be performed on the superficial aspect of the artery and for sutures to be placed on the common and external carotid arteries avoiding direct suturing to the carotid sinus thus reducing the risk of injury to these structures. The procedure was then repeated on the contralateral side. 


\section{Lead tunneling procedure and IPG implantation}

After confirming lead position and appropriate electrode function the level of anesthesia was deepened to allow tunneling of the lead bodies. This was accomplished by administering inhalational agents or intravenous narcotics or benzodiazepines. Next a subcutaneous pocket for the IPG was made inferior to the clavicle. A tunnel was created from the cervical incision ipsilateral to the IPG pocket to the space between the sternal and clavicular heads of the sternocleidomastoid muscle (SCM). This was between the vessels and the SCM and was large enough to allow the index finger to be inserted from above down to the fascial layer between the heads of the SCM. A tunnel was fashioned from the IPG pocket up to the space between the heads of the SCM which was then opened from below by spreading a clamp on the tip of the index finger thus protecting the underlying neurovascular structures. The lead from the ipsilateral electrode was advanced through the tunnel to the IPG pocket leaving excess lead body in the cervical incision to avoid traction on the electrode arterial interface. Next a tunnel was created between the two cervical incisions just deep to the SCM crossing the neck at the lowest point possible while avoiding injury to the thyroid and any superficial vessels. The lead body from the contralateral electrode system was advanced through the tunnel to the cervical incision ipsilateral to the IPG pocket and then through the tunnel to the IPG pocket. The lead bodies were repositioned within the tunnels with loops in each incision providing strain relief thus avoiding traction on the electrode-arterial interface. The leads were then connected to the IPG. The bilateral positioning of the CSL and location of the IPG is given schematically in Figure 4.1a and on an X-Ray in Figure 4.1b where the typical location of both CSLS can be seen. The unit was again interrogated to confirm the adequacy of the electrical connections. The hemodynamic response to a bilateral acute stimulation test was used to confirm appropriate function if the anesthetic agents used during the final phase of the procedure do not blunt the baroreflex. The IPG was then turned off. The IPG was sutured in place with permanent sutures (3-O Prolene $\left.{ }^{\circledR}\right)$ and the IPG pocket and cervical incisions closed in layers with absorbable sutures. 


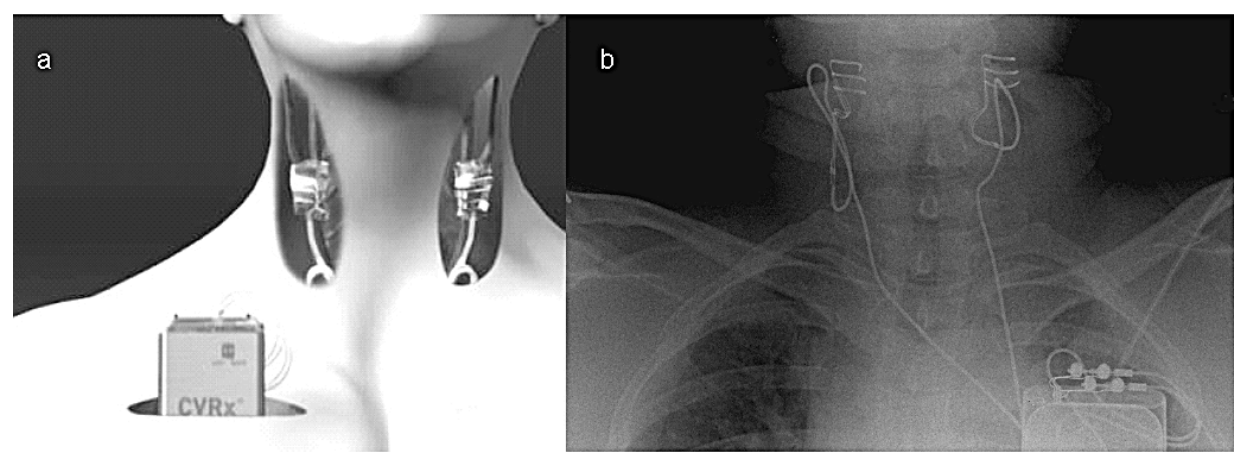

Figure 4.1 Position of carotid sinus leads and implantable pulse generator.

Panel a: schematic presentation of positions of bilateral perivascular carotid sinus stimulation electrodes and the pulse generator.

Panel b: postoperative radiograph of a patient after implantation of the Rheos ${ }^{\circledR}$ System.

\section{Safety analysis}

The safety analysis describes and analyses perioperative procedure- and device related adverse events as reported by the investigators. All adverse events are also reviewed by an independent adverse events committee. The perioperative period includes the time during which the implant procedure is being conducted and 30 days following this procedure.

\section{Statistical analysis}

Summary statistics (mean, standard deviation, minimum and maximum for continuous variables and frequency for categorical) were computed for baseline and follow-up variables of interest. The maximal response during dose response testing is calculated as the largest difference between the baseline measure at $0 \mathrm{~V}$ and the measures obtained at 1-6 V. The mean maximal change in BP and HR during dose response testing is given along with the standard deviation and confidence limits. $P$-values for tests of significant maximal reductions in BP and HR during dose response testing are by the $t$-Test for the mean change differing from zero. Ninety-five percent confidence intervals are provided to assist in determining the clinical significance of the differences. A repeated measure ANOVA was used to model the changes in BP and HR for increasing doses and across visits. Unless otherwise specified, data are expressed as mean \pm standard deviation. 


\section{Results}

Seventeen participants were enrolled between June 2004 and December 2005, all with severe hypertension despite a multi-drug therapy with a mean of $>5$ concomitant antihypertensive drugs. Table 4.3 presents the participant characteristics at entry. Implant procedures were successfully completed in all participants within an average of $202 \pm 43$ minutes, including $121 \pm 87$ minutes used for determining and testing the optimal location for CSL placement. The first acute dose response tests, performed in the awake state were conducted on postoperative day 1-3, prior to discharge from the hospital. At this time, these tests gave significant (all: $P \leq 0.001$ ) maximal reductions of systolic and diastolic BP and HR from $177 \pm 29 \mathrm{mmHg}, 99 \pm 16 \mathrm{mmHg}$ and $80 \pm 15$ beats/min, to $141 \pm 34 \mathrm{mmHg}, 78 \pm 21 \mathrm{mmHg}$ and $68 \pm 14$ beats $/ \mathrm{min}$, respectively, which were observed at a mean amplitude of $4.6 \pm 1.7 \mathrm{~V}$. Mean maximal changes, with standard deviations and $95 \%$ confidence limits for systolic BP, diastolic BP and HR are $28 \pm 22(17,39) \mathrm{mmHg}, 16 \pm 11(10,22) \mathrm{mmHg}$ and $8 \pm 4(6,11)$ beats/min, respectively.

Table 4.3 Participant characteristics ( $\mathrm{N}=17)$.

\begin{tabular}{lc}
\hline Characteristic & \\
\hline Gender, male/female & $8 / 9$ \\
Age, years & $52 \pm 9$ \\
Height, cm & $171 \pm 10$ \\
Weight, kg & $92 \pm 25$ \\
Body mass index, kg/m² & $31 \pm 6$ \\
Systolic blood pressure, $\mathrm{mmHg}$ & $190 \pm 28$ \\
Diastolic blood pressure, $\mathrm{mmHg}$ & $111 \pm 15$ \\
Heart rate, beats/min & $75 \pm 13$ \\
Number of antihypertensive drugs & $5 \pm 2$ \\
\hline
\end{tabular}

These tests, repeated monthly, showed consistent acute dose-dependent reductions in systolic BP, diastolic BP and HR in that the degree of hemodynamic change was directly related to the amplitude of stimulation. In Figure 4.2 the results for the 1-month follow-up visit (the formal baseline of the study) and 4-month follow-up visit in the cohort completing three months of carotid baroreceptor stimulation $(N=16)$ are presented. Data for BP and HR during the testing at both time points are given in Table 4.4. At both time points the relationship between amplitude of stimulation and hemodynamic response remained highly linear while the control measurements $(0 \mathrm{~V})$ before testing were lower at the 4-month visit when compared with the 1-month assessments. These lower control values after three months of therapy with the device turned off briefly (5-30 minutes) are related to the therapeutic effect of the device which has been previously reported for a subset of these participants ${ }^{25}$. A repeated measures ANOVA analysis of BP and HR readings during dose response testing across voltage steps tested ( $0 \mathrm{~V}$ to $6 \mathrm{~V})$ and visits (1-month and 4-month) 
demonstrated significant differences across doses ( $P<0.001$ for each) and by visit ( $P=0.003$ for systolic BP, $P=0.001$ for diastolic $B P$ and $P<0.001$ for $\mathrm{HR}$ ).

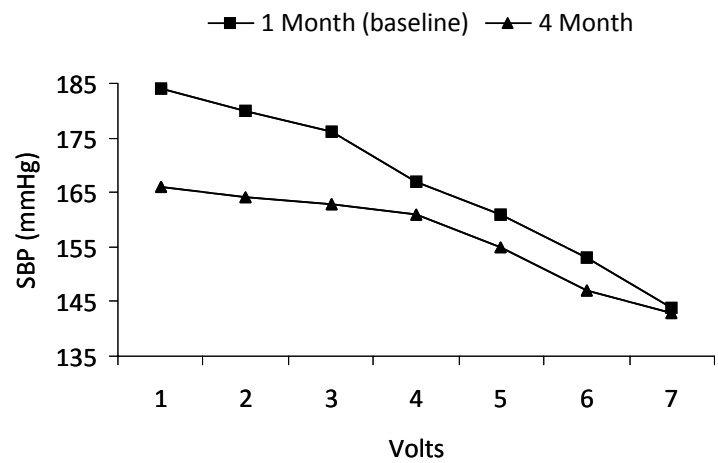

Figure 4.2 Systolic blood pressure during acute electrical carotid baroreceptor stimulation tests $(\mathrm{N}=16)$. With bilateral stimulation, the amplitude of the IPG is increased in steps of $1 \mathrm{~V}$ from $0-6 \mathrm{~V}$, each for 5 minutes. Mean systolic blood pressure at each step is given for the test results. The 1-month follow-up tests ( $\mathbf{a})$ were performed prior to the initiation of chronic therapy. The 4-month follow-up tests $(\boldsymbol{\Delta})$, were performed after three months of stimulation, the device was turned off for 5-30 minutes before acute testing was started.

Table 4.4 Dose response test results $(\mathrm{N}=16)$

Blood pressure (BP) and heart rate before chronic carotid baroreceptor stimulation (1-month) and after three months of stimulation (4-month).

\begin{tabular}{|c|c|c|c|c|c|c|c|}
\hline \multirow{2}{*}{$\begin{array}{l}\text { Parameter } \\
\text { and time point }\end{array}$} & \multicolumn{7}{|c|}{ Amplitude (V) of baroreflex activation } \\
\hline & 0 & 1 & 2 & 3 & 4 & 5 & 6 \\
\hline \multicolumn{8}{|l|}{ Systolic BP, mmHg } \\
\hline 1-month & $184 \pm 28$ & $180 \pm 29$ & $176 \pm 30$ & $167 \pm 32$ & $160 \pm 36$ & $153 \pm 31$ & $144 \pm 36$ \\
\hline 4-month & $165 \pm 21$ & $164 \pm 21$ & $163 \pm 27$ & $160 \pm 23$ & $155 \pm 27$ & $147 \pm 30$ & $143 \pm 30$ \\
\hline \multicolumn{8}{|l|}{ Diastolic BP, $\mathrm{mmHg}$} \\
\hline 1-month & $105 \pm 17$ & $104 \pm 18$ & $105 \pm 17$ & $98 \pm 21$ & $94 \pm 22$ & $92 \pm 21$ & $84 \pm 24$ \\
\hline 4-month & $95 \pm 17$ & $94 \pm 16$ & $93 \pm 17$ & $92 \pm 15$ & $89 \pm 17$ & $84 \pm 17$ & $81 \pm 17$ \\
\hline \multicolumn{8}{|l|}{ Heart rate, beats/min } \\
\hline 1-month & $80 \pm 14$ & $78 \pm 14$ & $77 \pm 15$ & $74 \pm 14$ & $72 \pm 14$ & $71 \pm 15$ & $68 \pm 14$ \\
\hline 4-month & $68 \pm 11$ & $67 \pm 10$ & $68 \pm 11$ & $65 \pm 11$ & $65 \pm 11$ & $64 \pm 12$ & $62 \pm 12$ \\
\hline
\end{tabular}

The implantation procedure was generally well tolerated. No unexpected serious procedure- or device-related adverse events or perioperative deaths were reported. In the perioperative period, there were 38 procedure-related adverse events reported in 17 participants, two device-related events in two patients and one event determined to be related to both the procedure and the device. Table 4.5 summarizes the assessment of perioperative adverse events, which were related to the procedure and/or the device. Of these events, three were classified as serious adverse events. First, infection, which led to the complete surgical removal of the device in one 
patient. The IPG pocket was infected with an spreading infection along the leads to the neck incision at both sides. High fever and serious pain with redness, necessitated surgical reintervention and explantation of the system. Second, procedure-related hypoglossal nerve injury with symptoms of hoarseness and eating disturbances which improved during follow-up. In this patient the electrodes had to be placed high on the carotid bifurcation which resulted in an accidentally injury to the nerve, that was sutured immediately with fine sutures (polypropylene 7x0), and third one case of intraoperative bradycardia (to 20 beats/min), which recovered spontaneously without any sustained effect. Device- and procedure-related bradycardia has occurred during system testing when brief periods of stimulation are applied to determine and confirm the effects of electrode positioning. Such episodes are expected and related to the mechanism of baroreflex activation and end within seconds by turning off the device.

Table 4.5 Perioperative device- and procedure-related adverse events ( $\mathrm{N}=17)$.

\begin{tabular}{|c|c|c|c|c|}
\hline Adverse event & $\begin{array}{l}\text { Device } \\
\text { related }\end{array}$ & $\begin{array}{c}\text { Procedure } \\
\text { related }\end{array}$ & $\mathrm{N}$ events & $\begin{array}{c}\mathrm{N} \text { participants } \\
\text { with event }\end{array}$ \\
\hline Infection* & 0 & 1 & 1 & 1 \\
\hline Hypoglossal nerve injury & 0 & 1 & 1 & 1 \\
\hline Intraoperative bradycardia & 2 & 1 & 2 & 2 \\
\hline Pain & 1 & 6 & 7 & 5 \\
\hline Wound complication & 0 & 3 & 3 & 3 \\
\hline Extravascular tissue stimulation & 0 & 1 & 1 & 1 \\
\hline Anaesthesia complications & 0 & 2 & 2 & 2 \\
\hline Injury to local tissue & 0 & 1 & 1 & 1 \\
\hline Other & 0 & 22 & 23 & 16 \\
\hline Total & 3 & 38 & 41 & 17 \\
\hline
\end{tabular}

*during follow-up, the complete device was surgically removed

\section{Discussion}

The results of acute dose response testing observed during postoperative activation of this implanted device confirm that the regulation of BP and HR by the central nervous system, is strongly influenced by input from the carotid baroreceptor pathways in patients with hypertension that are refractory to multi-drug therapy. Furthermore, these reductions in BP were consistently achieved throughout the first three months of active carotid baroreceptor stimulation. Finally, these results suggest that the Rheos ${ }^{\circledR}$ System can be implanted safely in this group of patients with significant cardiovascular risk factors.

Patients were only included in this study when they fulfilled to strict inclusion criteria like the height of the BP, number of antihypertensive medications and local factors at the carotid bifurcation site, as determined by duplex scanning. This means that any carotid artery stenosis $>50 \%$ was an exclusion criteria. In this respect one may wonder 
whether the risk on future significant (symptomatic) carotid artery stenosis may play a role in the decision to treat hypertensive patients with the Rheos ${ }^{\circledR}$ System. To date this question remains unanswered and long-term follow-up probably will give insight into this issue, with emphasis on the risk of carotid endarteriectomy in these patients. The present data demonstrated that during acute testing the reduction in BP occurs in a dose dependent manner, although only the amplitude of stimulation was adjusted in these tests. These observations are consistent with the findings of Schmidli et al. in a group of patients undergoing carotid artery surgery who underwent short-term unilateral electrical stimulation of the carotid sinus wall ${ }^{24}$.

There are some differences in dose response test results at 4-month visit as compared with the 1-month visit, which require discussion and further study. The baseline BP is significantly lower, even though the device was turned off for 5-30 minutes, at the 4-month time point: $165 \pm 21 \mathrm{mmHg}$ vs. $184 \pm 28 \mathrm{mmHg}$ at the 1-month time point. This chronic BP lowering effect of carotid baroreflex activation has been previously reported in a smaller cohort of these participants by de Leeuw and colleagues ${ }^{25}$. Thus, effects of chronic baroreflex activation appear to be maintained in part during this brief time that the stimulation was inactive. The lack of a rebound to baseline or greater BP is encouraging from a safety perspective for this device therapy, but does confound our ability to easily interpret the test findings. The second observation is that of an apparent threshold effect at the 4-month time point. This may reflect the development and organization of scar tissue within the surgical field. This observation will require data from longer follow-up and ongoing animal studies before a comprehensive explanation can be provided.

Since we observed a qualitatively reproducible linear relationship between the hemodynamic response to carotid baroreceptor stimulation and the used voltage, these acute tests may be considered "dose response" tests. The electrical parameters chosen for the acute dose response tests used a stepwise increase voltage with a constant frequency of $100 \mathrm{~Hz}$ and impulse width of $480 \mu \mathrm{s}$. Voltage increases are thought to increase the recruitment of afferent baroreceptor fibers which elicits a spatial summation at the brainstem neuronal network involved in the processing of the carotid baroreflex ${ }^{27,28}$. A high stimulation frequency is expected to minimize additional confounding influences of potential differences in transmission properties of the afferent neuronal fibers ${ }^{29,30}$.

The observations in this study, while new, are not unexpected given previous work using carotid sinus nerve stimulation. These studies conducted in the 1960s and 1970s evaluated the role of therapeutic modulation of the carotid baroreflex in the treatment of refractory hypertension and angina pectoris ${ }^{11-17}$. The current system is novel in that it uses perivascular electrodes to activate the baroreflex. The current system addresses many of the challenges of the earlier devices. Extraneous nerve and muscle stimulation and pain resulting from current spread have been largely solved with modern electrode technologies. The technique of placement of the electrode on the carotid sinus reduces the possibility of damage to the carotid sinus nerves and 
allows the use of established techniques employed in the treatment of atherosclerosis of the carotid bifurcation. Finally, advances in implantable medical devices allow the system to reliably deliver stable and controlled therapy that can be customized for each patient.

The long-term systolic BP reduction of more than $20 \mathrm{mmHg}$ observed even with the device turned off briefly before the 4-month dose response testing is impressive and exceeds the BP lowering effects demonstrated in a recent trial of a new antihypertensive agent in patients with refractory hypertension ${ }^{31}$.

A second similar study is underway in the USA ${ }^{32}$. At the time of this report, 39 participants have been enrolled worldwide in both studies. The available worldwide safety data from 39 implant procedures corroborate our findings. With regard to procedure- and device-related adverse events, the perioperative infection which occurred in one participant was treated with complete removal of the system and is unfortunately an expected event seen with the implantation of i.e. ICDs ${ }^{33}$ and other similar implantable medical devices. Taking the worldwide experience with the Rheos ${ }^{\circledR}$ System into account, two such infections have occurred (one in the US study in addition to our observation) which is within the expected rate of device-related infections and infection-related explants ${ }^{33-36}$.

In conclusion, the preliminary data from our cohort of 17 participants suggest that the Rheos $^{\circledR}$ System implant procedure can be performed with reasonable safety. However, we did saw serious complications in a minority of participants. This combined with the sustained hemodynamic response demonstrated for up to three months of stimulation support further clinical development of baroreflex activation as a new concept to treat drug-resistant hypertension. Such a concept is in line with the treatment goal of sympathetic deactivation as reviewed recently by Grassi ${ }^{37}$. Long-term therapeutic results of this ongoing safety and efficacy study are needed as the basis for a multi-center, controlled trial of the device for this indication. 


\section{References}

1 Alderman $\mathrm{MH}$, Budner N, Cohen H, Lamport B, Ooi WL. Prevalence of drug resistant hypertension. Hypertension 1988;11:II71-75.

2 Alper AB, Jr., Calhoun DA. Contemporary management of refractory hypertension. Curr Hypertens Rep 1999;1:402-407.

3 Bertholet N, Favrat B, Fallab-Stubi CL, Brunner HR, Burnier M. Why Objective Monitoring of Compliance is Important in the Management of Hypertension. J Clin Hypertens (Greenwich) 2000;2: 258-262.

4 Burnier M, Schneider MP, Chiolero A, Stubi CL, Brunner HR. Electronic compliance monitoring in resistant hypertension: the basis for rational therapeutic decisions. J Hypertens 2001;19:335-341.

5 Calhoun DA, Zaman MA, Nishizaka MK. Resistant hypertension. Curr Hypertens Rep 2002;4:221-228.

6 Levy El, Scarrow AM, Jannetta PJ. Microvascular decompression in the treatment of hypertension: review and update. Surg Neurol 2001;55:2-10.

7 Nuesch R, Schroeder K, Dieterle T, Martina B, Battegay E. Relation between insufficient response to antihypertensive treatment and poor compliance with treatment: a prospective case-control study. Bmj 2001;323:142-146.

8 Ram C, Fenves A. Refractory hypertension. Curr Conc Hypertens 2002;4:3-6.

9 Cuspidi C, Macca G, Sampieri L, Michev I, Salerno M, Fusi V, Severgnini B, Meani S, Magrini F, Zanchetti A. High prevalence of cardiac and extracardiac target organ damage in refractory hypertension. J Hypertens 2001;19:2063-2070.

10 Pierdomenico SD, Lapenna D, Bucci A, Di Tommaso R, Di Mascio R, Manente BM, Caldarella MP, Neri $\mathrm{M}$, Cuccurullo F, Mezzetti A. Cardiovascular outcome in treated hypertensive patients with responder, masked, false resistant, and true resistant hypertension. Am J Hypertens 2005;18:1422-1428.

11 Agishi T, Temples J, Peirce EC, 2nd. Electrical stimulation of the carotid sinus nerve as an experimental treatment of hypertension. J Surg Res 1969;9:305-309.

12 Bilgutay AM, Lillehei CW. Treatment of Hypertension with an Implantable Electronic Device. JAMA 1965;191:649-653.

13 Braunwald NS, Epstein SE, Braunwald E. Carotid sinus nerve stimulation for the treatment of intractable angina pectoris: surgical technic. Ann Surg 1970;172:870-876.

14 Brest AN, Wiener L, Bachrach B. Bilateral carotid sinus nerve stimulation in the treatment of hypertension. Am J Cardiol 1972;29:821-825.

15 Parsonnet V, Rothfeld EL, Raman KV, Myers GH. Electrical stimulation of the carotid sinus nerve. Surg Clin North Am 1969;49:589-596.

16 Reich T. Implantation of carotid sinus nerve stimulator. Aorn J 1969;10:53-56.

17 Schwartz SI, Griffith LS, Neistadt A, Hagfors N. Chronic carotid sinus nerve stimulation in the treatment of essential hypertension. Am J Surg 1967;114:5-15.

18 Grassi G. Counteracting the sympathetic nervous system in essential hypertension. Curr Opin Nephrol Hypertens 2004;13:513-519.

19 Lohmeier TE, Dwyer TM, Hildebrandt DA, Irwin ED, Rossing MA, Serdar DJ, Kieval RS. Influence of prolonged baroreflex activation on arterial pressure in angiotensin hypertension. Hypertension 2005; 46:1194-1200.

20 Lohmeier TE, Dwyer TM, Irwin ED, Rossing MA, Kieval RS. Prolonged activation of the baroreflex abolishes obesity-induced hypertension. Hypertension 2007;49:1307-1314.

21 Lohmeier TE, Irwin ED, Rossing MA, Serdar DJ, Kieval RS. Prolonged activation of the baroreflex produces sustained hypotension. Hypertension 2004;43:306-311.

22 Sleight P. Arterial baroreflexes can determine long-term blood pressure. Baroreceptors and hypertension: time for a re-think? Exp Physiol 2004;89:337-341.

23 Thrasher TN. Baroreceptors, baroreceptor unloading, and the long-term control of blood pressure. Am J Physiol Regul Integr Comp Physiol 2005;288:R819-827.

24 Schmidli J, Savolainen H, Eckstein F, Irwin E, Peters TK, Martin R, Kieval R, Cody R, Carrel T. Acute device-based blood pressure reduction: electrical activation of the carotid baroreflex in patients undergoing elective carotid surgery. Vascular 2007;15:63-69. 
25 Leeuw de P, Kroon A, Scheffers I, Tordoir J, Schmidli J, Mohaupt M, Allemann Y, Jordan J, Engeli S, Liebeskind U, Luft F, Eckert S, Hansky B, Kieval R, Cody R, Rossing M, Irwin E, Peters T. Baroreflex hypertension therapy with a chronically implanted system: preliminary efficacy and safety results from the Rheos DEBUT-HT study in patients with resistant hypertension. J Hypertens 2006;24: S300-S301.

26 Eberle B, Schmidli J, Irwin E, Peters T, Carrel T. Evaluation of an anesthetic regimen for testing electrical activation of the carotid baroreflex. Anesthesiology 2005;103:A372.

27 Gasser HS. The Control of Excitation in the Nervous System. Bull N Y Acad Med 1937;13:324-348.

28 Gorman PH, Mortimer JT. The effect of stimulus parameters on the recruitment characteristics of direct nerve stimulation. IEEE Trans Biomed Eng 1983;30:407-414.

29 Borst C, Karemaker JM, Dunning AJ, Bouman LN, Wagner J. Frequency limitation in the human baroreceptor reflex. J Auton Nerv Syst 1983;9:381-397.

30 Seller $\mathrm{H}$, Illert $\mathrm{M}$. The localization of the first synapse in the carotid sinus baroreceptor reflex pathway and its alteration of the afferent input. Pflugers Arch 1969;306:1-19.

31 Black H, El Shahawy M, Weiss R, Tannoury G, Marple R, Weber M, Linas S, Bakris GL. Darusentan antihypertensive effect in patients with resistant systolic hypertension. J Am Coll Cardiol 2006; 47:A299.

32 Bisognano J, Sloand JA, Papedemetriou V, Rothstein M, Sica D, Flack J, Pertile T, Jarvis G, Kieval R, Cody R. Baroreflex hypertension therapy with a chronically implanted system: early results from Rheos feasibility trial in patients with resistant hypertension. J Clin Hypertens 2006;8:A43.

33 Voigt A, Shalaby A, Saba S. Rising rates of cardiac rhythm management device infections in the United States: 1996 through 2003. J Am Coll Cardiol 2006;48:590-591.

34 Baddour LM, Bettmann MA, Bolger AF, Epstein AE, Ferrieri P, Gerber MA, Gewitz MH, Jacobs AK, Levison ME, Newburger JW, Pallasch TJ, Wilson WR, Baltimore RS, Falace DA, Shulman ST, Tani LY, Taubert KA. Nonvalvular cardiovascular device-related infections. Circulation 2003;108:2015-2031.

35 Reynolds MR, Cohen DJ, Kugelmass AD, Brown PP, Becker ER, Culler SD, Simon AW. The frequency and incremental cost of major complications among medicare beneficiaries receiving implantable cardioverter-defibrillators. J Am Coll Cardiol 2006;47:2493-2497.

36 Uslan DZ, Baddour LM. Cardiac device infections: getting to the heart of the matter. Curr Opin Infect Dis 2006;19:345-348.

37 Grassi G. Sympathetic deactivation as a goal of nonpharmacologic and pharmacologic antihypertensive treatment: rationale and options. Curr Hypertens Rep 2003;5:277-280. 
Novel carotid baroreflex activation therapy in resistant hypertension: Results of a European multi-center feasibility and proof-of-principle study

IJM Scheffers, AA Kroon, J Schmidli, J Jordan, JHM Tordoir, MG Mohaupt, FC Luft, H Haller, J Menne, S Engeli, J Ceral, S Eckert, A Erglis, K Narkiewicz, T Philipp, PW de Leeuw 


\section{Abstract}

The present study was intended to establish the safety and efficacy profile of a novel implantable device in hypertensive patients who are refractory to medical treatment. Despite the availability of potent antihypertensive drugs, a substantial proportion of the hypertensive population remains treatment-resistant. A novel implantable device which activates the carotid baroreflex may help to treat those patients.

We conducted a prospective, nonrandomized multi-center feasibility study to test safety and efficacy of this device. Participants had to have office systolic blood pressure above $160 \mathrm{mmHg}$ despite triple antihypertensive therapy and they kept taking their antihypertensive medications. Safety measures included adverse events and functional capacity assessment. The primary efficacy endpoint was the change in office blood pressure following three months of device therapy. Follow-up at one year and two years was obtained via an extension study.

Forty-five participants received the device. Their mean baseline office systolic/diastolic blood pressure was $179 / 105 \mathrm{mmHg}$ and heart rate 80 beats/minute. They used a median number of 5 (range 3-9) antihypertensive drugs. The device exhibited an acceptable safety profile. Following three months of device therapy, systolic and diastolic blood pressure were reduced by 21 and $12 \mathrm{mmHg}$, respectively. This result was sustained in a cohort of 17 subjects who completed two years of follow-up.

We showed that the device is acceptable and safe. We found a reduction in systolic blood pressure of over $20 \mathrm{mmHg}$ that was well sustained over two years follow-up. Larger prospective studies are needed to validate these early promising results. 


\section{Introduction}

Despite the availability of potent antihypertensive medications, a sizeable proportion of the hypertensive population remains treatment-resistant ${ }^{1}$. These patients are at increased risk to develop myocardial infarction, heart failure, stroke and kidney disease ${ }^{1-3}$. Early attempts to treat such patients with electrical carotid baroreflex activation $^{4-6}$ have been summarized previously ${ }^{7,8}$. These efforts were not very successful due to side effects and technical problems ${ }^{4,5,9-15}$, therefore developments in this area were hampered for may years. Recent advances in device technology and an increasing number of patients whose hypertension cannot be controlled with pharmacological agents only, has led to renewed interest in this approach to lower blood pressure. This has been reinforced by reports which suggest that the baroreceptors are involved in the long-term control of sympathetic activity and blood pressure $^{16-20}$

Recently, a novel implantable device (Rheos ${ }^{\circledR}$ System; CRVx. Inc., Minneapolis, MN, USA) has been developed, based on markedly improved technology, which works by electrical stimulation of the wall of the carotid sinus. Technical and practical specifications have been described before ${ }^{21}$. The device enhances afferent nerve traffic from the baroreceptors to the cardiovascular control centers in the brain which subsequently reduce sympathetic outflow and blood pressure. Canine studies have demonstrated sustained falls in arterial pressure in normotensive dogs and in several models of experimental hypertensive dogs ${ }^{8,22-24}$. Observations in patients undergoing elective carotid surgery have confirmed that short-term activation of the baroreflex acutely lowers blood pressure in humans ${ }^{25}$. Recently, a participant with malignant hypertension was described in whom blood pressure could be controlled by this new device over a longer period of time ${ }^{26}$. As a next step, in the present study, we evaluated the long-term safety and efficacy of the Rheos ${ }^{\circledR}$ System in participants with severe hypertension who were resistant to triple therapy. This paper presents the final 3-month and the initial 1-year and 2-year results from that study.

\section{Methods}

The Device Based Therapy in Hypertension Trial (DEBUT-HT) was a multi-center, prospective, nonrandomized feasibility study. Its purpose was to assess the safety and efficacy of the Rheos ${ }^{\circledR}$ System during a period of three months in treatment-resistant hypertensive humans. The Medical Ethics Committee of all participating centers had approved the study protocol and written informed consent was obtained from all participants. After the three months of device therapy had been completed, participants consented to an extended follow-up phase. 


\section{Participants}

Participants had to be between 21 and 80 years and had to have a blood pressure $\geq 160 \mathrm{mmHg}$ systolic and/or $\geq 90 \mathrm{mmHg}$ diastolic despite full therapy with at least three antihypertensive agents including a diuretic. They were certified by their physicians as being adherent to treatment. In all participants medication was kept constant for two months prior to inclusion in the study and during the first three months of device therapy, except when their clinical condition required a change in medication. Thereafter, medication withdrawal was only advised when blood pressure was stable at treatment goal. In addition, their carotid bifurcations as assessed by ultrasound examination needed to be at or below the C3-C4 level in order to ensure operative suitability.

Subjects were excluded if they had baroreflex failure, significant orthostatic hypotension, cardiac arrhythmias, chronic atrial fibrillation, clinically significant cardiac valvular disease, or hypertension secondary to a treatable cause. Other exclusion criteria were carotid artery atherosclerosis with $>50 \%$ stenosis as determined by routinely performed ultrasound, prior surgery or radiation in the carotid sinus region, currently implanted electrical medical devices, dialysis and pregnancy or contemplating pregnancy.

\section{Surgical implantation and device programming}

The Rheos ${ }^{\circledR}$ System consists of two electrode leads and an implantable pulse generator (IPG). The surgical procedure has been described in detail previously ${ }^{27,28}$. In brief, an incision was made at both sides of the neck at the level of the carotid bifurcation to expose the carotid artery. Several positions for the electrode at the level of the bifurcation of the carotid artery were tested, each side separately, to identify the position producing the optimal hemodynamic response. Stimulation at the correct location should immediately reduce systolic blood pressure (SBP) by 10-20 $\mathrm{mmHg}$ and heart rate (HR) by at least 5-10 beats/min. Once the optimal location had been identified, the electrode was sutured in place. A third incision was made inferior of the clavicle to create a subcutaneous pocket for the IPG. Leads were tunneled subcutaneously toward the pocket and connected to the IPG. For the first month following implantation the device therapy was programmed off in order not to interfere with wound healing. After this first month the device was turned on using continuous stimulation. At each follow-up visit we first turned off the device for a short period of time to evaluate the participants blood pressure under 'normal' conditions. Subsequently, we activated various program settings in order to find those which at that moment would produce an optimal blood pressure response. 


\section{Follow-up measurements}

Participants were followed monthly for the first three months of device therapy and thereafter at least annually. We recorded all information on antihypertensive agents including dosage, which allowed us to calculate the antihypertensive therapy index ${ }^{29}$. This index expresses the use of antihypertensive medications in relation to the maximal allowed dosages. Using the maximal dose of one given drug creates an index of ten.

An independent committee adjudicated all adverse events to determine the severity and relationship to the procedure or device. An event was classified as serious adverse event (SAE) when it resulted in one of the following outcomes: death, life-threatening situation, inpatient hospitalization, prolongation of existing hospitalization or persistent or significant disability. Functional safety measures were recorded at baseline, after three months, and after one year of device therapy and included orthostatic blood pressure changes and the participants ability to exercise during a 6-minute hall walk test ${ }^{30}$. Renal function was assessed using serum creatinine as measured by a central laboratory. Finally, carotid artery ultrasound was performed to determine whether carotid artery stenosis would develop. To detect orthostatic hypotension, we measured blood pressure after five minutes in the supine position and subsequently after one, three and five minutes of upright standing. Participants then reassumed the supine position for five minutes after which blood pressure was measured again. We defined orthostatic hypotension as a fall in SBP or diastolic blood pressure (DBP) by at least 20 and $10 \mathrm{mmHg}$, respectively, within 3-5 minutes of quiet standing.

To determine whether the device was effective, we recorded office blood pressure (OBP) and obtained 24-hour ambulatory blood pressure measurements (ABPM) at every scheduled visit. OBP was measured with a validated electronic device with an appropriate cuff and bladder size, while the participant was sitting for five minutes with the back supported and the arm supported at the level of the heart. Participants refrained from the consumption of food, caffeine containing products and tobacco for one hour before the measurements. Strenuous exercise was also avoided. A minimum of two readings was taken, at least one minute apart. We repeated the readings when the two consecutive measurements varied by $>5 \mathrm{mmHg}$. The recorded OBP was the average of the last two readings. ABPM was performed during 24 hours with a validated device which measured blood pressure at least every 30 minutes during the day ( $6 \mathrm{am}$ to $10 \mathrm{pm}$ ) and at least every 60 minutes during the night (10 pm to $6 \mathrm{am}$ ). We also followed a cohort of ten eligible patients via regular care, who for various reasons declined participation in this study. Their treating physicians recorded all information with respect to $\mathrm{OBP}$, antihypertensive treatment and (serious) adverse events. 


\section{Statistical analyses}

The safety analysis describes all reported SAEs and all procedure- and device-related events of any severity. The time to first SAE and the time to first procedure- or device-related SAE were calculated according to the Kaplan-Meier method. Data are presented as mean \pm standard deviation or mean change \pm standard error unless indicated otherwise. Statistical analysis was performed parametrically and two-sided using SAS V9.1 statistical software. A $P$-value $<0.05$ was considered to denote statistical significance.

Blood pressure responses were calculated as the difference between every scheduled follow-up visit and the baseline visit by means of a paired $t$-test. An ABPM recording was excluded from analysis when $>30 \%$ of the blood pressure readings failed, were missing, or the test was not at least 20 hours in duration. The baseline visit had a window of one month \pm one week post-implant and the 3-month visit had a window of three months \pm two weeks of device therapy. Data were not carried forward or imputed if a participant was not seen during the visit window. The first three participants enrolled were, by protocol, excluded from the safety and efficacy analyses to avoid effects of an expectable learning curve for the surgical procedure. Those first three procedures were executed by the same surgeon and thereafter every inexperienced surgeon was proctored by an experienced one.

\section{Results}

Forty-five participants at nine clinical centers in Europe received the device between March 2004 and November 2007. Baseline characteristics of the individuals are presented in Table 5.1. With the first three participants being excluded from the analyses, safety analysis after three months of device therapy comprises 42 subjects. Of these, four had dropped out early (see adverse events section) and one missed the 3-month evaluation, therefore the efficacy analysis comprises 37 subjects. At the time of analysis, 26 and 17 participants had completed one year and two years of chronic device therapy, respectively.

All participants received full doses of antihypertensive medication per the local guidelines of the participating center and individual tolerance. The median number of antihypertensive drugs taken at pre-implant was 5 (range 3-9) with a median antihypertensive therapy index (ATI) of 38 (range 10-82). No significant changes in medication occurred during the first year of device therapy. The number of medications and the ATI decreased after two years of therapy by 0.4 and 4, respectively. 
Table 5.1 Baseline characteristics.

Presented for all enrolled participants $(\mathrm{N}=45)$ and for the cohorts that completed three months $(\mathrm{N}=37)$, one year $(\mathrm{N}=26)$ and two years $(\mathrm{N}=17)$ of device therapy.

\begin{tabular}{|c|c|c|c|c|}
\hline Characteristic & Total enrolled & $\begin{array}{l}\text { Completed } \\
3 \text { month } \\
\text { of therapy } \\
(\mathrm{N}=37)\end{array}$ & $\begin{array}{l}\text { Completed } \\
1 \text { year } \\
\text { of therapy } \\
(\mathrm{N}=26)\end{array}$ & $\begin{array}{c}\text { Completed } \\
2 \text { year } \\
\text { of therapy } \\
(\mathrm{N}=17)\end{array}$ \\
\hline \multicolumn{5}{|l|}{ Demographics } \\
\hline Gender, male (N \%) & $26(58)$ & $21(57)$ & $14(54)$ & $8(47)$ \\
\hline Racial, Caucasian (N \%) & $45(100)$ & $37(100)$ & $26(100)$ & $17(100)$ \\
\hline Age, years (mean $\pm S D)$ & $54 \pm 9$ & $55 \pm 9$ & $53 \pm 9$ & $51 \pm 9$ \\
\hline Body mass index, $\mathrm{kg} / \mathrm{m}^{2}$ (mean $\left.\pm \mathrm{SD}\right)$ & $32 \pm 6$ & $32 \pm 7$ & $33 \pm 7$ & $31 \pm 6$ \\
\hline \multicolumn{5}{|l|}{ Sitting office readings (mean $\pm S D$ ) } \\
\hline Systolic blood pressure, mmHg & $179 \pm 29$ & $179 \pm 28$ & $180 \pm 31$ & $188 \pm 32$ \\
\hline Diastolic blood pressure, $\mathrm{mmHg}$ & $105 \pm 22$ & $105 \pm 22$ & $108 \pm 24$ & $114 \pm 23$ \\
\hline Heart rate, beats/min & $80 \pm 13$ & $80 \pm 13$ & $80 \pm 15$ & $81 \pm 11$ \\
\hline \multicolumn{5}{|l|}{ Antihypertensive treatment (median, range) } \\
\hline Number of different drugs & $5(3-9)$ & $5(3-9)$ & $5(3-9)$ & $5(3-8)$ \\
\hline Antihypertensive therapy index & $38(10-82)$ & $38(10-82)$ & $40(10-82)$ & $34(10-56)$ \\
\hline \multicolumn{5}{|l|}{ Antihypertensive treatment per class ( $\mathrm{N} \%$ ) } \\
\hline ACE inhibitor/A2 blocker & $41(91)$ & $34(92)$ & $24(92)$ & $16(94)$ \\
\hline$\beta$ blocker & $37(82)$ & $29(78)$ & $21(81)$ & $14(82)$ \\
\hline$\alpha$ blocker & $21(47)$ & $16(43)$ & $11(42)$ & $6(35)$ \\
\hline Calcium channel blocker & $34(76)$ & $29(78)$ & $21(81)$ & $12(71)$ \\
\hline Diuretic & $45(100)$ & $37(100)$ & $26(100)$ & $17(100)$ \\
\hline Sympatholitic & $17(38)$ & $14(38)$ & $10(39)$ & $6(35)$ \\
\hline Direct vasodilator & $5(11)$ & $3(8)$ & $3(12)$ & $1(6)$ \\
\hline \multicolumn{5}{|l|}{ Medical history (N \%) } \\
\hline Cardiovascular disease & $34(76)$ & $28(76)$ & $21(81)$ & $13(76)$ \\
\hline Diabetes & $14(31)$ & $11(30)$ & $9(35)$ & $3(18)$ \\
\hline
\end{tabular}

$\mathrm{ACE}=$ angiotensin converting enzyme; $\mathrm{A} 2=$ angiotensin 2.

\section{Adverse events}

All related events of any severity and all unrelated SAEs are listed in Table 5.2. Most procedure-related events are directly related to the incision (i.e. skin numbness, wound complication and pain) or to the anesthetic procedure (i.e. nausea/sickness and temporary throat discomfort caused by intubation). Fifty-two percent of the procedure-related events and $46 \%$ of the device-related events were scored as mild. A total of seven procedure- and one device-related SAEs were reported in 42 subjects (19\%) over 75.8 patient-years of follow-up. There was one fatal procedure-related event due to angioneurotic oedema that occurred six days following implant. Because of procedure-related infections, three other subjects had the device explanted prior to its activation. However, one of these participants in whom the leads were not removed, subsequently had an IPG successfully re-implanted 12 months later. Three additional procedure-related SAEs occurred, including stroke during surgery, tongue paresis (without any abnormalities on MRI of the brain), and moderate pulmonary edema that resolved within six days. The only device-related SAE was due to 
movement of the IPG resulting in the need for further surgery to reposition the IPG, which resolved the problem. An additional 25 nonrelated SAEs were reported which included two additional deaths, one due to a sudden cardiac event and another due to myocardial infarction at 11 and 15 months following implantation, respectively.

Table 5.2 Related and serious adverse events.

All related events of any severity and all unrelated events classified as serious are listed. Events are categorized as procedure-related, device-related and unrelated.

\begin{tabular}{|c|c|c|}
\hline Adverse Event & Events $(\mathrm{N})$ & Participants (N) \\
\hline Procedure-related events & 80 & 42 \\
\hline Temporary throat discomfort & 19 & 17 \\
\hline Numbness skin & 15 & 12 \\
\hline Wound complication & 11 & 10 \\
\hline Sickness/ nausea & 10 & 10 \\
\hline Pain & 8 & 7 \\
\hline Infection* & 3 & 3 \\
\hline Stimulation of extravascular tissue & 2 & 2 \\
\hline Fever & 2 & 2 \\
\hline Sleeping problems & 2 & 2 \\
\hline Stroke* & 1 & 1 \\
\hline Palpitations & 1 & 1 \\
\hline Bradycardia & 1 & 1 \\
\hline Sinus arrest & 1 & 1 \\
\hline Tongue paresis* & 1 & 1 \\
\hline Angioneurotic edema*† & 1 & 1 \\
\hline Pulmonary edema* & 1 & 1 \\
\hline Cranial nerve injury & 1 & 1 \\
\hline Device-related events & 41 & 42 \\
\hline Hypotension-related complaints & 13 & 10 \\
\hline Stimulation of extra vascular tissue & 11 & 10 \\
\hline IPG discomfort & 7 & 6 \\
\hline Pain & 7 & 4 \\
\hline Hypertension & 2 & 2 \\
\hline Moving IPG* & 1 & 1 \\
\hline Unrelated serious events & 25 & 42 \\
\hline Hypertensive crisis & 7 & 2 \\
\hline Chest pain/ short of breath & 3 & 3 \\
\hline Eye cataract surgery & 2 & 1 \\
\hline Bronchitis & 2 & 1 \\
\hline Somatic and psychiatric complaints & 1 & 1 \\
\hline Tooth extraction & 1 & 1 \\
\hline Arthritis & 1 & 1 \\
\hline Syncope & 1 & 1 \\
\hline Hyper hydration & 1 & 1 \\
\hline PTCA & 1 & 1 \\
\hline Increased aortic stenosis & 1 & 1 \\
\hline Acute coronary syndrome & 1 & 1 \\
\hline Sudden cardiac event ${ }^{\dagger}$ & 1 & 1 \\
\hline Myocardial infarction' & 1 & 1 \\
\hline Stroke & 1 & 1 \\
\hline
\end{tabular}

* denotes a related serious adverse event, + denotes a fatal serious adverse event. 
Figure $5.1 \mathrm{a}$ shows the percentage of participants who remained free from a procedure- or device-related SAE. All related events occurred in the first month postimplant and over $80 \%$ of subjects remained free from any procedure- or device-related SAE after two years of follow-up. Figure $5.1 \mathrm{~b}$ shows that $48 \%$ of the participants remained free from any unrelated SAE after two years of follow-up.

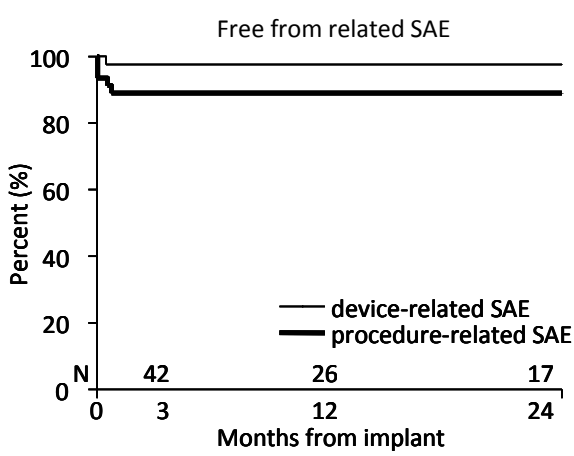

b

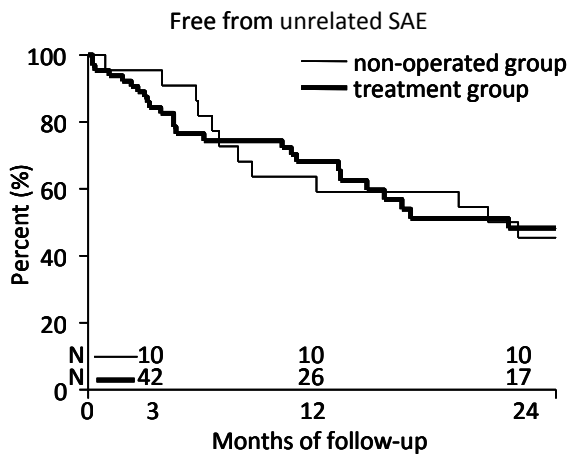

Figure 5.1 Kaplan-Meier analysis for the percent of participants free from a serious adverse event (SAE). Panel a: percentage of participants who remained free from a procedure-related SAE (thick line) and a device-related SAE (thin line).

Panel b: percentage of participants who remained free from an unrelated SAE in the operated group (thick line) and the non-operated group (thin line). The latter group consists of those participants, who were eligible but refused device implant. The number of participants $(\mathrm{N})$ at each data point is shown on the $\mathrm{X}$-axis.

\section{Functional safety measurements}

Figure 5.2 presents the outcome of the additional safety measures. The 6 -minute hall walk distance increased by 17 meters at three months $(P=0.2)$ as measured in 32 participants. At one year, the walk distance significantly rose by 48 meters $(P=0.02)$ in the 14 participants in whom this was measured. Serum creatinine did not change after three months and one year of therapy in 37 and 22 participants, respectively. None of the participants had developed carotid artery stenosis at the 1-year visit. Orthostatic blood pressure recordings were obtained in 32 participants at baseline and following three months of device therapy. No evidence for orthostatic hypotension was found and no events of collapse or syncope were reported. 
a

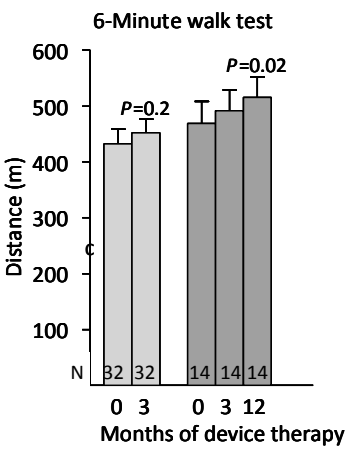

b

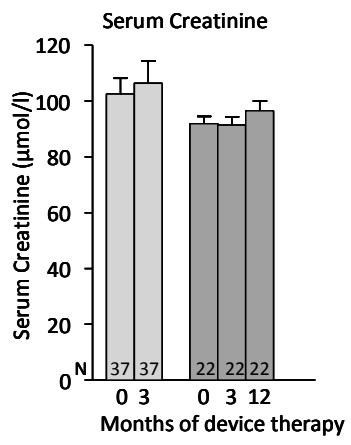

C

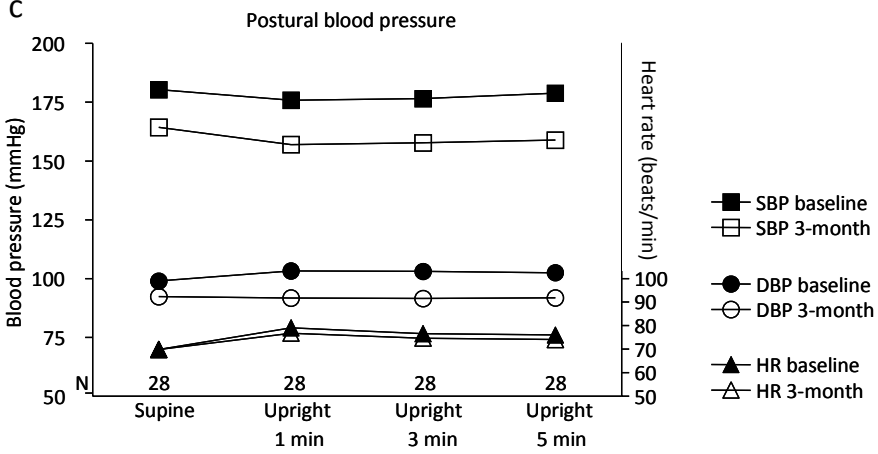

Figure 5.2 Functional safety results following three months and one year of device therapy.

Panel a: distance walked during the 6-minute hall walk test.

Panel b: serum creatinine.

Panel c: orthostatic blood pressure readings.

The number of participants $(\mathrm{N})$ is shown on the $\mathrm{X}$-axis. Paired $P$-values refer to the changes at each time point compared with baseline.

\section{Blood pressure responses}

Longitudinal data on mean OBP are presented in Figure 5.3a. OBP shows a significant decrease at every visit with all decrements being highly significant, as compared with baseline. In 37 participants who completed three months of device therapy, OBP fell by $21 \mathrm{mmHg}(P<0.001)$ and $12 \mathrm{mmHg}(P<0.001)$ for systolic and diastolic $B P$, respectively. HR was significantly reduced by 9 beats/min $(P<0.001)$. Due to several test failures, mean 24-hour ABPM recordings are available in only 26 participants, nevertheless the data show modest decreases during the first three months of device therapy (Figure 5.3b).

In the cohort of 26 participants who completed one year of follow-up, OBP fell significantly by $30 \mathrm{mmHg}(P<0.001)$ systolic and by $20 \mathrm{mmHg}(P<0.001)$ diastolic. $\mathrm{HR}$ was significantly reduced by 9 beats/min ( $P=0.001)$ (Figure 5.3a). Mean 24-hour ABPM 
data are available in 15 participants and demonstrate significant reductions of $13 \mathrm{mmHg}(P<0.001)$ systolic and $8 \mathrm{mmHg}(P=0.001)$ diastolic. HR was lowered by 6 beats/min ( $P=0.01$ ) (Figure $5.3 b)$.
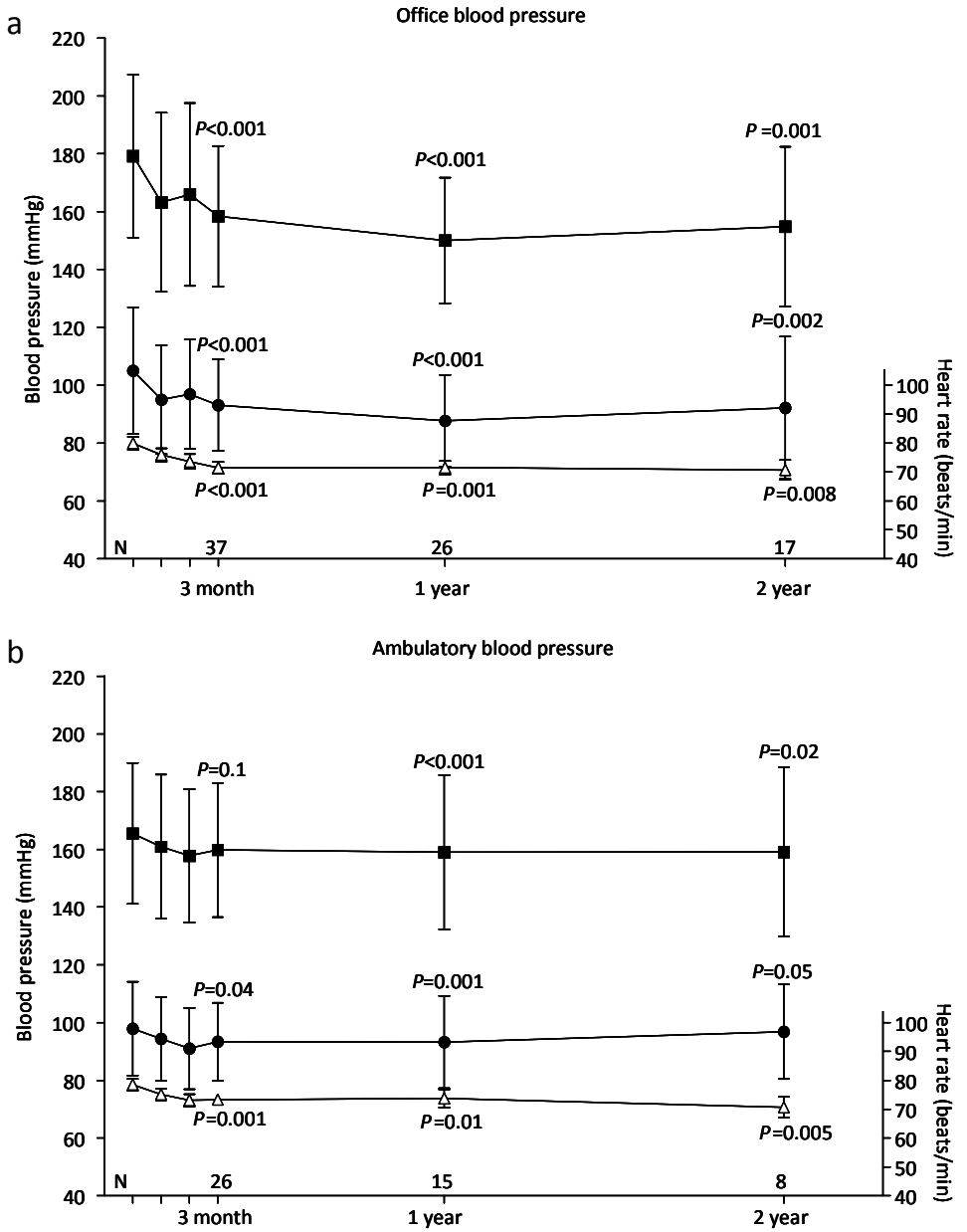

Figure 5.3 Longitudinal blood pressure results.

Blood pressure results for systolic blood pressure (SBP, $\mathbf{\square})$, diastolic blood pressure (DBP, •) and heart rate $(H R, \Delta)$ following three months, one year and two years of device therapy. Panel a: office blood pressure results.

Panel b: 24-hour ambulatory blood pressure measurement results.

The number of participants $(\mathrm{N})$ at each data point is shown on the X-axis. Data presented as means and standard deviations. Paired $P$-values were calculated for the changes at each time point as compared with baseline. 
In the cohort of 17 participants who completed two years of follow-up, OBP showed significant reductions of $33 \mathrm{mmHg}(P=0.001)$ systolic and $22 \mathrm{mmHg}(P=0.002)$ diastolic. HR was significantly reduced by 11 beats/min $(P=0.008)$ (Figure $5.3 \mathrm{a})$. In this cohort, ABPM data are available in eight participants and show statistically significant decreases in blood pressure of $24 \mathrm{mmHg}(P=0.02)$ systolic and $13 \mathrm{mmHg}(P=0.05)$ diastolic. HR was significantly reduced by 11 beats/min ( $P=0.005)$ (Figure $5.3 \mathrm{~b}$ ). In comparison, OBP in this group of eight subjects was decreased by $32 \mathrm{mmHg}(P=0.04)$ systolic and $24 \mathrm{mmHg}(P=0.07)$ diastolic.

At each visit, the device was temporarily turned off to assess the blood pressure level without carotid artery stimulation. Remarkably, blood pressure increased only to fall again when the device was reactivated.

\section{Follow-up of patients who refused device implant}

A cohort of ten patients, who for various personal reasons declined participation in the study were followed-up via regular care. Analysis of their OBP data fails to show a significant change after two years, while the mean number of antihypertensive agents they were taken slightly increased by 0.3 drugs. In total, 12 SAEs were reported during two years of follow-up in those ten patients. Figure $5.1 \mathrm{~b}$ shows that $45 \%$ of the patients in this 'control' group remained free from a SAE, which is comparable to the percentage of participants in the treatment group.

\section{Discussion}

DEBUT-HT was a nonrandomized proof-of-principle study of a carotid sinus stimulator in the treatment of drug-resistant hypertension. Its primary aim was to establish safety but with additional measures to assess efficacy. We found that 42 participants had no unexpected procedure- or device-related SAE during the perioperative and follow-up period. One participant developed an intraoperative stroke, despite our precaution of imaging the carotid arteries, and another developed a tongue paresis, most likely due to peripheral injury to the glossophayngeal and hypoglossal nerves. At least, we found no brainstem lesion on MRI in that participant. We cannot explain the angioneurotic edema occurring in one participant. Overall, the reported SAEs are likely related to the participants individual risks and co-morbidities. While the rate of these events was higher than those usually observed with pacemaker implantation, the events are not entirely unexpected considering the more complex nature of the surgery as compared to a pacemaker implant. The nonserious procedure-related adverse events include items which are often associated with a surgical procedure, such as nausea and vomiting, numbness in the skin, hematoma, and wound complications. Most participants tolerated the device well and were not encumbered by its presence.

Exercise tolerance, as measured with the 6-minute hall walk test, improved significantly in 14 participants following one year of device therapy. No adverse effect 
on renal function was found, as inferred from measurements of serum creatinine and none of the subjects developed carotid artery stenosis. Remarkably, no orthostatic events were reported and orthostatic blood pressure readings in 32 participants did not show evidence of postural hypotension. Altogether, these data indicate that baroreflex sensitivity is not impaired during postural stress. Proper functioning of baroreceptors in the aortic arch may be responsible for the prevention of orthostatic problems.

The office blood pressure data in 37 participants show a statistically significant fall of $21 / 12 \mathrm{mmHg}$ after three months of therapy with the baroreflex activating system. At the same time, the intensity of antihypertensive drug treatment was still unchanged suggesting that the blood pressure changes were related to the procedure rather than to the medical therapy. Paired data, available in 26 of the participants after one year of therapy, showed a sustained decrease in OBP of $30 / 20 \mathrm{mmHg}$, again without any alteration in medication. Thus, as far as the primary efficacy outcome is concerned, the device appeared to fulfill its promises. Still, some caution is needed in the interpretation of these results. As it would be unethical at this stage in the evaluation of the device to include a formal control group, we cannot entirely rule out a nonspecific or placebo-like effect. However, two of our observations argue against that possibility. First, those patients who refused participation in the study were followed as closely as the others but did not show any relevant decrease in their blood pressure. Their medication even had to be intensified which was not the case in the study group. Second, when the device was temporarily switched off at the beginning of the follow-up visits, blood pressure rose toward its original level only to fall again when we reactivated the carotid baroreceptor stimulation. This provides strong evidence in favor of the device.

The fall in pressure was not only evident for OBP but also, albeit less conspicuously, for 24-hour blood pressure. Although we could not obtain ABPM data in all participants, those who had adequate recordings after one year of carotid baroreceptor stimulation showed a statistically significant decline in pressure of $13 / 8$ $\mathrm{mmHg}$. Paired OBP and ABPM data after two years of therapy, available in 17 and eight participants, respectively, confirmed this observation. The fact that changes in blood pressure were lesser for ABPM than for OBP does not detract from our findings. Indeed, a meta-analysis of a large number of studies concluded that the reduction in blood pressure during ABPM is almost invariably smaller than the concomitant reduction in $\mathrm{OBP}^{31}$. Moreover, different levels of activity during follow-up as compared with baseline may have confounded the data ${ }^{32,33}$.

In conclusion, implantation of the Rheos ${ }^{\circledR}$ System in participants with drug-resistant hypertension is feasible and the device is acceptable to the participants. We found a clinically and statistically significant reduction in blood pressure of over $20 \mathrm{mmHg}$ systolic that could be sustained for at least two years, although this has to be viewed in the context of no placebo group. The reproducibility of these findings will have to be determined via a randomized controlled trial which is currently underway. 


\section{References}

1 Chobanian AV, Bakris GL, Black HR, Cushman WC, Green LA, Izzo JL, Jr., Jones DW, Materson BJ, Oparil S, Wright JT, Jr., Roccella EJ. The Seventh Report of the Joint National Committee on Prevention, Detection, Evaluation, and Treatment of High Blood Pressure: the JNC 7 report. JAMA 2003;289: 2560-2572.

2 Hajjar I, Kotchen TA. Trends in prevalence, awareness, treatment, and control of hypertension in the United States, 1988-2000. JAMA 2003;290:199-206.

3 Fields LE, Burt VL, Cutler JA, Hughes J, Roccella EJ, Sorlie P. The burden of adult hypertension in the United States 1999 to 2000: a rising tide. Hypertension 2004;44:398-404.

4 Schwartz SI, Griffith LS, Neistadt A, Hagfors N. Chronic carotid sinus nerve stimulation in the treatment of essential hypertension. Am J Surg 1967;114:5-15.

5 Neistadt A, Schwartz SI. Effects of electrical stimulation of the carotid sinus nerve in reversal of experimentally induced hypertension. Surgery 1967;61:923-931.

6 Brest AN, Wiener L, Bachrach B. Bilateral carotid sinus nerve stimulation in the treatment of hypertension. Am J Cardiol 1972;29:821-825.

7 Filippone JD, Sloand JA, Illig KA, Bisognano JD. Electrical stimulation of the carotid sinus for the treatment of resistant hypertension. Curr Hypertens Rep 2006;8:420-424.

8 Lohmeier TE, Barrett AM, Irwin ED. Prolonged activation of the baroreflex: a viable approach for the treatment of hypertension? Curr Hypert Rep 2005;7:193-198.

9 Bilgutay AM, Lillehei CW. Treatment of Hypertension with an Implantable Electronic Device. JAMA 1965;191:649-653.

10 Griffith LS, Schwartz SI. Reversal of renal hypertension by electrical stimulation of the carotid sinus nerve. Surgery 1964;56:232-239.

11 Bilgutay AM, Lillehei CW. Surgical treatment of hypertension with reference to baropacing. Am J Cardiol 1966;17:663-667.

12 Tuckman J, Lyon AF, Reich T, Jacobson JH, 2nd. Evaluation of carotid sinus nerve stimulation in the treatment of hypertension. Ther Umsch 1972;29:382-391.

13 Braunwald NS, Epstein SE, Braunwald E. Carotid sinus nerve stimulation for the treatment of intractable angina pectoris: surgical technic. Ann Surg 1970;172:870-876.

14 Wagner J, Korsukewitz J, Meyer W, Dittberner KH, Zerbst E, Schaede A. CarotissinusnervenStimulation. Dtsch Med Wochenschr 1973;98:37-43.

15 Saadjian A, Torresani J, Pudddu PE. Clinical interest of carotid sinus nerve stimulation in man. G Ital Cardiol 1980;10:1578-1582.

16 Grassi G. Counteracting the sympathetic nervous system in essential hypertension. Curr Opin Nephrol Hypertens 2004;13:513-519.

17 Guyenet PG. The sympathetic control of blood pressure. Nat Rev Neurosci 2006;7:335-346.

18 Malpas SC. What sets the long-term level of sympathetic nerve activity: is there a role for arterial baroreceptors? Am J Physiol Regul Integr Comp Physiol 2004;286:R1-R12.

19 Thrasher TN. Baroreceptors and the long-term control of blood pressure. Exp Physiol 2004;89: 331-335.

20 Thrasher TN. Arterial baroreceptor input contributes to long-term control of blood pressure. Curr Hypertens Rep 2006;8:249-254.

21 Scheffers IJ, Kroon AA, Tordoir JH, de Leeuw PW. Rheos ${ }^{\circledR}$ Baroreflex Hypertension Therapy ${ }^{\mathrm{TM}}$ System to treat resistant hypertension. Expert Rev Med Devices 2008;5:33-39.

22 Lohmeier TE, Dwyer TM, Hildebrandt DA, Irwin ED, Rossing MA, Serdar DJ, Kieval RS. Influence of prolonged baroreflex activation on arterial pressure in angiotensin hypertension. Hypertension 2005;46:1194-1200.

23 Lohmeier TE, Dwyer TM, Irwin ED, Rossing MA, Kieval RS. Prolonged activation of the baroreflex abolishes obesity-induced hypertension. Hypertension 2007;49:1307-1314.

24 Lohmeier TE, Irwin ED, Rossing MA, Serdar DJ, Kieval RS. Prolonged activation of the baroreflex produces sustained hypotension. Hypertension 2004;43:306-311. 
25 Schmidli J, Savolainen H, Eckstein F, Irwin E, Peters TK, Martin R, Kieval R, Cody R, Carrel T. Acute device-based blood pressure reduction: electrical activation of the carotid baroreflex in patients undergoing elective carotid surgery. Vascular 2007;15:63-69.

26 Mohaupt MG, Schmidli J, Luft FC. Management of uncontrollable hypertension with a carotid sinus stimulation device. Hypertension 2007;50:825-828.

27 Tordoir JH, Scheffers I, Schmidli J, Savolainen H, Liebeskind U, Hansky B, Herold U, Irwin E, Kroon AA, de Leeuw P, Peters TK, Kieval R, Cody R. An implantable carotid sinus baroreflex activating system: surgical technique and short-term outcome from a multi-center feasibility trial for the treatment of resistant hypertension. Eur J Vasc Endovasc Surg 2007;33:414-421.

28 Illig KA, Levy M, Sanchez L, Trachiotis GD, Shanley C, Irwin E, Pertile T, Kieval R, Cody R. An implantable carotid sinus stimulator for drug-resistant hypertension: surgical technique and shortterm outcome from the multicenter phase II Rheos feasibility trial. J Vasc Surg 2006;44:1213-1218.

29 Carlini R, Obialo $\mathrm{Cl}$, Rothstein M. Intravenous erythropoietin (rHuEPO) administration increases plasma endothelin and blood pressure in hemodialysis patients. Am J Hypertens 1993;6:103-107.

30 Solway S, Brooks D, Lacasse Y, Thomas S. A qualitative systematic overview of the measurement properties of functional walk tests used in the cardiorespiratory domain. Chest 2001;119:256-270.

31 Mancia G, Parati G. Office compared with ambulatory blood pressure in assessing response to antihypertensive treatment: a meta-analysis. J Hypertens 2004;22:435-445.

32 Ben-Dov IZ, Ben-Arie L, Mekler J, Bursztyn M. In clinical practice, masked hypertension is as common as isolated clinic hypertension: predominance of younger men. Am J Hypertens 2005;18:589-593.

33 Pickering TG, Gerin W. Ambulatory blood pressure and reactivity. J Hypertens 1992;10:299-300. 



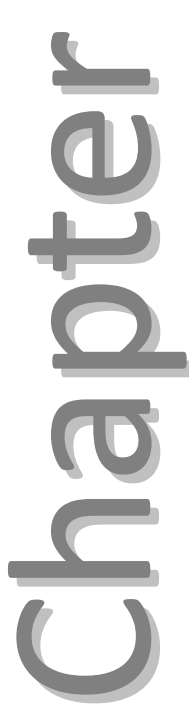

Effects of chronic baroreceptor stimulation on the autonomic cardiovascular regulation in humans with drug-resistant arterial hypertension

K Wustmann, JP Kucera, IJM Scheffers, M Mohaupt, AA Kroon, PW de Leeuw, J Schmidli, Y Allemann, E Delacrétaz

Hypertension 2009;54:530-536 


\section{Abstract}

In patients with drug-resistant hypertension, chronic electrical activation of the carotid baroreflex is an investigational therapy for blood pressure reduction. We hypothesized that changes in cardiac autonomic regulation can be demonstrated in response to chronic baroreceptor stimulation, and we analysed the correlation with blood pressure changes.

Twenty-one participants with drug-resistant hypertension were prospectively included in a substudy of the Device Based Therapy in Hypertension Trial. Heart rate variability and heart rate turbulence were analysed using 24-hour ECG. Recordings were obtained one month after device implantation before chronic activation of the stimulator (OFF) and after three months of chronic electrical stimulation (ON).

Chronic baroreceptor stimulation decreased office systolic/diastolic blood pressure from 185/109 $\mathrm{mmHg}$ to $154 / 95 \mathrm{mmHg}(P<0.001$ and $P=0.002$, respectively). Mean heart rate decreased from 81 to 76 beats $/ \mathrm{min}$ $(P=0.001)$. Heart rate variability frequency-domain parameters assessed using fast Fourier transformation (FFT= ratio of low frequency: high frequency; 2.78 versus 2.24 ; OFF versus $O N ; P<0.001$ ) were significantly changed during stimulation of the carotid baroreceptor, and heart rate turbulence onset was significantly decreased (turbulence onset: -0.002 versus -0.015 for OFF versus $O N ; P=0.004$ ).

In conclusion, chronic baroreceptor stimulation causes sustained changes in heart rate variability and heart rate turbulence that are consistent with inhibition of sympathetic activity and increase of parasympathetic activity in participants with drug-resistant systemic hypertension; these changes correlate with blood pressure reduction. Whether the autonomic modulation has favorable cardiovascular effects beyond blood pressure control should be investigated in further studies. 


\section{Introduction}

Systemic arterial hypertension is one of the leading cardiovascular diseases in the world and a major cardiovascular risk for coronary artery disease, cerebrovascular disease, and heart and renal failure. Despite carefully assessing causes and stratifying therapeutic approaches using all of the existing antihypertensive pharmacological agents, not all hypertensive patients sufficiently respond to pharmacologic treatment. Stimulation of the carotid baroreceptor has been considered several decades ago as a potential treatment for blood pressure (BP) lowering in humans ${ }^{1-3}$. The roles of carotid baroreceptors in acute regulation of BP and the acute effect of carotid baroreceptor stimulation are well documented ${ }^{3,4}$. However, whether arterial baroreceptors play a role in long-term regulation of arterial pressure is still debated ${ }^{5}$ and the benefit of chronic carotid baroreceptor stimulation as treatment of hypertension in humans is currently under investigation. Lohmeier et al. ${ }^{6,7}$ demonstrated that electrical activation of the baroreflex lasting seven days produces sustained hypotension in dogs using an implantable stimulation device (Rheos ${ }^{\circledR}$ System; CVRx. Inc., Minneapolis, MN, USA). Implantation of permanent bilateral perivascular carotid sinus electrodes and a pulse generator for chronic stimulation was shown to be feasible in humans ${ }^{8-11}$. The Device Based Therapy in Hypertension Trial (DEBUT-HT) was conducted to test the safety and efficacy of chronic electric baroreceptor stimulation with Rheos ${ }^{\circledR}$ System for BP control in patients with drug-resistant essential arterial hypertension ${ }^{12}$.

We hypothesized in the present study a long-term modulation of the sympathetic and parasympathetic activities during chronic carotid baroreceptor stimulation with a corresponding decrease in BP, and we investigated a subgroup of the DEBUT-HT study population. The modulation of the autonomic nervous system was assessed by analysis of heart rate variability (HRV) and heart rate turbulence (HRT) before and during carotid baroreceptor stimulation ${ }^{13-15}$. Both methods are clinically established to analyse the sympathovagal modulation of sinus node activity.

\section{Methods}

This study is a substudy of the prospective, multi-center, nonrandomized phase II DEBuT-HT study, which was conducted to assess the safety and efficacy of the electrical carotid sinus baroreceptor stimulation Rheos ${ }^{\circledR}$ System for chronic BP reduction in patients with drug-resistant arterial hypertension. The 21 participants included in this substudy were from Bern and Maastricht.

\section{Participants}

Participants with essential arterial hypertension and uncontrolled BP (>160/90 mmHg) despite medical treatment with $\geq 3$ antihypertensive agents (including a diuretic) for more than two months and aged 21 years or more, were eligible to be included in the 
DEBuT-HT study. Exclusion criteria included secondary hypertension, known cerebrovascular disease, carotid artery stenosis (defined as $>50 \%$ luminal stenosis), previous carotid artery surgery, previous radiotherapy of the carotid sinus region, persistent atrial fibrillation, significant orthostatic hypotension, clinically significant cardiac valvular disease, heart transplantation, dialysis, and pregnancy. In addition, patients with implanted pacemaker, defibrillator, or neurologic stimulator were excluded $^{8}$.

The DEBuT-HT protocol was approved by the Ethics Committees in Bern and Maastricht and written informed consent was obtained from all participants before entering into the study. Although 24-hour ECG recordings were performed in all DEBuT-HT study centers for safety purpose according to study protocol, only participants from Bern and Maastricht were included in the present substudy. Participants were enrolled from March 2004 to July 2007.

\section{Study protocol}

The surgical procedure and intraoperative testing of the baroreceptor stimulation device have been described previously ${ }^{8-10}$. After surgical implantation, the device was left turned off during the healing process. One month after implantation, a baseline 24-hour ECG was registered with the stimulation device turned off (OFF). Afterwards, the Rheos ${ }^{\circledR}$ System was turned on, and a dose response test was performed in the following manner: bilateral carotid baroreceptor stimulation was started at a pulse amplitude of 1 volt (V). After one minute of stimulation, blood pressure was measured and recorded. This step was repeated with outputs of 2, 3, 4, 5 and $6 \mathrm{~V}$. On the basis of the participants BP response, the electrical parameters of the device were then programmed to achieve approximately $10 \%$ reduction in current participants BP. The goal was not to achieve maximal BP reduction. At follow-up visits, a 24-hour ECG was also recorded. The 24-hour ECG obtained after optimization of electrical therapy at the 3-month visit (ON) was compared with the recording obtained with the device OFF (one month after implantation). Pharmacological antihypertensive therapy was continued without any change throughout the study period.

\section{4-hour ECG recordings}

The 24-hour ECGs were recorded with two bipolar electrodes in the V2 and V5 positions using the CardioDay system (Getemed, Teltow, Germany) in Bern and the Marquette system (GE Marquette Medical Systems, Milwaukee, Wisconsin, USA) in Maastricht. Sample rates for both Holter ECG recordings were $128 \mathrm{~Hz}$. Raw data were labelled for normal QRS complexes, supraventricular and ventricular premature depolarizations (both with prematurity $\leq 80 \%$ ), arrhythmias, electrical noise, and other aberrant electrocardiographic signals by a well-trained technician using a customwritten program developed in the IDL environment (IDL version 6.2., ITT Visual Information Solutions, Boulder, CO, USA). The program permitted to identify the 
R-waves (times of occurrence defined by the local maxima) and to edit the detected events manually. The entire Holter recordings were carefully inspected to ensure that all R-waves were detected correctly and thus that correct R-R interval series were generated.

\section{Heart rate variability}

Series of R-R intervals were derived from the 24-hour ECG data for the analysis of HRV according to the guidelines of the Task Force of the European Society of Cardiology and the North American Society of Pacing and Electrophysiology ${ }^{13}$. Time-domain and frequency-domain HRV analyses were conducted on 24-hour R-R interval sequences devoid of ectopic beats and artefacts using the HRV analysis software developed by Niskanen et al. ${ }^{16}$ (kindly provided by $\mathrm{Dr}$ J. Niskanen and $\mathrm{Dr}$ P. A. Karjalainen). HRV analysis was conducted on nondetrended 24-hour R-R interval series.

Time-domain analysis was conducted. Standard deviation of all normal R-R intervals (NN) during a 24-hour period (SDNN, ms) reflecting both long- and short-term NN interval variations, and SDNN index (mean of the standard deviations of all NN intervals for all 5-minute segments in 24 hours, $\mathrm{ms}$ ) reflecting short-term variations, were determined. Additionally, the percentage of intervals of $>50 \mathrm{~ms}$ than the preceding interval (pNN50,\%), and the root mean square successive difference of all NN intervals (RMDSS, ms), were computed ${ }^{13}$.

Frequency-domain analysis of the HRV power (in $\mathrm{ms}^{2}$ ) was computed in the high frequency (HF: $0.15-0.5 \mathrm{~Hz}$ ) and low frequency (LF; $0.04-0.15 \mathrm{~Hz}$ ) bands based on the Welch's periodogram (based on the FFT) using windows of $1500 \mathrm{~s}$ (25 min), with an overlap of $750 \mathrm{~s}$. The LF:HF ratio was computed as well ${ }^{13}$.

\section{Heart rate turbulence}

Turbulence onset (TO) reflects the initial acceleration of sinus rhythm following a single premature atrial or ventricular beat, whereas turbulence slope (TS) describes the rate of heart rate deceleration following the sinus acceleration. Available physiologic investigations confirm that the initial heart rate acceleration is triggered by transient vagal inhibition in response to the missed baroreflex afferent input caused by hemodynamically inefficient ventricular contraction. A sympathetically mediated overshoot of arterial pressure is responsible for the subsequent heart rate deceleration through vagal recruitment ${ }^{17}$. Both parameters were derived from 24-hour Holter data for supraventricular premature depolarization (SVPD) and ventricular premature depolarization (VPD) according to the method of Schmidt et al. using HRT View (version 1.11, Klinikum rechts der Isar) ${ }^{15}$.

A prerequisite for the determination of HRT parameters is the presence of sinus rhythm free of ectopic beats and artefacts immediately $\geq 2$ beats before and $>16$ beats after the considered single premature beats. Because TO and TS must be averaged for several ectopic beats, their predictive power is low in the presence of only one ectopic 
beat. Therefore, we analysed HRT only in the presence of $\geq 2$ either atrial or ventricular premature beats fulfilling the analysis criteria above. HRT analysis was conducted on nondetrended R-R interval series as well.

\section{Statistical analysis}

Normally distributed data are presented as mean \pm standard deviation, whereas median are used for data with nonnormal distribution. Baseline and follow-up clinical data, HRV and HRT measurements were compared using the Wilcoxon signed-rank test. Univariate correlations were performed with Spearman rank correlation. Statistical significance was assumed for $P<0.05$. Statistical analyses were performed using StatView (Version 4.57, Abacus Concepts, Berkeley, USA) and SPSS for Windows (version 15.0.1., Chicago, USA).

\section{Results}

The characteristics of the 21 participants are shown in Table 6.1. At inclusion, systolic and diastolic office BP were significantly above the recommended target of 140/90 $\mathrm{mmHg}$ despite a pharmacological treatment with three to eight different antihypertensive agents, and on average, they were consistent with hypertension stage III for systolic and stage II for diastolic BP values.

Table 6.1 Participant characteristics $(\mathrm{N}=21)$.

\begin{tabular}{lr}
\hline Characteristic & $11(52)$ \\
\hline Gender, male (N \%) & $53 \pm 10$ \\
Age, year (mean \pm SD) & \\
Sitting office readings (mean \pm SD) & $190 \pm 34$ \\
Systolic blood pressure, mmHg & $108 \pm 14$ \\
Diastolic blood pressure, mmHg & $79 \pm 13$ \\
Heart rate, beats/min & \\
Antihypertensive treatment, (N \%) & $2(10)$ \\
Participants with 3 different agents & $15(71)$ \\
Participants with 4 or 5 different agents & $4(19)$ \\
Participants with $\geq 6$ different agents & \\
Class of drugs used, (N \%) & $17(81)$ \\
$\beta$-blockers & $9(43)$ \\
Angiotensin-converting enzyme inhibitors & $12(57)$ \\
Angiotensin receptor antagonist & $4(19)$ \\
Loop diuretics & $17(81)$ \\
Thiazide diuretics & $5(24)$ \\
Aldosterone antagonists & $2(10)$ \\
Potassium-sparing diuretics & $15(71)$ \\
Calcium channel blockers & $9(43)$ \\
Peripheral $\alpha$-blockers & $5(24)$ \\
Central $\alpha$-agonists & $5(24)$ \\
Nitrates & $1(5)$ \\
\hline
\end{tabular}




\section{Effect on heart rate variability}

HRV time-domain are measures from series of instantaneous heart rates or cycle intervals. Results from the HRV time-domain analysis are reported in Table 6.2. Mean heart rate over 24 hours significantly decreased during stimulation therapy $(P=0.001)$. All of the time-domain HRV parameters significantly changed during carotid baroreceptor stimulation when compared with baseline values. RMSSD, pNN50, SDNN and SDNN index significantly increased during stimulation therapy, consistent with decreased sympathetic activity and increased parasympathetic activity.

Table 6.2 Mean 24-hour results $(\mathrm{N}=21)$ on heart rate variability. HRV time-domain and frequency-domain measures and office BP values before (OFF) and with chronic electrical baroreceptor stimulation (ON).

\begin{tabular}{lccc}
\hline Variable & Stimulator OFF & Stimulator ON & $P$ \\
\hline Time-domain measures & & & \\
Heart rate, 1/min & $81 \pm 11$ & $76 \pm 10$ & 0.001 \\
R-R intervals, ms & $743 \pm 182$ & $818 \pm 107$ & 0.002 \\
SDNN, ms & $89 \pm 20$ & $95 \pm 23$ & 0.2 \\
SDNN index, ms & $37 \pm 10$ & $44 \pm 13$ & $<0.001$ \\
pNN50, \% & $1.3(2.2)$ & $2.6(4.8)$ & $<0.001$ \\
RMSSD, ms & $18.6 \pm 6.7$ & $24.3 \pm 9.5$ & $<0.001$ \\
Frequency-domain measures (FFT) & & & $<0.001$ \\
HF power, ms2 & $42(59)$ & $67(105)$ & $<0.001$ \\
LF power, ms2 & $150(196)$ & $117(135)$ & $<0.001$ \\
Ratio LF:HF & $2.78(2.75)$ & $2.24(2.09)$ & $<0.001$ \\
Office blood pressure & & & 0.002 \\
Systolic, mmHg & $184 \pm 31$ & $154 \pm 23$ & $95 \pm 15$ \\
Diastolic, mmHg & $109 \pm 23$ & & \\
\hline
\end{tabular}

SDNN index indicates the mean of the SDNN intervals for all 5-minute segments in four hours. Data are mean \pm SD or median (mean).

HRV frequency-domain measures power spectral density/variation as a function of frequency. In the FFT analysis, the spectral power of the HF and components was significantly changed during carotid baroreceptor stimulation (Table 6.2). The HF component significantly increased in power during carotid baroreceptor stimulation compared with the data without stimulation, whereas the LF component was diminished in power. Consequently, there was a decrease of LF:HF ratio (Table 6.2 and Figure 6.1), which can be attributed to a sustained decline of the adrenergic level and increased vagal activity during chronic baroreceptor stimulation.

Tables 6.3 and 6.4 display the same analysis for night and day measurements. All of the changes found in the 24-hour analysis were also observed during day and night. Although the heart rate was significantly lower during the night, the changes in HRV measurements during chronic baroreceptor stimulation appeared similar during the day and night. 


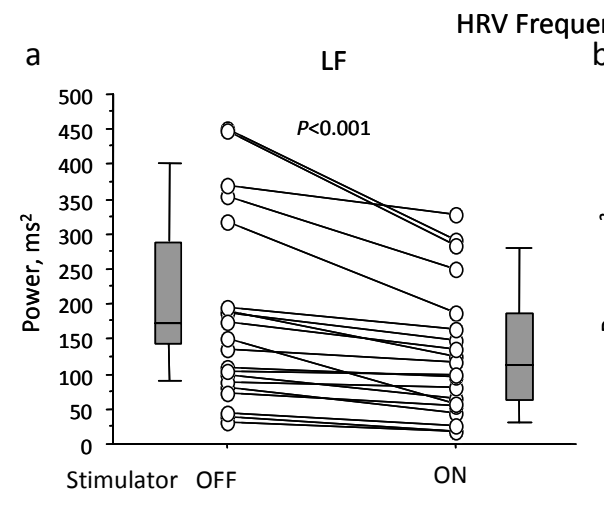

b HF
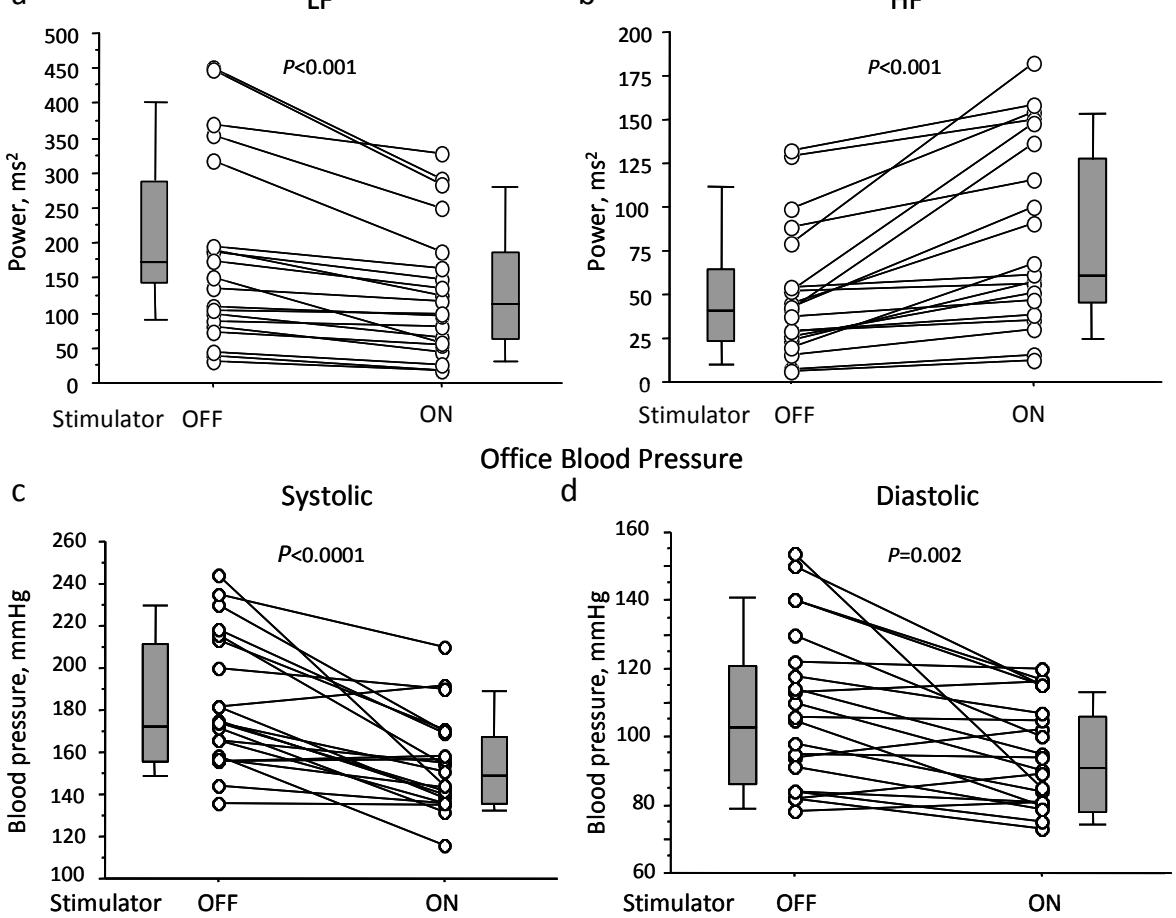

Figure 6.1 Individual data points $(\mathrm{N}=21)$.

Effect of chronic electric baroreceptor stimulation (ON) compared with baseline (OFF).

Panel a: LF power, consistent with a decreased sympathetic activity.

Panel b: HF power, consistent with enhanced vagel outflow.

Panel c: systolic blood pressure.

Panel d: diastolic blood pressure.

Table 6.3 Mean daytime results ( $\mathrm{N}=21)$.

HRV measures during day before (OFF) and during chronic baroreceptor stimulation (ON).

\begin{tabular}{lccc}
\hline Variable & Stimulator OFF & Stimulator ON & $P$ \\
\hline Time-domain measures & & & \\
Heart rate, 1/min & $86 \pm 13$ & $81 \pm 13$ & 0.01 \\
R-R intervals, ms & $718 \pm 110$ & $764 \pm 121$ & 0.009 \\
SDNN, ms & $56 \pm 16$ & $66 \pm 20$ & 0.01 \\
SDNN index, ms & $31 \pm 9$ & $28 \pm 12$ & 0.006 \\
pNN50, \% & $0.3(0.6)$ & $1.6(2.6)$ & $<0.001$ \\
RMSSD, ms & $14.1 \pm 4.0$ & $19.7 \pm 6.7$ & 0.001 \\
Frequency-domain measures (FFT) & & & $<0.001$ \\
HF power, ms2 & $27(24)$ & $36(55)$ & 0.033 \\
LF power, ms2 & $103(120)$ & $74(92)$ & $<0.001$ \\
Ratio LF:HF & $3.63(3.70)$ & $2.44(2.46)$ & \\
\hline
\end{tabular}

SDNN index indicates the mean of the SDNN intervals for all 5-minute segments in four hours. Data are mean \pm SD or median (mean). 
Table 6.4 Mean night time results $(\mathrm{N}=21)$.

HRV measures during night before (OFF) and during chronic baroreceptor stimulation (ON).

\begin{tabular}{lccr}
\hline Variable & Stimulator OFF & Stimulator ON & $P$ \\
\hline Time-domain measures & & & \\
Heart rate, 1/min & $69 \pm 9$ & $65 \pm 8$ & 0.006 \\
R-R intervals, ms & $885 \pm 124$ & $938 \pm 111$ & 0.006 \\
SDNN, ms & $60 \pm 18$ & $71 \pm 22$ & 0.003 \\
SDNN index, ms & $41 \pm 14$ & $51 \pm 19$ & $<0.001$ \\
pNN50, \% & $1.9(4.6)$ & $5.2(10.7)$ & $<0.001$ \\
RMSSD, ms & $22.4 \pm 9.9$ & $32.2 \pm 16.8$ & $<0.001$ \\
Frequency-domain measures (FFT) & & & \\
HF power, ms2 & $67(97)$ & $116(196)$ & $<0.001$ \\
LF power, ms2 & $199(245)$ & $126(215)$ & 0.007 \\
Ratio LF:HF & $2.10(2.63)$ & $1.63(1.81)$ & $<0.001$ \\
\hline
\end{tabular}

SDNN index indicates the mean of the SDNN intervals for all 5-minute segments in four hours. Data are mean \pm SD or median (mean).

\section{Effect on heart rate turbulence}

TO reflects the initial acceleration of sinus rhythm after a single premature atrial or ventricular beat, whereas TS describes the heart rate deceleration after the previous sinus rhythm acceleration. Analysis of HRT following supraventricular premature beats was available in 17 participants and after ventricular premature beats in 13 participants before and during chronic carotid baroreceptor stimulation (Table 6.5). TO and TS were significantly altered during stimulation therapy consistent with an enhanced parasympathetic activity and decreased sympathetic activity by chronic baroreflex activation (Table 6.4).

Table 6.5 Median results on HRT.

HRT measures for TO and TS in participants before (OFF) and with chronic electrical baroreceptor stimulation (ON) after supraventricular premature depolarizations and vertricular premature depolarizations.

\begin{tabular}{lccc}
\hline Turbulence measure & Stimulator OFF & Stimulator ON & $P$ \\
\hline TO SVPD, $\%(n=17)$ & 0.018 & 0.007 & 0.076 \\
TS SVPD, ms per beat $(n=17)$ & 1.94 & 4.2 & 0.01 \\
TO VPD, $\%(n=13)$ & -0.002 & -0.015 & 0.004 \\
TS VPD, ms per beat $(n=13)$ & 3.75 & 5.6 & 0.02 \\
\hline
\end{tabular}

SVPD indicates supraventricular premature depolarization; VPD, ventricular premature depolarization

\section{Blood pressure results and correlation}

Chronic carotid baroreceptor stimulation, applied on top of the continued antihypertensive pharmacotherapy, significantly lowered systolic and diastolic office BP (Table 6.1 and Figure 6.1). Overall, changes in systolic and diastolic BP correlated significantly in the 21 participants (correlation coefficient $0.81, P<0.001$ ). Diastolic BP 
decreased in all but one participant with systolic BP decrement of $\geq 10 \mathrm{mmHg}$. In four participants there was only a modest or no response of systolic $(<10 \mathrm{mmHg})$ and diastolic BPs. Only one participant without systolic BP change showed a decrease in diastolic BP. The magnitude of BP reduction was related to baseline systolic $(P=0.001$, correlation coefficient 0.66$)$ and baseline diastolic BP level $(P=0.001$, correlation coefficient 0.69 ). The changes in heart rate did not correlate significantly with the changes in BP ( $P=0.39$ for systolic $B P, P=0.23$ for diastolic $B P)$.

As illustrated in Figure 6.2, we found a significant positive correlation between the decrease in systolic BP and the LF:HF ratio for the nonparametric analysis $(P=0.02)$. Changes in diastolic pressure did not correlate with variations in HRV or HRT parameters.

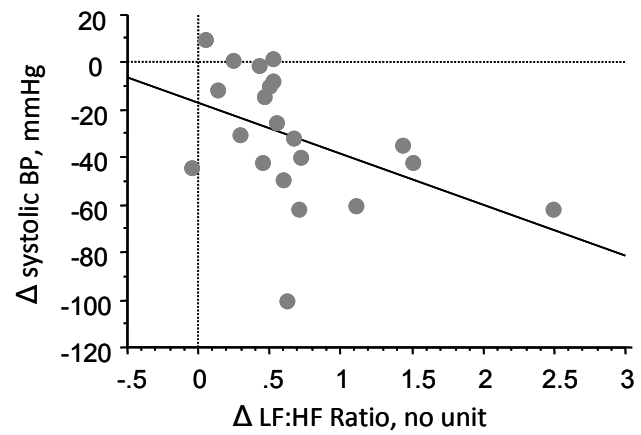

$\Delta$ systolic BP $=-16.92-21.52 * \Delta \mathrm{LF}: \mathrm{HF}$ Ratio $\mathrm{R}=0.47, P=0.04$

Figure 6.2 Correlation ( $\mathrm{N}=21$ ) between the difference in systolic BP ( $\Delta$ systolic BP) and LF:HF ratio from the FFT model.

\section{Discussion}

The study demonstrates that chronic bilateral electrical carotid baroreceptor stimulation is associated with a sustained modulation of HRV and HRT in drug-resistant, severely hypertensive patients. Changes in HRV parameters and changes in HRT are consistent with a decrease of sympathetic activity and an increase of vagal tone. These changes are correlated with a significant decrease in systolic BP. Thus, chronic carotid baroreceptor stimulation likely contributes to a better BP control through sympathovagal modulation in severely hypertensive patients.

Previous studies showed the acute effect of carotid baroreceptor stimulation on BP measurements ${ }^{1,2,10}$. In addition, short-term (usually 5-7 days) experimental observations provided evidence that the efferent response to BP stimuli persists over five to seven days in diverse experimental settings ${ }^{18-24}$. Lohmeier et al. ${ }^{6}$ demonstrated 
that electrical activation of the baroreflex during seven days using the same stimulation device as that in our study produces sustained hypotension in dogs. Our study provides for the first time evidence in humans that chronic carotid baroreceptor stimulation has a sustained effect on HRV parameters, HRT, and BP values in drug-resistant severely hypertensive patients, without adaptation blunting the effect of stimulation.

In humans, alterations of the cardiac autonomic balance and BP changes over several days have been reported after vascular interventions close to the carotid bifurcation. Carotid arterial stenting was associated with a short-term parasympathetic predominance that was associated with decreased $\mathrm{BP}^{25-27}$. This may be due to stimulation of the baroreceptors through stretching of the carotid sinus by angioplasty and stent deployment. In contrast, HRV measurements in participants after carotid endarteriectomy showed an increased sympathetic and a decreased vagal activity during the first four days postprocedure compared with baseline ${ }^{27}$. Carotid endarterectomy and complete bilateral surgical removal of carotid body tumors led to a significant postoperative hypertension ${ }^{26,28,29}$. The mechanism responsible for the baroreflex dysfunction, for increased sympathetic activity, and for arterial hypertension postsurgery is suspected to be related to the damaging of carotid baroreceptors and the afferent nerves situated on the adventitial site. In the present study, the first Holter recording with the device off was performed one month after surgery. An alteration of carotid baroreceptor function at the time of the baseline measurements cannot be fully ruled out. However, all of the participants had clinically fully recovered from surgery. In addition, the integrity of the carotid baroreflex was verified intraoperatively. Therefore, it is very likely that the HRV and HRT changes observed are really showing the effect of carotid baroreceptor stimulation.

Although significant, the correlation between BP reduction and HRV parameters was not very strong. Thus, it may be difficult to predict the BP response to chronic carotid baroreceptor stimulation with HRV and HRT parameters. There were important interindividual differences in BP reduction, for example there were six participants without BP decrease in response to chronic carotid baroreceptor stimulation. The interindividual variability in the response to treatment may be related to factors affecting the autonomous nervous system such as diabetic polyneuropathy; to factors responsible for salt retention such as renal failure; or to conditions associated with an increased sympathetic activity such as neurovascular compression at the rostral ventrolateral medulla ${ }^{30}$. None of these conditions were exclusion criteria. In addition, some drug interference with the effect of carotid baroreceptor stimulation is possible, that is, five participants received central $\alpha$-agonists and nine were treated with peripheral $\alpha$-blockers. All these factors may have influenced the response to carotid baroreceptor stimulation and the relationship between HRV parameters and BP changes.

Previous studies in patients with congestive heart failure or postmyocardial infarction have demonstrated that decreases in HRV and HRT are predictors for cardiovascular 
mortality and morbidity ${ }^{14,15,31-33}$. Increased vagal tone exerts pronounced antiarrhythmic effects counteracting the proarrhythmic effects of the sympathetic nervous activity. Carotid baroreceptor stimulation prolonged survival in dogs with heart failure provoked by rapid pacing ${ }^{34}$ which was possibly mediated by modulation of the cardiac autonomic system. Indeed, modulation of the autonomic system by carotid baroreceptor stimulation may have beneficial effects beyond BP control in humans, and future studies in larger populations are needed.

HRV is sensitive to changes in respiration, and it can not be excluded in this study that carotid baroreceptor stimulation could have affected breathing patterns, given the proximity of chemoreceptors. Extrinsic stimulation of the corresponding afferent axons may possibly induce a regulatory increase of ventilation and possibly exert a feedback on HRV. Blood gas analyses would represent the method of choice to exclude a possible respiratory alkalosis as an adverse effect. However, these analyses were not implemented in the DEBUT-HT study protocol. Nevertheless, no obvious hyperventilation was observed clinically by the investigators during the follow-up visits for the tuning of the stimulation device.

The current study is subject to certain limitations. There was no control group, and the BP measurements were not performed in a blinded fashion. Although HRV measurements and HRT are established non-invasive parameters reflecting sympathetic and parasympathetic activity, they are no direct measurements of nerve trafficking; HRV and HRT can be influenced by many factors, including cardiac adrenergic receptor sensitivity and pharmacological treatment ${ }^{35}$. However, all of these variables remained stable during the follow-up, and it is likely that observed HRV changes truly reflect the effect of carotid baroreceptor stimulation on the cardiovascular autonomic system. A longer follow-up period might have given additional information. However, in these severely hypertensive participants, changes in medication may be needed and cardiovascular events may occur, and such confounding factors would considerably limit the interpretation of the data.

\section{Perspectives}

Carotid baroreceptor stimulation with HRV and HRT changes that are consistent with a decrease of sympathetic activity and an increase of vagal tone. These changes are correlated with a significant decrease in BP. Thus, the data suggest that the modulation of the autonomic nervous system contributes to a better BP control through carotid baroreceptor stimulation in severely hypertensive participants. Whether the modulation of the autonomic system has favourable cardiovascular effects beyond BP control should be investigated in further studies. 


\section{References}

1 Bilgutay AM, Lillehei CW. Surgical treatment of hypertension with reference to baropacing. Am J Cardiol 1966;17:663-667.

2 Schwartz SI, Griffith LS, Neistadt A, Hagfors N. Chronic carotid sinus nerve stimulation in the treatment of essential hypertension. Am J Surg 1967;114:5-15.

3 Agishi T, Temples J, Peirce EC, 2nd. Electrical stimulation of the carotid sinus nerve as an experimental treatment of hypertension. J Surg Res 1969;9:305-309.

4 Peters TK, Kaczmarczyk G. Plasma renin activity during hypotensive responses to electrical stimulation carotid sinus nerves in conscious dogs. Clin Exp Pharmacol Physiol 1994;21:1-8.

5 Thrasher TN. Baroreceptors, baroreceptor unloading, and the long-term control of blood pressure. Am J Physiol Regul Integr Comp Physiol 2005;288:R819-827.

6 Lohmeier TE, Irwin ED, Rossing MA, Serdar DJ, Kieval RS. Prolonged activation of the baroreflex produces sustained hypotension. Hypertension 2004;43:306-311.

7 Lohmeier TE, Dwyer TM, Irwin ED, Rossing MA, Kieval RS. Prolonged activation of the baroreflex abolishes obesity-induced hypertension. Hypertension 2007;49:1307-1314.

8 Illig KA, Levy M, Sanchez L, Trachiotis GD, Shanley C, Irwin E, Pertile T, Kieval R, Cody R. An implantable carotid sinus stimulator for drug-resistant hypertension: surgical technique and shortterm outcome from the multicenter phase II Rheos feasibility trial. J Vasc Surg 2006;44:1213-1218.

9 Tordoir JH, Scheffers I, Schmidli J, Savolainen H, Liebeskind U, Hansky B, Herold U, Irwin E, Kroon AA, de Leeuw P, Peters TK, Kieval R, Cody R. An implantable carotid sinus baroreflex activating system: surgical technique and short-term outcome from a multi-center feasibility trial for the treatment of resistant hypertension. Eur J Vasc Endovasc Surg 2007;33:414-421.

10 Schmidli J, Savolainen H, Eckstein F, Irwin E, Peters TK, Martin R, Kieval R, Cody R, Carrel T. Acute device-based blood pressure reduction: electrical activation of the carotid baroreflex in patients undergoing elective carotid surgery. Vascular 2007;15:63-69.

11 Mohaupt MG, Schmidli J, Luft FC. Management of uncontrollable hypertension with a carotid sinus stimulation device. Hypertension 2007;50:825-828.

12 National Institutes of Health. Device Based Therapy in Hypertension Extension Trial (DEBuT-HET). In: http://clinicaltrials.gov/ct2/show/NCT00710294.

13 Heart rate variability. Standards of measurement, physiological interpretation, and clinical use. Task Force of the European Society of Cardiology and the North American Society of Pacing and Electrophysiology. Eur Heart J 1996;17:354-381.

14 Kleiger RE, Stein PK, Bigger JT, Jr. Heart rate variability: measurement and clinical utility. Ann Noninvasive Electrocardiol 2005;10:88-101.

15 Schmidt G, Malik M, Barthel P, Schneider R, Ulm K, Rolnitzky L, Camm AJ, Bigger JT, Jr., Schomig A. Heart-rate turbulence after ventricular premature beats as a predictor of mortality after acute myocardial infarction. Lancet 1999;353:1390-1396.

16 Niskanen JP, Tarvainen MP, Ranta-Aho PO, Karjalainen PA. Software for advanced HRV analysis. Comput Methods Programs Biomed 2004;76:73-81.

17 Bauer A, Malik M, Schmidt G, Barthel P, Bonnemeier H, Cygankiewicz I, Guzik P, Lombardi F, Muller A, Oto A, Schneider R, Watanabe M, Wichterle D, Zareba W. Heart rate turbulence: standards of measurement, physiological interpretation, and clinical use: International Society for Holter and Noninvasive Electrophysiology Consensus. J Am Coll Cardiol 2008;52:1353-1365.

18 Carroll RG, Lohmeier TE, Brown AJ. Chronic angiotensin II infusion decreases renal norepinephrine overflow in conscious dogs. Hypertension 1984;6:675-681.

19 Lohmeier TE, Hildebrandt DA. Renal nerves promote sodium excretion in angiotensin-induced hypertension. Hypertension 1998;31:429-434.

20 Lohmeier TE, Lohmeier JR, Haque A, Hildebrandt DA. Baroreflexes prevent neurally induced sodium retention in angiotensin hypertension. Am J Physiol Regul Integr Comp Physiol 2000;279:R1437-1448.

21 Lohmeier TE, Lohmeier JR, Reckelhoff JF, Hildebrandt DA. Sustained influence of the renal nerves to attenuate sodium retention in angiotensin hypertension. Am J Physiol Regul Integr Comp Physiol 2001;281:R434-443. 



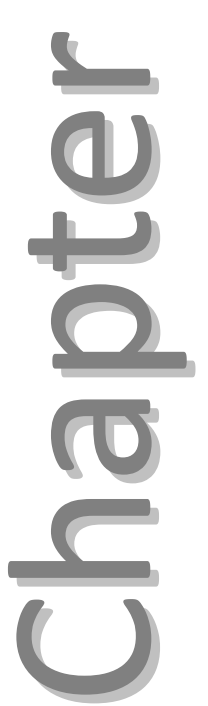

Chronic carotid baroreceptor stimulation in humans does not induce orthostatic hypotension during head-up tilt 


\section{Abstract}

Chronic carotid baroreceptor stimulation using the Rheos ${ }^{\circledR}$ System to treat resistant hypertension activates the carotid baroreflex. This results in a fall in blood pressure. The effects on sympathetic and vagal activity in human have been studied before, but the way it may affect orthostasis is as yet unknown.

We measured beat-to-beat blood pressure, and heart rate (Task Force ${ }^{\circledR}$ Monitor, CNSystems) at supine rest and during head-up tilt in 16 participants that were on continuous carotid baroreceptor stimulation for one year. Furthermore, we performed power spectral analysis in the frequency domain to estimate sympathetic activity and vagal activity. These variables were assessed before implant and after one year of carotid baroreceptor stimulation, at that time the measurements were repeated after 45 minutes of discontinuing stimulation.

One year of chronic baroreceptor stimulation significantly reduced blood pressure accompanied by a decrease in sympathetic activity and an inversed balance of the estimated sympathetic and vagal activity in supine rest. During head-up tilt a limited increase in sympathetic activity and a significant larger decrease in vagal activity were shown, without negative effects on blood pressure maintenance. There is no evidence for impaired baroreceptor sensitivity. Discontinuing carotid baroreceptor stimulation, rapidly restored blood pressure, heart rate and vagal activity toward pre-implant levels, while sympathetic activity stayed significantly suppressed.

We concluded that chronic carotid baroreceptor stimulation significantly reduces blood pressure and estimated sympathetic activity at supine rest. Suppressed sympathetic activity did not cause orthostatic hypotension during head-up tilt, and baroreceptor sensitivity was not impaired during carotid baroreceptor stimulation. Discontinuing stimulation for 45 minutes restored blood pressure toward pre-implant levels, which suggests that there is no evidence for permanent baroreflex resetting after chronic carotid baroreceptor stimulation. 


\section{Introduction}

For decades, the prevailing paradigm on baroreflex activation has been that it affects short-term blood pressure (BP) regulation only ${ }^{1,2}$. This view, however, has been challenged by others who agreed that the baroreceptors are also involved in long-term BP control $^{3-6}$. This idea is supported by recent data on electrical stimulation

of the carotid baroreceptors, which has the potential to reduce BP chronically ${ }^{7-10}$. First results from a European multi-center feasibility study demonstrated a significant reduction in BP after two year of stimulation in 17 subjects with drug-resistant hypertension with an average BP reduction of $33 / 22 \mathrm{mmHg}$ and a mean fall in heart rate (HR) of 11 beats/min. The exact mechanism that causes the sustained BP fall during carotid baroreceptor stimulation is unclear.

Since administration of the centrally acting drug clonidine can induce orthostatic hypotension, suppression of sympathetic outflow using carotid baroreceptor stimulation may be expected to show a comparable adverse effect. However, a previous report on carotid baroreceptor stimulation did not show any clinically significant orthostatic hypotension.

The present study was undertaken to measure whether one year of chronic carotid baroreceptor stimulation affects orthostatic BP. Therefore, we performed head-up tilt (HUT) tests and measured blood pressure variability (BPV) and heart rate variability (HRV) in the frequency domain as a measurement of autonomic cardiovascular regulation. We hypothesized that chronic carotid baroreceptor stimulation in supine rest reduces BPV in the low-frequency (LF) band, reflecting reduced sympathetic outflow, and increases HRV in the high-frequency (HF) band, reflecting increased vagal outflow. Furthermore, we evaluated the effects of carotid baroreceptor stimulation on autonomic cardiovascular regulation during HUT and after acutely discontinuing electrical stimulation for 45 minutes.

\section{Methods}

The present study was executed at the Maastricht University Medical Center as a substudy within the Device Based Therapy in Hypertension Trial (DEBuT-HT). The purpose of this multi-center, chronic, prospective, nonrandomized feasibility study is to assess safety and efficacy of the Rheos ${ }^{\circledR}$ System (CVRx. Inc., Minneapolis, MN, USA) in drug-resistant hypertensive subjects. All participants underwent implantation of the Rheos $^{\circledR}$ System with an electrode around the carotid sinus bifurcation at both sides and a pulse generator at the breast that delivers activation energy. This energy is expected to stimulate the baroreceptors in the wall of the carotid sinus to activate the carotid baroreflex. As a consequence, blood pressure is reduced ${ }^{9,11}$. The device is activated at one month after implant and during the next three months reprogrammed monthly in order to optimize therapy and to receive the optimal blood 
pressure reduction. Thereafter, participants were followed-up at least annually with reprogramming of the device when necessary to further decrease blood pressure. Antihypertensive medication was preferably kept constant, except when the participants health required changes in medication.

\section{Participants}

To be included, participants were $\geq 21$ years old and had systolic blood pressures (SBP) $\geq 160 \mathrm{mmHg}$ and/or diastolic blood pressure (DBP) $\geq 90 \mathrm{mmHg}$ despite full medical therapy with at least three antihypertensive agents including a diuretic. Participants were certified as being compliant by their physicians. Furthermore, carotid bifurcations had to be located at or below C3-C4 in order to ensure operative suitability. Participants were excluded if they had baroreflex failure, significant orthostatic hypotension, cardiac arrhythmias, chronic atrial fibrillation, clinically significant cardiac valvular disease, or secondary hypertension. Other exclusion criteria were carotid artery atherosclerosis with $>50 \%$ stenosis as determined by ultrasound, prior surgery or radiation in the carotid sinus region, currently implanted electrical medical devices, dialysis and pregnancy or contemplating pregnancy.

All participants enrolled in the DEBUT-HT at the Maastricht University Medical Center and followed-up for one year were asked to participate in this substudy to evaluate autonomic cardiovascular regulation. This substudy was approved by the local ethics committee. Written informed consent was obtained from all participants.

Office blood pressure (OBP) was recorded while the participant was sitting for five minutes with the back supported and the arm supported at the level of the heart. A minimum of two readings was taken and readings were repeated when two consecutive measurements varied by $>5 \mathrm{mmHg}$. The recorded OBP was the average of the last two readings. Diabetes mellitus was defined as a previous history and/or the use of oral antidiabetic drugs or insulin at enrolment. Hyperlipidemia was defined as a previous history and/or the use of hypolipidemic agents at enrolment. A history of cardiovascular events was defined as one or more events of TIA, stroke or myocardial infarction before enrolment. Antihypertensive treatment was presented per drug class and also as the median number of different drugs.

\section{Evaluation of autonomic cardiovascular regulation}

The Task Force ${ }^{\circledR}$ Monitor (CNSystems) was used for continuous measurement of 2-channel ECG, impedance cardiography (ICG) and beat-to-beat BP using a finger cuff. The finger cuff measurement was calibrated using simultaneous arm cuff BP readings and recalibrated every three minutes. Measurements were performed twice in every participant, once in the month before implant (PRE) and again after one year of baroreceptor stimulation. All measurements were scheduled in the early afternoon, after a light breakfast and usual dose of medication in the morning. Participants had normal respiration and were comfortably lying on a tilt-table in a quiet room at 
constant temperature of $24^{\circ} \mathrm{C}$. After at least ten minutes in supine position, when all parameters were stable, recording was started. Participants remained in supine position for another ten minutes, thereafter the table was raised to a 60 -degree upright position and participants remained immobile for another ten minutes. Thereafter, the table was turned back to supine position for at least ten minutes to become stable again. At post-implant, HUT was initially performed with the carotid baroreceptor stimulator activated (CHRONIC-ON). Subsequently, stimulation was discontinued for 45 minutes (ACUTE-OFF), while the participants remained in supine position. Analyses were performed during the last ten minutes, thereafter the table was raised again to a 60-degree upright HUT position for ten minutes.

R-R interval (RRI) and HR are directly measured from the ECG signal. SBP, DBP and mean arterial pressure (MAP) are measured from the continuous BP signal. And total peripheral resistance (TPR) is calculated (MAP/stroke volume*HR) ${ }^{12}$. Stroke volume (SV) is derived from the ICG signal ${ }^{12,13}$.

Custom-build software allows power spectral analysis of variability in SBP, DBP and RRI using an adaptive autoregressive parameter algorithm, as described by Schlogl ${ }^{14}$. Time domain signals are therefore transferred into the frequency domain. Vascular sympathetic modulation is estimated from analysis of the beat-to-beat SBP and DBP signal in the LF band, ranging $0.04-0.15 \mathrm{~Hz}^{15}$ expressed as SBP-LF[nu] and DBP-LF[nu], respectively. Cardiac vagal modulation is estimated from analysis of the RRI signal in the HF band, ranging $0.15-0.40 \mathrm{~Hz}^{16-18}$ and expressed as RRI-HF[nu]. Values are calculated in normalized units (nu, \%). Combination of LF and HF oscillations in RRI, expressed as LF:HF ratio, is considered to reflect sympatho-vagal balance ${ }^{15,19}$. The software also offers the sequence-method to identify episodes of at least three consecutive beats in the time domain, characterized by either a progressive rise in SBP and lengthening of RRI or by a progressive decrease in SBP and shortening of RRI ${ }^{20,21}$. The thresholds are defined with $6 \mathrm{~ms}$ (RRI) and $1 \mathrm{mmHg}$ (SBP). These sequences have been shown to specifically reflect spontaneous baroreceptor activity and the mean slope is taken as an index of baroreflex sensitivity (BRS) ${ }^{20,21}$. BRS is also plotted as the ratio of the mean change in HR during HUT to the mean change in MAP during HUT. These curves are also used to evaluate the occurrence of baroreflex resetting.

\section{Statistical analysis}

Statistical analysis was performed using SPSS 16.0 statistical software for Windows. Distribution of scores was tested for normality using Shapiro-Wilk test. Normally distributed data was presented as mean \pm standard deviation and analysed parametrically and two-sided using the paired samples $t$-test. Nonnormally distributed data was presented as median (range) and analysed nonparametrically using Wilcoxon signed-rank test. A $P$-value of $<0.05$ was considered statistically significant. Data at supine rest is presented as means over periods of ten minutes and data during HUT was presented as mean changes over periods of one minute. 


\section{Results}

Between November 2004 and April 2007, 18 participants were enrolled in the DEBUT-HT at the Maastricht University Medical Center. Two participants dropped-out during the first month after implant, their device was partially or completely removed because of an infection. Sixteen participants were followed for at least one year and all were willing to participate in this study. Baseline characteristics are presented in Table 7.1. Antihypertensive treatment was changed in three participants during the one year of follow-up, because their health required adaptations. Therefore, at post-implant mean use of antihypertensive medication was slightly decreased by $0.4 \pm 0.2(P=0.054)$.

Table 7.1 Baseline characteristics $(\mathrm{N}=16)$.

\begin{tabular}{lc}
\hline Characteristic & \\
\hline Demographics & $7(44)$ \\
Gender, male (N \%) & $16(100)$ \\
Race, Caucasian (N \%) & $53 \pm 11$ \\
Age, years (mean $\pm \mathrm{SD}$ ) & $32 \pm 7$ \\
Body mass index, kg/m² (mean $\pm \mathrm{SD}$ ) & \\
Sitting office readings (mean $\pm \mathrm{SD})$ & $174 \pm 22$ \\
Systolic blood pressure, mmHg & $103 \pm 13$ \\
Diastolic blood pressure, mmHg & $74 \pm 14$ \\
Heart rate, beats/min & \\
Co-morbidities (N \%) & $2(13)$ \\
Diabetes mellitus & $8(50)$ \\
Hyperlipidemia & $8(50)$ \\
History of cardiovascular event & \\
Antihypertensive treatment per class (N \%) & $8(50)$ \\
ACE inhibitor & $8(50)$ \\
Angiotensin receptor blocker & $14(88)$ \\
$\beta$-blocker & $11(69)$ \\
Calcium channel blocker & $16(100)$ \\
Diuretic & $9(56)$ \\
Others & \\
Mean antihypertensive treatment (median , range) & $4(3-7)$ \\
Number of different drugs & \\
\hline
\end{tabular}

$A C E$, angiotensin converting enzyme

\section{Autonomic cardiovascular regulation in supine rest}

Mean results for all measured variables in supine rest are presented in Table 7.2. At CHRONIC-ON both SBP and DBP were significantly decreased by $28 \mathrm{mmHg}(P<0.001)$ and $19 \mathrm{mmHg}(P<0.001)$, respectively. Figure 7.1 presents the individual data points. All participants showed, more or less, a fall in SBP and DBP (Figure 7.1a and 7.1b, respectively). At ACUTE-OFF both SBP and DBP were significantly increased by $17 \mathrm{mmHg}(P<0.001)$ and $14 \mathrm{mmHg}(P=0.001)$, respectively, and no longer significantly different from levels at PRE. The changes in HR are somewhat more variable 
(Figure 7.1c) and at CHRONIC-ON a modest decrease is shown ( $P=0.103)$. TPR shows a significant decrease at CHRONIC-ON $(P=0.036)$ and a significant increase at ACUTE-OFF ( $P=0.004)$ (Table 7.2).

Fourteen participants showed a decrease in SBP-LF[nu] and DBP-LF[nu] at CHRONIC-ON (Figure 7.1d and 7.1e, respectively) and the mean decreases compared with PRE were highly significant, $(P=0.002$ and $P=0.002$, respectively). ACUTE-OFF showed slight increases in SBP-LF[nu] and DBP-LF[nu]. A majority of participants showed an increase in RRI-HF[nu] (Figure 7.1f) at CHRONIC-ON compared with PRE. At CHRONIC-ON, LF:HF ratio was significantly decreased $(P=0.05)$ (Table 7.2).

Table 7.2 Means and mean changes $(\mathrm{N}=16)$ in supine rest.

\begin{tabular}{lccc}
\hline Variable & $\begin{array}{c}\text { PRE } \\
\text { (mean } \pm \text { SD) or } \\
\text { median (range) }\end{array}$ & $\begin{array}{c}\text { CHRONIC-ON } \\
\text { (mean } \pm \text { SD) or } \\
\text { median (range) }\end{array}$ & $\begin{array}{c}\text { ACUTE-OFF } \\
\text { (mean } \pm \text { SD) or } \\
\text { median (range) }\end{array}$ \\
\hline Systolic blood pressure, $\mathrm{mmHg}$ & $169 \pm 20$ & $141 \pm 21^{\mathrm{b}}$ & $158 \pm 23^{\mathrm{c}}$ \\
Diastolic blood pressure, $\mathrm{mmHg}$ & $110 \pm 15$ & $91 \pm 16^{\mathrm{b}}$ & $105 \pm 19^{\mathrm{c}}$ \\
Heart rate, beats/min & $72 \pm 12$ & $69 \pm 15$ & $71 \pm 13$ \\
& & & $75 \pm 22$ \\
Stroke volume, ml & $80 \pm 19$ & $1659(995-2562)^{\mathrm{a}}$ & $1914(904-3170)^{\mathrm{c}}$ \\
Peripheral resistance, dyne ${ }^{*} \mathrm{sec}^{*} \mathrm{~cm}^{5}$ & $1918(1188-3615)$ & & $31 \pm 10$ \\
SBP-LF[nu], \% & $40 \pm 14$ & $28 \pm 11^{\mathrm{b}}$ & $35 \pm 12$ \\
DBP-LF[nu], \% & $41 \pm 16$ & $31 \pm 12^{\mathrm{b}}$ & $37(15-78)$ \\
RRI-HF[nu], \% & $28(16-88)$ & $37(12-94)$ & $1.4 \pm 1.2$ \\
LF/HF ratio & $1.5 \pm 0.7$ & $1.1 \pm 0.9^{\mathrm{a}}$ & $8.2 \pm 5.2$ \\
Baroreceptor sensitivity, $\mathrm{ms} / \mathrm{mmHg}$ & $7.9 \pm 3.1$ & $9.3 \pm 4.6$ & \\
\hline
\end{tabular}

SBP, systolic blood pressure; DBP, diastolic blood pressure; RRI, RR-interval; LF, low frequency; HF, high frequency; nu, normalized units

Results are presented as mean \pm standard deviation or median (range).

${ }^{\mathrm{a}} P<0.05,{ }^{\mathrm{b}} P<0.01, \mathrm{CHRONIC}-\mathrm{ON}$ vs. PRE; ${ }^{\mathrm{c}} \quad P<0.01$, ACUTE-OFF VS. CHRONIC-ON 

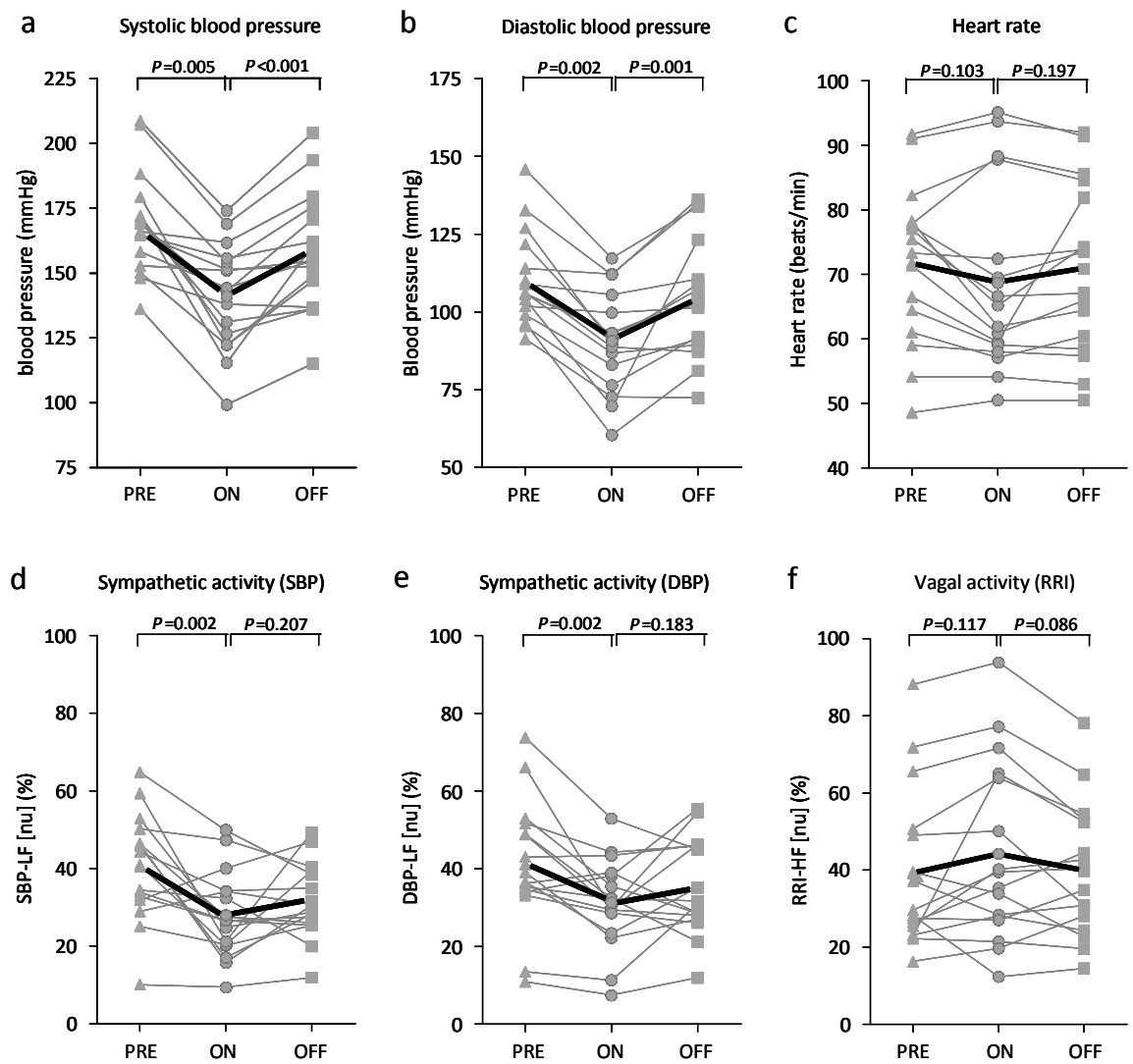

Figure 7.1 Individual data points $(\mathrm{N}=16)$ in supine rest.

Results at PRE-implant (PRE, $\triangle$ ), CHRONIC-ON (ON, •) and ACUTE-OFF (OFF, $=$ ). Panel a shows results for systolic blood pressure, panel $b$ for diastolic blood pressure, and panel $c$ for heart rate. Panel $d$ and e show results for sympathetic activity (SBP-LF[nu] and DBP-LF[nu], respectively), and panel f for vagal activity (RRI-HF[nu]).

\section{Autonomic cardiovascular regulation during head-up tilt}

The mean trends of SBP, DBP and HR and the mean trends for sympathetic and vagal activity during ten minutes of HUT are shown in Figure 7.2. Also mean changes after three and ten minutes compared with the first minute of HUT are presented in this figure. At CHRONIC-ON the patterns of DBP-LF[nu] and RRI-HF[nu] are changed (Figure 7.2e) compared with PRE (Figure 7.2d). The increase in DBP-LF[nu] after three and ten minutes of HUT seems suppressed compared with PRE, although the changes at CHRONIC-ON are not significantly different from the changes at PRE. RRI-HF[nu] is significantly decreased after three minutes of HUT at CHRONIC-ON $(P=0.013)$, while the decrease at PRE is modest. 

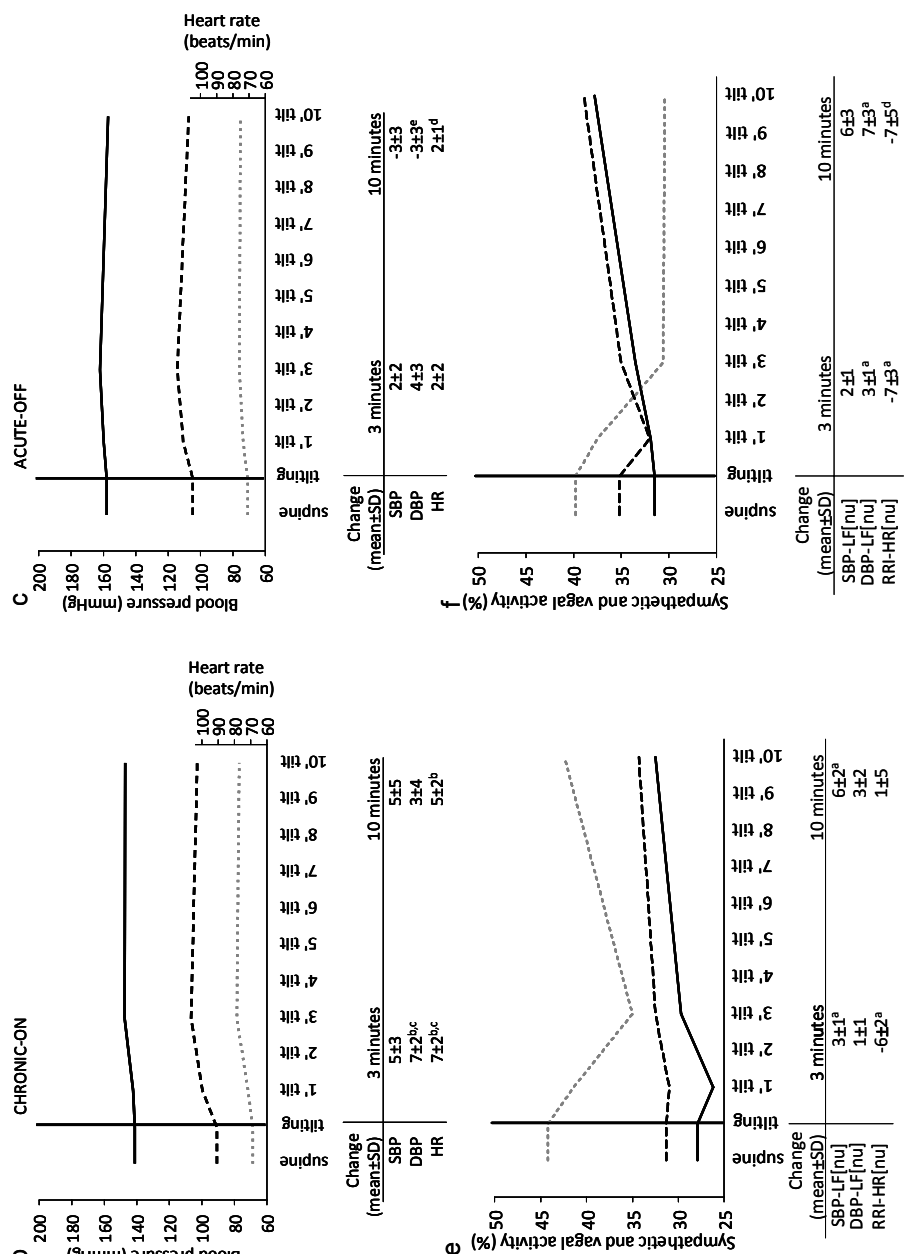

ค (8Hum) adnssadd poolg

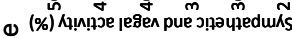
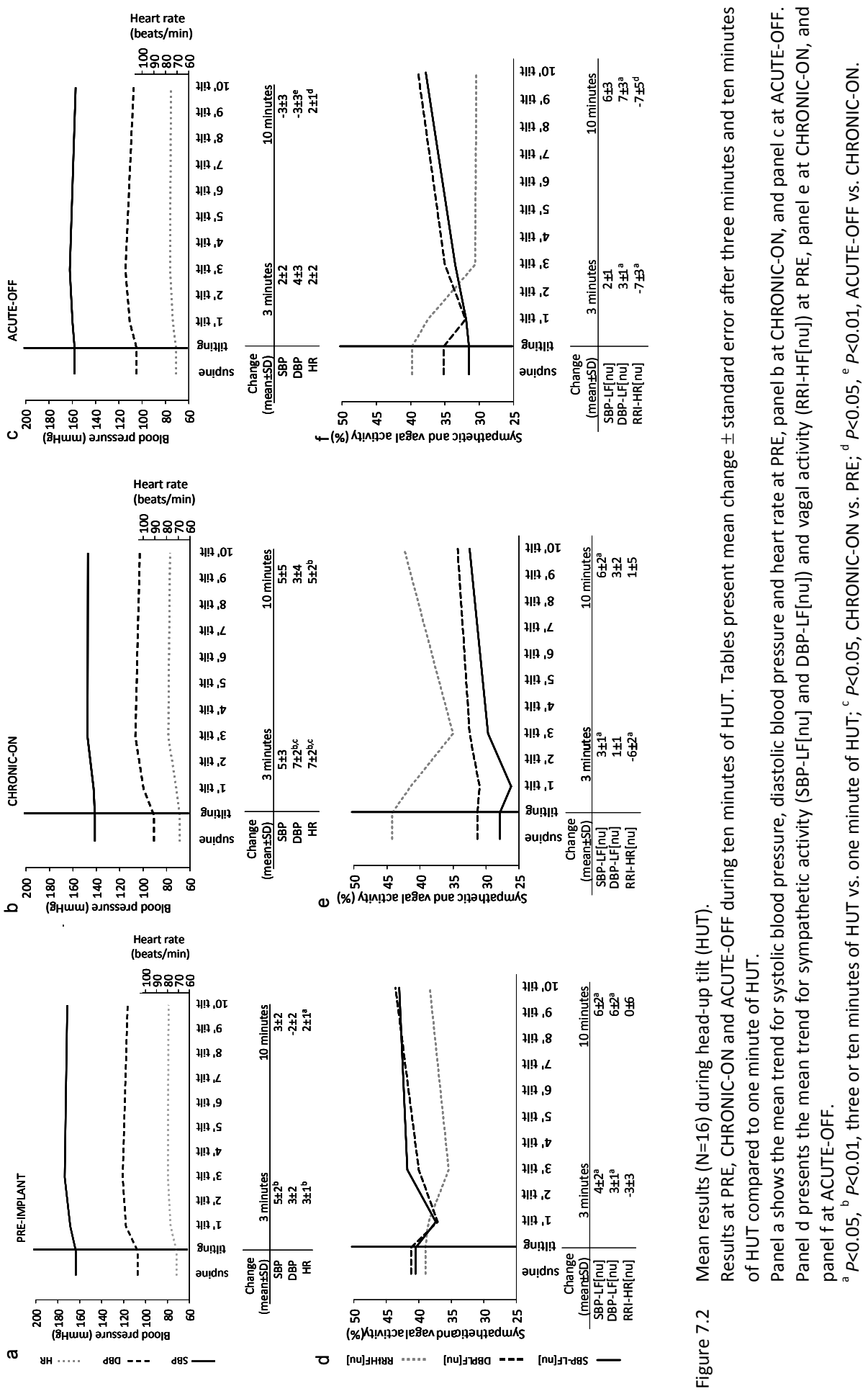
The maintenance of SBP, DBP and HR during HUT is not disturbed at CHRONIC-ON (Figure 7.2b) compared with PRE (Figure 7.2a). Though, the increases in DBP and HR after three minutes of HUT at CHRONIC-ON are significantly higher compared with $\operatorname{PRE}(P=0.049$ and $P=0.037$, respectively).

At ACUTE-OFF the pattern of DBP-LF[nu] (Figure 7.2f) seems not suppressed anymore and is comparable to PRE (Figure 7.2d). The decrease in RRI-HF[nu] after three minutes of HUT is comparable to the decrease at CHRONIC-ON, but the decrease is sustained and after ten minutes of HUT it is significantly larger than the decrease at CHRONIC-ON ( $P=0.036)$. This sustained decrease in RRI-HF[nu] is accompanied by an increase in HR and a decrease in DBP after ten minutes of HUT (Figure 7.2c), which are significantly different from the changes after ten minutes of HUT at CHRONIC-ON ( $P=0.003$ and $P=0.041$, respectively, Figure $7.2 \mathrm{a}$ ).

\section{Baroreceptor sensitivity and baroreflex resetting}

Using the sequence method, BRS shows a modest increase of $1.4 \pm 0.9 \mathrm{~ms} / \mathrm{mmHg}$ $(P=0.144)$ at CHRONIC-ON compared with PRE (Table 7.2). Figure 7.3 presents the HR:MAP-responses, i.e. the mean change in HR during HUT plotted against the mean change in MAP during HUT. At PRE the slope of the curve, indicating BRS, is $32^{\circ}$ and is slightly increased to $38^{\circ}$ at CHRONIC-ON (Figure 7.3a). Furthermore, the curve at CHRONIC-ON is shifted leftward from a hypertensive to a normotensive level. At ACUTE-OFF the curve is shifted backward to a hypertensive level, comparable to the level at PRE, with no significant change in slope (Figure 7.3b).
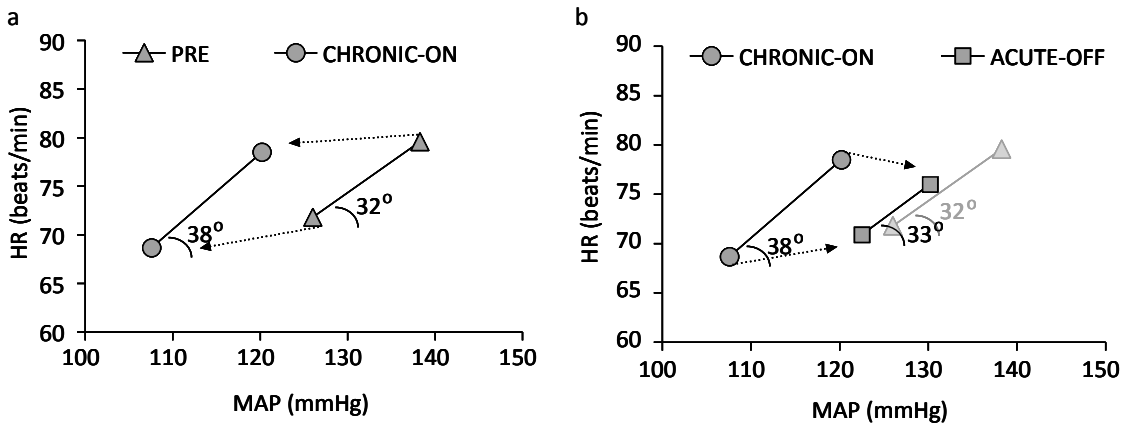

Figure 7.3 Baroreceptor resetting.

Ratio of the mean changes in HR to the mean changes in MAP during head-up tilt at PRE-implant $(\Delta)$, CHRONIC-ON $(\bullet)$ and ACUTE-OFF ( $\square)$. The slope of the curve indicates baroreflex sensitivity. A sideward shift in the curve indicates baroreflex resetting to a different blood pressure level.

Panel a shows the change in HR:MAP-response at CHRONIC-ON compared with PRE.

Panel $b$ shows the change in HR:MAP-response at ACUTE-OFF compared with CHRONIC-ON. 


\section{Discussion}

The present data show a significant fall in blood pressure and its variability during chronic electrical carotid baroreceptor stimulation. Orthostatic hypotension is not observed during HUT and there is no evidence for impaired BRS. The baroreflex resets to a lower blood pressure level during carotid baroreceptor stimulation, but acutely turning off stimulation increases blood pressure toward pre-implant level within 45 minutes.

After one year of chronic baroreceptor stimulation resting supine BP was significantly decreased by $28 / 19 \mathrm{mmHg}$, while the mean use of antihypertensive medication was unchanged or decreased. The sustained decrease in BP is expected to be caused by suppressed sympathetic outflow due to chronic carotid baroreflex activation. Using power spectral analysis of BPV and HRV with an adaptive autoregressive parameter algorithm, we showed highly significant reductions in sympathetic activity and a slight increase in vagal activity in supine rest following one year of carotid baroreceptor stimulation. This observation confirms earlier data by Wustmann et al. on 24-hour ECG registration in these participants ${ }^{22}$. Furthermore, it strengthens the hypothesis of sustained suppression of sympathetic outflow and also augmentation of vagal outflow during chronic carotid baroreceptor stimulation. This combination of effects on cardiovascular regulation may explain why orthostatic hypotension is not induced. In comparison, clonidine suppresses total sympathetic outflow with no stimulating effect on vagal outflow. The increased vagal activity and also the function of baroreceptors located elsewhere in the body may protect the participants from orthostatic hypotension during chronic carotid baroreceptor stimulation.

BRS measured by the sequence-method in supine rest and by the slope of the HR:MAP-response during HUT, indicated an intact baroreflex and no impaired sensitivity during chronic carotid baroreceptor stimulation. On the contrary, it showed a slight increase, which is in accordance with the decrease in arterial pressure.

Discontinuing carotid baroreceptor stimulation for 45 minutes restored SBP and DBP toward pre-implant levels, also HR and vagal activity showed a trend toward pre-implant levels. Overall, sympathetic activity increased after discontinuing stimulation, but did not reach the pre-implant level of activity within 45 minutes. The HR:MAP-response suggests baroreflex resetting from a hypertensive to a normotensive level during continuous carotid baroreceptor stimulation. But the increase in blood pressure and the rightward shift in HR:MAP-response after discontinuing stimulation is in accordance with a rapid resetting of the baroreflex to the hypertensive level. In case of complete baroreflex resetting, one would expect a sustained decrease in blood pressure after 45 minutes of discontinuing therapy. Possibly, the leftward shift in HR:MAP-response during chronic baroreceptor stimulation is due to the continuous manner of carotid baroreceptor stimulation and not due to a permanent and complete resetting of the baroreflex. 
There are several limitations in this study. Apart from the small number of participants, the measurements have shown a considerable variability between and within subjects. Reproducibility of SBP-LF[nu], DBP-LF[nu], RRI-HF[nu], and BRS may be somewhat limited ${ }^{23}$, but the overall hemodynamic response to HUT is reproducible in $80 \%{ }^{24}$. Also, reliability and reproducibility of ICG is limited. Nevertheless, this method, that assesses changes in impedance over the chest across the cardiac cycle using refined hardware and software, showed a higher estimation capability compared with thermodolution ${ }^{12}$. Although, other methods to measure nervous activity and cardiac parameters may be more reliable, the ones we used are less invasive and do not have a high burden for the participants. Unfortunately, plasma catecholamine levels and more direct measurements of peripheral resistance that would have given better insight in the peripheral vasodilator effect of chronic baroreflex activation were not available in the present study. Another limitation in this study is the lack of a control group and the impossibility to perform the measurements in a double-blind design. All participants are followed-up according to the DEBUT-protocol and are receiving chronic carotid baroreceptor stimulation, which limits the possibilities for the study design. A final limitation can be the relative short period of discontinuing stimulation. Possibly, a longer period may have given more information on the effects on blood pressure and autonomic cardiovascular regulation during baroreceptor stimulation.

In conclusion, our data on 16 participants showed significantly reduced blood pressure at supine rest following one year of chronic carotid baroreceptor stimulation, accompanied by a highly significant decrease in BPV in the LF-band, which reflects decreased sympathetic activity. The exact mechanism responsible for the sustained fall in blood pressure during chronic sympathetic suppression is unknown and further investigation is emphasized. Suppressed sympathetic activity did not lead to orthostatic hypotension. During HUT a limited increase in BPV in the LF-band and an enlarged decrease in HRV in the HF-band were observed, suggesting a compensatory role for vagal activity. BRS is not impaired after one year of carotid baroreceptor stimulation. Although the HR:MAP-response suggests baroreflex resetting from hypertensive to normotensive levels during carotid baroreceptor stimulation, turning off stimulation immediately reversed this, suggesting no chronic resetting of the baroreflex during continuous carotid baroreceptor stimulation. 


\section{References}

1. Cowley AW, Jr., Liard JF, Guyton AC. Role of baroreceptor reflex in daily control of arterial blood pressure and other variables in dogs. Circ Res. 1973;32:564-576.

2. Guyton AC, Coleman TG, Fourcade JC, Navar LG. Physiologic control of arterial pressure. Bull N Y Acad Med. 1969;45:811-830.

3. Thrasher TN. Baroreceptors and the long-term control of blood pressure. Exp Physiol. 2004;89: 331-335.

4. Thrasher TN. Baroreceptors, baroreceptor unloading, and the long-term control of blood pressure. Am J Physiol Regul Integr Comp Physiol. 2005;288:R819-827.

5. Lohmeier TE, Hildebrandt DA, Warren S, May PJ, Cunningham JT. Recent insights into the interactions between the baroreflex and the kidneys in hypertension. Am J Physiol Regul Integr Comp Physiol. 2005;288:R828-836.

6. Sleight P. Arterial baroreflexes can determine long-term blood pressure. Baroreceptors and hypertension: time for a re-think? Exp Physiol. 2004;89:337-341.

7. Illig KA, Levy M, Sanchez L, Tranchiotis GD, Shanley C, Irwin E, Pertile T, Kieval R, Cody R. An implantable carotid sinus stimulator for drug-resistant hypertension: surgical technique and shortterm outcome from the multicenter phase II Rheos feasibility trial. J Vasc Surg. 2006;44:1213-1218.

8. Filippone JD, Sloand JA, Illig KA, Bisognano JD. Electrical stimulation of the carotid sinus for the treatment of resistant hypertension. Curr Hypertens Rep. 2006;8:420-424.

9. Tordoir JH, Scheffers I, Schmidli J, Savolainen H, Liebeskind U, Hansky B, Herold U, Irwin E, Kroon AA, de Leeuw P, Peters TK, Kieval R, Cody R. An implantable carotid sinus baroreflex activating system: surgical technique and short-term outcome from a multi-center feasibility trial for the treatment of resistant hypertension. Eur J Vasc Endovasc Surg. 2007;33:414-421.

10. Mohaupt MG, Schmidli J, Luft FC. Management of uncontrollable hypertension with a carotid sinus stimulation device. Hypertension. 2007;50:825-828.

11. Scheffers IJ, Kroon AA, Tordoir JH, de Leeuw PW. Rheos ${ }^{\circledR}$ Baroreflex Hypertension Therapy ${ }^{\mathrm{TM}}$ System $^{\mathrm{T}}$ to treat resistant hypertension. Expert Rev Med Devices. 2008;5:33-39.

12. Gratze G, Fortin J, Holler A, Grasenick K, Pfurtscheller G, Wach P, Schonegger J, Kotanko P, Skrabal F. A software package for non-invasive, real-time beat-to-beat monitoring of stroke volume, blood pressure, total peripheral resistance and for assessment of autonomic function. Comput Biol Med. 1998;28:121-142.

13. Fortin J, Habenbacher W, Heller A, Hacker A, Grullenberger R, Innerhofer J, Passath H, Wagner Ch, Haitchi G, Flotzinger D, Pacher R, Wach P. Non-invasive beat-to-beat cardiac output monitoring by an improved method of transthoracic bioimpedance measurement. Comput Biol Med. 2006;36: 1185-1203.

14. Schlog| A, Flotzinger D, Pfurtscheller G. Adaptive autoregressive modeling used for single-trial EEG classification. Biomed Tech (Berl). 1997;42:162-167.

15. Laitinen T, Hartikainen J, Niskanen L, Geelen G, Lansimies E. Sympathovagal balance is major determinant of short-term blood pressure variability in healthy subjects. Am J Physiol. 1999;276:H1245-1252.

16. Akselrod S, Gordon D, Ubel FA, Shannon DC, Berger AC, Cohen RJ. Power spectrum analysis of heart rate fluctuation: a quantitative probe of beat-to-beat cardiovascular control. Science. 1981;213: 220-222.

17. Goldberger JJ. Sympathovagal balance: how should we measure it? Am J Physiol. 1999;276: H1273-1280.

18. Pomeranz B, Macaulay RJ, Caudill MA, Kutz I, Adam D, Gordon D, Kilborn KM, Barger AC, Shannon DC, Cohen RJ. Assessment of autonomic function in humans by heart rate spectral analysis. Am J Physiol. 1985;248:H151-153.

19. Pagani M, Lombardi F, Guzzetti S, Rimoldi O, Furlan R, Pizzinelli P, Sandrone G, Malfatto G, Dell"Orto $\mathrm{S}$, Piccaluga E. Power spectral analysis of heart rate and arterial pressure variabilities as a marker of sympatho-vagal interaction in man and conscious dog. Circ Res. 1986;59:178-193.

20. Parati G, Di Rienzo M, Mancia G. How to measure baroreflex sensitivity: from the cardiovascular laboratory to daily life. J Hypertens. 2000;18:7-19. 
21. Persson PB, DiRienzo M, Castiglioni P, Cerutti C, Pagani M, Honzikova N, Akselrod S, Parati G. Time versus frequency domain techniques for assessing baroreflex sensitivity. J Hypertens. 2001;19: 1699-1705.

22. Wustmann K, Kucera JP, Scheffers I, Mohaupt M, Kroon A, de Leeuw P, Schmidli J, Allemann Y, Delacrétaz. Effects of chronic baroreceptor stimulation on the autonomic cardiovascular regulation in patients with drug-resistant arterial hypertension. Hypertension. 2009;54:530-536.

23. Hojgaard MV, Holstein-Rathlou NH, Agner E, Kanters JK. Reproducibility of heart rate variability, blood pressure variability and baroreceptor sensitivity during rest and head-up tilt. Blood Press Monit. 2005; 10:19-24.

24. Aerts AJ, Dendale P, Block P, Dassen WR. Reproducibility of nitrate-stimulated tilt testing in patients with suspected vasovagal syncope and a healthy control group. Am Heart J. 2005;150:251-256. 
Renal hemodynamics and neurohormonal profile during chronic carotid baroreceptor stimulation in humans with drug-resistant hypertension 


\section{Abstract}

Sympathetic nerve activity is important for maintenance of blood pressure and renal function. Electrical carotid baroreceptor stimulation using the Rheos ${ }^{\circledR}$ System to treat resistant hypertension results in suppressed sympathetic activity and reduced blood pressure. The concomitant effects on renal hemodynamics and the renin-angiotensin system in human have not been studied yet.

We measured the effect on effective renal plasma flow and glomerular filtration rate using continuous infusion with para-aminohippurate and inulin in 15 participants who were on continuous carotid baroreceptor stimulation. Furthermore, we analysed active plasma renin and norepinephrine concentrations. All variables were assessed pre-implant and after one year of carotid baroreceptor stimulation; at post-implant measurements were repeated after 45 minutes of discontinuing stimulation.

Arterial blood pressure was significantly reduced by carotid baroreceptor stimulation. One year of stimulation did not change glomerular filtration rate significantly. Four participants showed a decrease in effective renal plasma flow, but on average it did not change. No changes in plasma renin and norepinephrine concentrations were detected. Discontinuing carotid baroreceptor stimulation, increased blood pressure toward pre-implant level, which was accompanied by a rise in effective renal plasma flow, but no change in glomerular filtration rate.

We concluded that chronic carotid baroreceptor stimulation significantly reduces arterial blood pressure while maintaining effective renal plasma flow and glomerular filtration rate. The present data do not show any impairment of renal function after one year of chronic carotid baroreceptor stimulation. 


\section{Introduction}

Sympathetic nerve activity is important for the maintenance of blood pressure (BP), as well as renal function ${ }^{1,2}$. Experiments by DiBona ${ }^{3}$ showed that renal denervation caused an increase in renal blood flow in spontaneously hypertensive rats. On the contrary, Neistadt and Swartz ${ }^{4}$ observed a fall in renal blood flow in dogs during suppression of sympathetic activity using carotid sinus nerve stimulation. Currently, a novel implantable device (Rheos ${ }^{\circledR}$ System; CVRx. Inc., Minneapolis, MN, USA) for chronic electrical stimulation of the carotid baroreceptors is under investigation for treatment of drug-resistant hypertension, but its effect on renal function is as yet unknown.

Previous reports on the Rheos ${ }^{\circledR}$ System showed a sustained decrease in BP in chronically instrumented dogs ${ }^{5}$ and humans ${ }^{6}$. Recent data ${ }^{7}$ suggest that this sustained decrease in BP is caused by suppressed sympathetic activity. The suppressed sympathetic activity is possibly accompanied by changes in cardiovascular hemodynamics, that could affect renal hemodynamics and the renin-angiotensin system (RAS) as well.

The present study investigates the effect on renal hemodynamics and neurohormonal profile after one year of chronic carotid baroreceptor stimulation with the Rheos ${ }^{\circledR}$ System in humans with drug-resistant hypertension. We measured effective renal plasma flow (ERPF) and glomerular filtration rate (GFR). Furthermore, we analysed active plasma renin (APR) concentration since the release of renin is regulated by sympathetic activity, and plasma norepinephrine (NE) concentration as an index of sympathetic activity. In addition, we investigated the immediate effects of discontinuing the Rheos ${ }^{\circledR}$ System for 45 minutes after one year of continuous carotid baroreflex activation to assess whether the expected cardiovascular and renal hemodynamic changes during chronic carotid baroreceptor stimulation are reversible or not.

\section{Methods}

This study was conducted at the Maastricht University Medical Center as a substudy of the Device Based Therapy in Hypertension Trial (DEBUT-HT). The purpose of this multi-center, chronic, prospective, nonrandomized feasibility study was to assess safety and efficacy of the Rheos ${ }^{\circledR}$ System in drug-resistant hypertensive subjects ${ }^{6}$. All participants underwent implantation of the Rheos ${ }^{\circledR}$ System with an electrode around the carotid sinus bifurcation at both sides and a pulse generator at the breast that delivers activation energy. This energy stimulates the baroreceptors in the wall of the carotid sinus thus activating the carotid baroreflex. As a consequence, sympathetic outflow is reduced and this causes a fall in $\mathrm{BP}^{8,9}$. The device is activated at one month after implantation and during the next three months reprogrammed monthly in order 
to optimize therapy and to achieve the optimal BP reduction. Thereafter, participants were followed-up annually. Antihypertensive medication was preferably kept constant, for at least one year post-implant, except when the participants health required changes in medication.

\section{Participants}

To be included, participants had to be $\geq 21$ years old and to have a systolic blood pressure (SBP) $\geq 160 \mathrm{mmHg}$ and/or a diastolic blood pressure (DBP) $\geq 90 \mathrm{mmHg}$ despite full medical therapy with at least three antihypertensive agents including a diuretic. Participants were certified as being compliant by their physicians. Furthermore, carotid bifurcations had to be located at or below C3-C4 in order to ensure operative suitability.

Participants were excluded if they had baroreflex failure, significant orthostatic hypotension, cardiac arrhythmias, chronic atrial fibrillation, clinically significant cardiac valvular disease, or secondary hypertension. Other exclusion criteria were carotid artery atherosclerosis with $>50 \%$ stenosis as determined by ultrasound, prior surgery or radiation in the carotid sinus region, currently implanted electrical medical devices, dialysis and pregnancy or contemplating pregnancy.

All participants enrolled in the DEBUT-HT at the Maastricht University Medical Center and followed-up for at least one year were asked to participate in this substudy to evaluate renal hemodynamics at supine rest. This study was approved by the local ethics committee. Written informed consent was obtained from all participants.

Office blood pressure (OBP) was recorded while the participant was sitting with the back supported for five minutes and the arm supported at the level of the heart. A minimum of two readings were taken and readings were repeated when two consecutive measurements varied by $>5 \mathrm{mmHg}$. The recorded OBP is the average of the last two readings. Antihypertensive treatment is presented per drug class. Mean use of antihypertensive drugs is expressed as the mean number of different drugs.

\section{Hemodynamic measurements}

Measurements were performed twice in every participant, once in the month before implant (PRE) and again after one year of active therapy with the Rheos ${ }^{\circledR}$ System. All measurements were performed in the morning after an overnight fast and after one week of standardized salt intake. Participants remained supine during the entire session. BP was measured continuously using beat-to-beat measurements (TaskForce ${ }^{\circledR}$ Monitor, CNSystems, Austria) with the arm supported at the level of the heart. The presented BP is the average of a 10-minute period. Heart rate (HR) was measured using ECG signals and also averaged over ten minutes of recording. Mean arterial pressure (MAP) was calculated as DBP $+1 / 3 *$ (SBP - DBP). ERPF and GFR were measured as the clearance of para-aminohippurate (PAH; Merck \& Co., Inc., USA) and inulin (Inutest; Fresenius Kabi, Austria), respectively, using the continuous infusion 
method. In both arms, an antecubital vein was cannulated. One cannula was used for the infusion of PAH and inulin, whereas the other cannula was used for blood sampling. After a two-hour equilibrium period, necessary to reach steady state plasma concentrations of PAH and inulin, blood sampling was started for measurement of $\mathrm{PAH}$ and inulin. Three consecutive blood samples were drawn at a 10-minute interval period. During the third sampling, additional blood samples were drawn for measurement of hematocrit, creatinine, APR and plasma concentrations of aldosterone, angiotensin II (AII), NE, and epinephrine (E). Both ERPF and GFR were corrected for body surface area and expressed as $\mathrm{ml} / \mathrm{min} / 1.73 \mathrm{~m}^{2}$. Effective renal blood flow (ERBF) was calculated as ERPF/1 - hematocrit and filtration fraction (FF) was calculated as GFR/ERPF. Renal vascular resistance (RVR) was calculated as (MAP/ERBF)*80.000 and expressed in dynes* $\mathrm{sec}^{*} \mathrm{~cm}^{-5}$.

At 1-year post-implant, measurements were initially performed with the Rheos ${ }^{\circledR}$ System chronically activated (CHRONIC-ON). Subsequently, the stimulation was switched off (ACUTE-OFF) while the PAH/inulin infusion and blood pressure measurements were continued. After 45 minutes, to allow renal clearances to reach a new steady state, blood sampling was repeated.

\section{Assay methods}

$\mathrm{PAH}$ and inulin levels were measured by means of a spectrophotometric analysis ${ }^{10}$. APR was measured by a 2-site direct immunoradiometric assay (IBA Pharma, Belgium $)^{11}$. Aldosterone was assayed by means of a solid-phase protein binding radioimmunoassay (Diagnostic Products Cooperation, The Netherlands) ${ }^{12}$. For measuring All, blood samples were collected in tubes containing an inhibitor solution to prevent in vitro generation and degradation of this peptide, and spun immediately in a cooled centrifuge ${ }^{13}$. All was determined by radioimmunoassay following Seppack C-18 extraction (Peninsula Laboratory, Bachem AG, Switzerland). NE and E were concentrated from plasma by liquid-liquid extraction and derivatized with the fluorescent agent 1.2-diphenylethylenediamine prior to quantitative high performance liquid chromatography ${ }^{14}$.

\section{Statistical analysis}

Statistical analysis was performed using SPSS 16.0 statistical software for Windows. Distribution of scores was tested for normality using Shapiro-Wilk test. Normally distributed data was presented as mean \pm standard deviation and analysed parametrically and two-sided using the paired samples $t$-test. Nonnormal distributed data was presented as median (range) and analysed nonparametrically using Shapiro signed-rank test. A $P$-value of $<0.05$ was considered statistically significant. The difference between two measurements of GFR, ERPF and FF at different time points were transformed into relative changes and plotted against the relative decrease in MAP between the same time points. 


\section{Results}

In total, 45 participants were enrolled in the DEBuT-HT of whom 18 were from the Maastricht University Medical Center. Two out of the 18 participants in Maastricht dropped-out during the first month after implant, since their device had to be partially or completely removed because of an infection. Sixteen participants were followed-up for at least one year and 15 of those were willing to participate in the present study. Baseline characteristics are presented in Table 8.1. Mean number of different antihypertensive drug classes was 4 (range 3-7) drugs per participant. After one year of chronic carotid baroreceptor stimulation, mean use of antihypertensive medication had not significantly changed.

Table 8.1 Baseline characteristics $(\mathrm{N}=15)$.

\begin{tabular}{lc}
\hline Characteristic & \\
\hline Demographics & \\
Gender, male (N \%) & $6(40)$ \\
Race, Caucasian (N \%) & $15(100)$ \\
Age, years (mean \pm SD) & $52 \pm 11$ \\
Body Mass Index, kg/m ${ }^{2}$ (mean $\pm \mathrm{SD}$ ) & $32 \pm 7$ \\
Co-morbidities (N \%) & \\
Diabetes Mellitus & $2(13)$ \\
Hyperlipidemia & $7(47)$ \\
History of cardiovascular event & $8(53)$ \\
Sitting office readings (mean $\pm \mathrm{SD}$ ) & \\
Systolic blood pressure, mmHg & \\
Diastolic blood pressure, mmHg & $175 \pm 22$ \\
Heart rate, beats/min & $104 \pm 12$ \\
Antihypertensive treatment (mean, range) & $75 \pm 13$ \\
Number of different drugs & \\
Treatment per class (N \%) & $4(3-7)$ \\
ACE inhibitor & \\
Angiotensin receptor blocker & $8(53)$ \\
$\alpha$-blocker & $8(53)$ \\
$\beta$-blocker & $5(33)$ \\
Calcium channel blocker & $13(87)$ \\
Direct sympatolytic agent & $9(60)$ \\
Diuretic & $3(20)$ \\
- Thiazide diuretic & $15(100)$ \\
- Loop diuretic & $13(87)$ \\
- Aldosterone blocker & $3(20)$ \\
\hline
\end{tabular}

\section{Blood pressure and renal hemodynamics}

Table 8.2 presents the mean results of BP, renal hemodynamics, neurohormonal plasma concentrations, and blood and urine laboratory values at PRE and CHRONIC-ON. All 15 participants showed more or less a decrease in beat-to-beat BP. Mean SBP and DBP fell significantly by $27 \mathrm{mmHg}(P<0.001)$ and $19 \mathrm{mmHg}(P<0.001)$, respectively. 
Table 8.2 Mean results for PRE-implant and CHRONIC-ON ( $\mathrm{N}=15)$.

\begin{tabular}{|c|c|c|c|}
\hline Variable & $\begin{array}{c}\text { PRE } \\
\text { (mean } \pm \text { SD) or } \\
\text { median (range) }\end{array}$ & $\begin{array}{l}\text { CHRONIC-ON } \\
\text { (mean } \pm \text { SD) or } \\
\text { median (range) }\end{array}$ & $P$ \\
\hline \multicolumn{4}{|l|}{ Beat-to-beat readings } \\
\hline Systolic blood pressure, mmHg & $169 \pm 20$ & $142 \pm 21$ & $<0.001$ \\
\hline Diastolic blood pressure, $\mathrm{mmHg}$ & $110 \pm 15$ & $91 \pm 17$ & $<0.001$ \\
\hline Mean arterial pressure, $\mathrm{mmHg}$ & $139 \pm 17$ & $108 \pm 18$ & $<0.001$ \\
\hline Heart rate, beats/min & $74 \pm 13$ & $69 \pm 15$ & 0.062 \\
\hline \multicolumn{4}{|l|}{ Renal hemodynamics } \\
\hline Glomerular filtration rate, $\mathrm{ml} / \mathrm{min}^{*} 1.73 \mathrm{~m}^{2}$ & $113 \pm 29$ & $115 \pm 25$ & 0.597 \\
\hline Effective renal plasma flow, $\mathrm{ml} / \mathrm{min}^{*} 1.73 \mathrm{~m}^{2}$ & $372 \pm 112$ & $348 \pm 91$ & 0.104 \\
\hline Effective renal blood flow, $\mathrm{ml} / \mathrm{min}^{*} 1.73 \mathrm{~m}^{2}$ & $646 \pm 182$ & $607 \pm 145$ & 0.176 \\
\hline Filtration fraction, $\%$ & $31 \pm 6$ & $34 \pm 7$ & 0.037 \\
\hline Renal vascular resistance, dynes* $\mathrm{sec}^{*} \mathrm{~cm}^{-5}$ & $16808 \pm 5357$ & $15069 \pm 4305$ & 0.123 \\
\hline \multicolumn{4}{|l|}{ Neurohormonal plasma concentrations } \\
\hline Active renin, $\mu \mathrm{U} / \mathrm{ml}$ & $7.2(2-18)$ & $6.2(1-20)$ & 0.225 \\
\hline Aldosteron, pmol/l & $8(0-28)$ & $12(2-31)$ & 0.116 \\
\hline Angiotensin II, pmol/I & $25(23-28)$ & $18(10-36)$ & 0.910 \\
\hline Norepinephrine, nmol/l & $1.2(0.8-1.6)$ & $1.4(0.9-3.0)$ & 0.463 \\
\hline Epinephrine, nmol/l & $0.2(0-0.6)$ & $0.1(0-0.4)$ & 0.248 \\
\hline \multicolumn{4}{|l|}{ Laboratory } \\
\hline Plasma sodium, mmol/l & $140 \pm 2$ & $140 \pm 3$ & 0.601 \\
\hline Plasma potassium, mmmol/l & $3.8 \pm 0.4$ & $4.1 \pm 0.8$ & 0.179 \\
\hline Plasma creatinine, $\mu \mathrm{mol} / \mathrm{l}$ & $90 \pm 13$ & $95 \pm 17$ & 0.109 \\
\hline Urine sodium extraction, $\mathrm{mmol} / 24 \mathrm{~h}$ & $184 \pm 55$ & $178 \pm 64$ & 0.744 \\
\hline Urine microalbuminuria, $\mathrm{mg} / 24 \mathrm{~h}$ & $19(4-514)$ & $24(0-180)$ & 0.307 \\
\hline
\end{tabular}

Figure 8.1 presents individual data points for the relative change in GFR, ERPF and FF in relation to the relative decrease in MAP. The left side of each panel presents the change at CHRONIC-ON compared with PRE (O). Both the relative change in GFR (Figure 8.1a) and that in ERPF (Figure 8.1b) showed a wide variation between PRE and CHRONIC-ON. The majority of participants showed an increase in FF (Figure 8.1c). Mean FF was significantly increased from 31 to $34 \%(P=0.037)$. RVR was not significantly decreased, but showed a decreasing trend from 16808 to 15069 dynes* $\sec ^{*} \mathrm{~cm}^{-5}(P=0.123 ;$ ) (Table 8.2).

\section{Neurohormonal profile and laboratory}

No significant changes in NE and APR were found at CHRONIC-ON compared with PRE (Table 8.2). Plasma aldosterone concentration showed a slight increase in most participants and median increased from 8 to $12 \mathrm{pmol} / \mathrm{I}(P=0.116)$. Plasma sodium and potassium were unchanged at CHRONIC-ON compared with PRE and plasma creatinine showed a slight increasing trend from 90 to $95 \mu \mathrm{mol} / \mathrm{I}(P=0.109)$. Mean urinary 24-hour sodium excretion and 24-hour urinary microalbuminuria excretion were unchanged. 
a

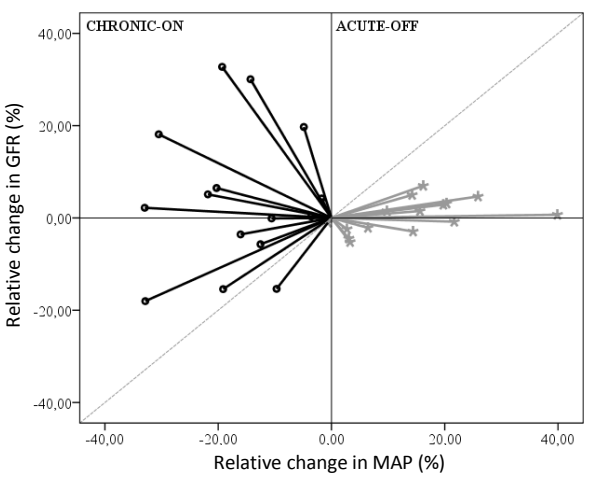

b

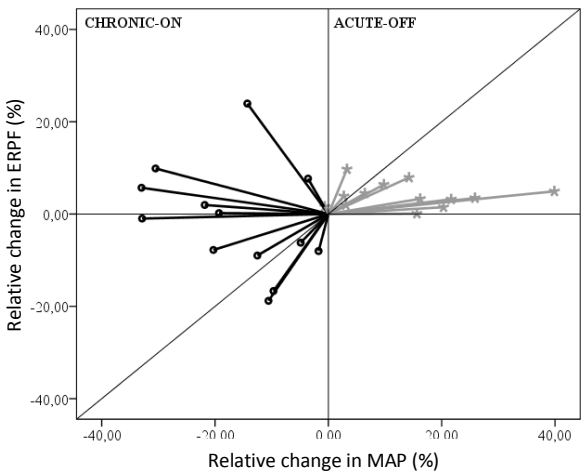

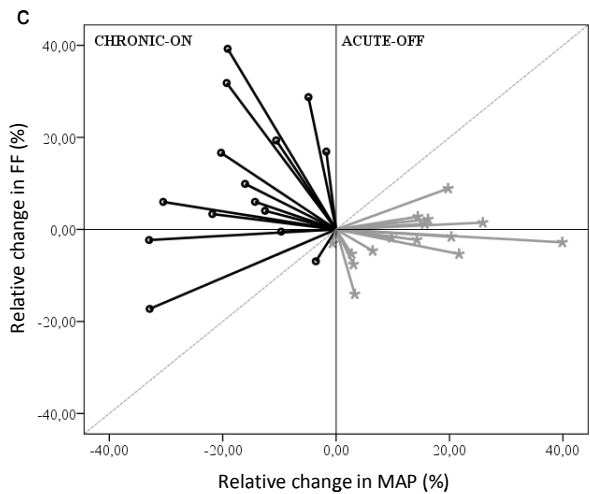

Figure 8.1 Relation between relative change in renal function and mean arterial pressure (MAP) (N=15). Left side of each panel presents the changes at CHRONIC-ON compared with PRE (o). Right side of each panel presents the changes at ACUTE-OFF compared with CHRONIC-ON (*).

Panel a presents glomerular filtration rate (GFR).

Panel b presents effective renal plasma flow (ERPF).

Panel c presents filtration fraction (FF).

\section{Temporary discontinuing of device therapy}

Figure 8.2 presents the mean level of SBP, DBP, ERPF, and RVR at PRE, CHRONIC-ON and ACUTE-OFF. At ACUTE-OFF both SBP and DBP were significantly increased compared with CHRONIC-ON ( $P<0.001$ and $P=0.001$, respectively) and both reached a level that was not statistically different from PRE ( $P=0.543$ and $P=0.813$, respectively) (Figure $8.2 \mathrm{a}$ and $8.2 \mathrm{~b}$ ). HR did not show a significant difference at ACUTE-OFF compared with CHRONIC-ON. GFR was unchanged at ACUTE-OFF compared with CHRONIC-ON, while ERPF was significantly increased ( $P=0.024)$ (Figure 8.2C). Also RVR was significantly increased at ACUTE-OFF compared with CHRONIC-ON $(P=0.007)$ and reached the level of PRE (Figure 8.2d). Neurohormones did not significantly change at ACUTE-OFF. 
In figure 8.1, the right side of each panel presents the individual data points for the relative change in renal hemodynamic parameters in relation to relative change in MAP at ACUTE-OFF compared with CHRONIC-ON (*). Despite the rapid increase in BP between time point CHRONIC-ON and ACUTE-OFF, the relative changes in GFR were only small (Figure 8.1a). All participants showed some increase in ERPF between those time points (Figure 8.1b) while FF showed a wide variation (Figure 8.1c).

a
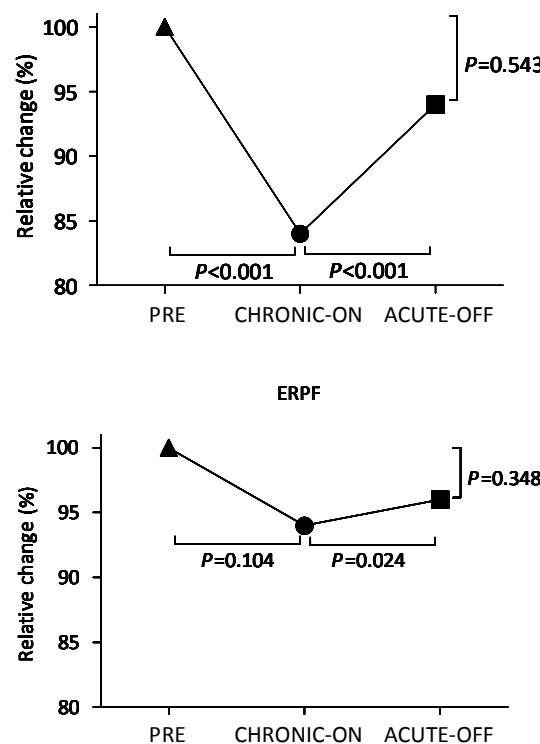

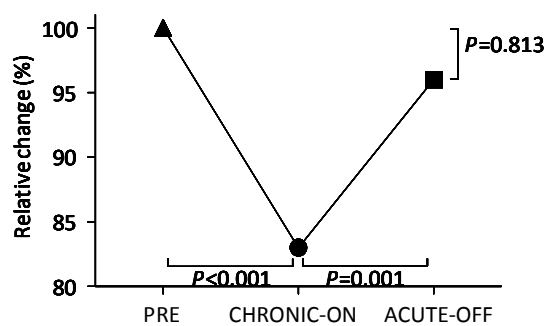

d

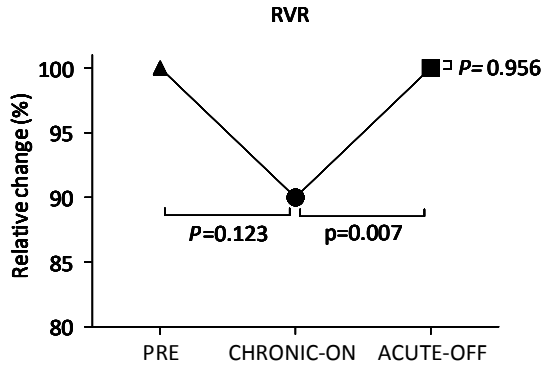

Figure 8.2 Results for temporary discontinuing device therapy ( $N=15)$.

Panel a presents systolic blood pressure (SBP), panel b presents diastolic blood pressure (DBP), panel c presents effective renal plasma flow (ERPF), and panel $d$ presents renal vascular resistance (RVR) at PRE-implant $(\boldsymbol{\Delta})$, CHRONIC-ON $(\bullet)$ and ACUTE-OFF ( $\bullet$ ). P-values by paired statistics were calculated by the difference between two time points.

\section{Discussion}

The present study shows that renal function during chronic electrical carotid baroreceptor stimulation in drug-resistant hypertensive subjects remains intact. GFR and ERPF are maintained despite a fall in RVR in most participants and neurohormonal profile is unchanged after one year of device therapy. Furthermore, our results suggest that the effect of chronic carotid baroreflex activation is a rapid reversible phenomenon, since BP and also RVR rise toward PRE-implant levels within 45 minutes after switching off the stimulation. 
Although effective antihypertensive treatment in itself may minimize deterioration of renal function, a drastic reduction of arterial pressure can result in decreased kidney perfusion and renal impairment. This has been shown before in humans during administration of direct vasodilator drugs such as hydralazine ${ }^{15}$. On the other hand, the central acting drug clonidine decreases BP without changes in ERBF or GFR ${ }^{16}$. Whereas, earlier work by Neistadt and Swartz suggested that the decrease in BP during carotid sinus nerve stimulation in dogs was accompanied by a fall in BP and $\mathrm{ERBF}^{4}$. The present data, however, show that sustained BP reduction using chronic baroreflex activation in human does not compromise renal blood flow. The implication of these observations is that systemic and renal vascular resistance must have fallen in parallel. It also suggest that autoregulatory responses within the kidney were not impaired.

While switching off the device for 45 minutes had no effect on the neurohormonal profile, it significantly increased RVR, probably as a result of enhanced adrenergic tone. Despite the rise in resistance, renal blood flow was not reduced but even rose significantly with variable effects on filtration. Taken together, our data is comparable with the view that the renal autoregulation curve had shifted to the left during one year of carotid baroreceptor stimulation. Consequently, after acutely switching off the stimulation, blood pressure may have risen above the breakthrough point. A similar shift of the autoregulation curve during a sustained fall in pressure has previously been described for the cerebral vasculature ${ }^{17}$. Despite the fall in blood pressure, the renin-angiotensin-system (RAS) was not activated, suggesting that under the conditions of our study beta-receptor mediated renin release was inhibited in a similar way as during treatment with clonidine. In addition we also showed that FF significantly increased after one year of carotid baroreceptor stimulation. This may suggest that chronic suppression of sympathetic activity directly or indirectly results in predominantly pre-glomerular vasodilatation and that a rise in post-glomerular resistance is necessary to maintain GFR. However, this may be expected to result in an increased glomerular pressure, while our data above show that microalbuminuria is not increased.

A limitation of this study is its small sample size and large interindividual variation in the measured variables among the participants. The design of the main study, DEBuT-HT, and the small number of participants included in this study gives no opportunity to increase the sample size. Furthermore, all participants were on full antihypertensive medication therapy during the entire follow-up period and therefore plasma levels of neurohormones were already low before device therapy. For this reason one may not expect major detectable changes in plasma concentrations. Another limitation is the lack of information on the initial effects of this therapy on renal hemodynamics and neurohormonal profile, since we only observed the stable situation after one year, while previous studies have shown significant changes in sodium balance during the first 24 hours of chronic sympathetic suppression ${ }^{18}$. 
In conclusion, chronic carotid baroreceptor stimulation significantly decreases arterial pressure while GFR and ERPF are maintained. Therefore, chronic electrical carotid baroreceptor stimulation using the Rheos ${ }^{\circledR}$ System may be a safe treatment option for resistant hypertension. More research is necessary, however, to ascertain if and how autoregulatory responses within the kidney will change over time. 


\section{References}

1 Zanchetti A, Stella A. Sympatho-renal interactions. Ital J Neurol Sci 1987;8:477-485.

2 DiBona GF. Physiology in perspective: The Wisdom of the Body. Neural control of the kidney. Am J Physiol Regul Integr Comp Physiol 2005;289:R633-641.

3 DiBona GF, Sawin LL. Effect of renal denervation on dynamic autoregulation of renal blood flow. Am J Physiol Renal Physiol 2004;286:F1209-1218.

4 Neistadt A, Schwartz SI. Effects of electrical stimulation of the carotid sinus nerve in reversal of experimentally induced hypertension. Surgery 1967;61:923-931.

5 Lohmeier TE, Irwin ED, Rossing MA, Serdar DJ, Kieval RS. Prolonged activation of the baroreflex produces sustained hypotension. Hypertension 2004;43:306-311.

6 Scheffers I, Schmidli J, Kroon A, Tordoir J, Mohaupt M, Allemann Y, Jordan J, Engeli S, Liebeskind U, Luft F, Eckert S, Hansky B, Baal T, P. dL. Sustained blood pressure reduction by Baroreflex Hypertension Therapy with a chronically implanted system: 3-year data from the Rheos DEBuT-HT study in patients with resistant hypertension. J Hypertens 2009;27(S1):S302.

7 Lohmeier TE, Hildebrandt DA, Warren S, May PJ, Cunningham JT. Recent insights into the interactions between the baroreflex and the kidneys in hypertension. Am J Physiol Regul Integr Comp Physiol 2005;288:R828-836.

8 Tordoir JH, Scheffers I, Schmidli J, Savolainen H, Liebeskind U, Hansky B, Herold U, Irwin E, Kroon AA, de Leeuw P, Peters TK, Kieval R, Cody R. An implantable carotid sinus baroreflex activating system: surgical technique and short-term outcome from a multi-center feasibility trial for the treatment of resistant hypertension. Eur J Vasc Endovasc Surg 2007;33:414-421.

9 Scheffers IJ, Kroon AA, Tordoir JH, de Leeuw PW. Rheos ${ }^{\circledR}$ Baroreflex Hypertension Therapy ${ }^{\top \mathrm{M}}$ System to treat resistant hypertension. Expert Rev Med Devices 2008;5:33-39.

10 Cole BR, Giangiacomo J, Ingelfinger JR, Robson AM. Measurement of renal function without urine collection. A critical evaluation of the constant-infusion technic for determination of inulin and paraaminohippurate. N Engl J Med 1972;287:1109-1114.

11 Simon D, Hartmann DJ, Badouaille G, Caillot G, Guyenne TT, Corvol P, Pau B, Marchand J. Two-site direct immunoassay specific for active renin. Clin Chem 1992;38:1959-1962.

12 Kubasik NP, Warren K, Sine HE. Evaluation of a new commercial radioassay kit for aldosterone using an iodinated tracer. Clin Biochem 1979;12:59-61.

13 Nussberger J, Brunner DB, Waeber B, Brunner HR. True versus immunoreactive angiotensin II in human plasma. Hypertension 1985;7:I1-7.

14 van der Hoorn FA, Boomsma F, Man in 't Veld AJ, Schalekamp MA. Determination of catecholamines in human plasma by high-performance liquid chromatography: comparison between a new method with fluorescence detection and an established method with electrochemical detection. J Chromatogr 1989;487:17-28.

15 Onesti G. Renal pharmacodynamics of antihypertensive drugs: clinical applications. Am J Cardiol 1966;17:668-672.

16 Onesti G, Schwartz AB, Kim KE, Paz-Martinez V, Swartz C. Antihypertensive effect of clonidine. Circ Res 1971;28(S2):53-69.

17 Paulson OB, Strandgaard S, Edvinsson L. Cerebral autoregulation. Cerebrovasc Brain Metab Rev 1990;2:161-192.

18 Lohmeier TE, Dwyer TM, Hildebrandt DA, Irwin ED, Rossing MA, Serdar DJ, Kieval RS. Influence of prolonged baroreflex activation on arterial pressure in angiotensin hypertension. Hypertension 2005;46:1194-1200. 


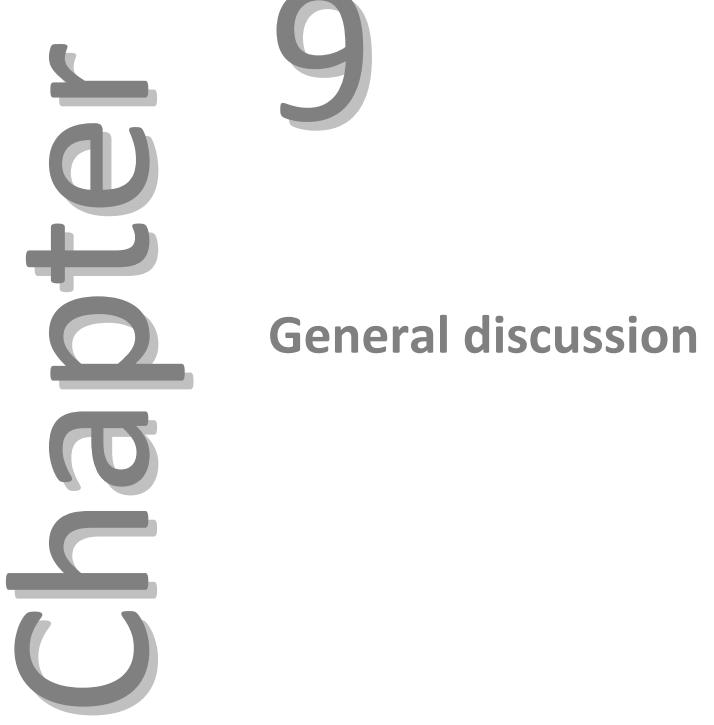





\section{Introduction}

Carotid baroreflex activation is a former concept, described and investigated 40 years ago (Chapter 2). Nowadays a renewed device with improved technology is available for investigational use (Chapter 3$)^{1}$. Surgical procedure and initial safety and efficacy data of this new Rheos ${ }^{\circledR}$ System (Chapter 4$)^{2}$ as well as long-term feasibility data (Chapter 5) are presented and published in the mean time. A randomized double-blind controlled multi-center trial is underway. This chapter discusses the results presented in this thesis together with the possible modes of action. For example, the mechanism behind the sustained blood pressure fall during chronic carotid baroreceptor stimulation is discussed. In addition, baroreceptor adaptation, resetting and sensitivity are considered in more detail in the context of data presented in this thesis and in the literature. Next, the expected functional and structural effects of this device therapy are debated. Furthermore, the feasibility data of the Rheos ${ }^{\circledR}$ System on safety and efficacy is discussed in more detail and possible device and therapy improvements are described. Finally, the clinical implications of chronic electrical carotid baroreflex activation are described.

\section{Sustained fall in blood pressure}

Chronic electrical stimulation of the carotid baroreceptors using the Rheos ${ }^{\circledR}$ System causes carotid baroreflex activation, expecting to result in suppression of sympathetic nerve outflow and a fall in blood pressure. There is an ongoing debate about the way sympathetic tone can influence long-term blood pressure regulation, but there is considerable evidence that the sympathetic nervous system plays an important role in the pathogenesis of hypertension ${ }^{4-7}$. In this same line, the exact mechanism responsible for the fall in blood pressure during chronic carotid baroreflex activation is not completely clear. Neural control of the circulation operates via parasympathetic neurons that innervate the heart and sympathetic efferents that innervate blood vessels, the heart, kidneys, and adrenal medulla ${ }^{8}$. The sympathetic efferents that innervate the kidneys are commonly presented as the only sympathetic efferents that are capable of influencing the 24-hour average blood pressure, although the rise in sympathetic activity is not restricted to the renal nerves in hypertensive humans, but is generalized ${ }^{8}$. Others are convinced that not only the renal sympathetic efferents, but many different neural and hormonal systems are involved in the long-term control of blood pressure ${ }^{9}$.

Measurement of plasma norepinephrine concentration in dogs ${ }^{10}$ and direct recording of muscle sympathetic nerve activity using microneurography in humans ${ }^{11}$ suggest that peripheral sympathetic activity is indeed decreased during therapy with the Rheos $^{\circledR}$ System. In addition, indirect measurement of sympathetic and vagal activity using power spectral analysis in the frequency domain (Chapter 6 and 7) suggested a 
decreased sympathetic activity and an increased vagal activity during chronic device therapy. Sympathetic inhibition is expected to cause peripheral vasodilatation and a decrease in heart rate and stroke volume. This has been confirmed in participants who were on chronic baroreceptor stimulation for one year, in which blood pressure reduction was accompanied by a decrease in total peripheral resistance and a slight decrease in heart rate and stroke volume (Chapter 7).

\section{Role of the kidneys}

It is doubtful whether the changes in peripheral resistance and stroke volume in itself are responsible for the fall in blood pressure during baroreflex activation. Increased urinary sodium excretion is expected in addition, since neurally induced changes in peripheral resistance and cardiac function are supposed not to alter arterial pressure chronically, unless they are associated with sustained changes in renal excretory function $^{12,13}$. Long-term regulation of blood pressure is closely linked to volume homeostasis through the renal body fluid feedback system ${ }^{14}$ based on the intrinsic ability of the kidneys to respond to alterations in pressure by altering the renal excretion of salt and water. This acute regulation of body fluid is influenced by baroreflex-mediated changes in renal sympathetic nerve activity ${ }^{14}$. Nonetheless, experiments with renal denervation in dogs showed that the presence of the renal nerves is not essential for achieving long-term reductions in arterial pressure during prolonged activation of the baroreflex ${ }^{15}$.

Animal experiments with prolonged baroreflex activation in both renal denervated ${ }^{15}$ and intact dogs ${ }^{16}$ showed a net retention, not loss, of sodium during the first 24 hours of baroreflex activation. The authors suggested that it was probably a result of the decreased peripheral resistance and the acute fall in blood pressure, and that apparently the hemodynamic response favouring sodium retention predominated over any natriuretic influence associated with suppression of renal sympathetic nerve activity. Therefore, they concluded, based on computer analysis, when baroreflex activation not increased renal excretory function there would have been a greater degree of sodium retention and only a transient reduction in blood pressure ${ }^{16}$. After the first 24 hours, urinary sodium excretion returned to baseline values while baroreflex activation was continued and, consequently, the sodium balance was maintained at reduced arterial pressure, indicating the sustained effect to enhance renal sodium excretory function. So far, this mechanism has not been investigated and confirmed in human.

Inhibition of the renal sympathetic activity could also reduce the activity of the reninangiotensin-system (RAS). However, it is not very likely that a decreased activity of the RAS added much to the fall in blood pressure during therapy with the Rheos ${ }^{\circledR}$ System, since this RAS in human was already down-regulated by prescribed antihypertensive medications. The already low plasma concentrations of neurohormones were not 
significantly changed after one year of device therapy (Chapter 8). In addition, experiments in instrumented dogs showed no significant change in active plasma renin concentration during sustained activation of the baroreflex ${ }^{16}$. Normally, a considerable decrease in blood pressure stimulates renin secretion. The absence of an increase in renin suggests that prolonged activation of the baroreflex exert an inhibitory effect on renin secretion ${ }^{10,16}$. This inhibitory effect may predominate over any RAS activation while blood pressure has fallen.

Altogether, it seems that the kidneys do not play a direct role in the fall of blood pressure during chronic electrical carotid baroreflex activation, since the presence of the renal nerves are not essential. Renal hemodynamics, sodium excretion, and renin release induced by changes in renal sympathetic nerve activity are therefore not expected to play an important role in blood pressure reduction. On the contrary, an important role for the kidneys is suggested for enabling the sustained effect on blood pressure. This is based on the observations of unchanged urinary sodium excretion after the first day of stimulation and the absence of increased renin concentration. Normally when blood pressure falls, renal excretory function is diminished and the RAS becomes activated to maintain the preset level of blood pressure. In case of chronic carotid baroreceptor stimulation, the activation of those mechanisms seems to be predominated by the effect of chronic baroreflex activation.

\section{Baroreceptor adaptation}

The fall in blood pressure during chronic carotid baroreceptor stimulation is maintained with unchanged magnitude of electrical impulses, as presented in Chapter 5. The fact that an increase in amplitude and/or frequency of the electrical pulses over time is not necessary to keep the blood pressure at the lower level suggests that baroreceptor adaptation may not occur. In addition, the dose response results presented in Chapter 4 shows that the effect on blood pressure during acute testing does not diminish over time. Especially during acute testing of high voltages (4-7 V), the fall in blood pressure before chronic carotid baroreceptor stimulation is comparable with the fall in blood pressure after three months of stimulation (Figure 4.2).

Normally, baroreceptor firing does not persist during sustained pressure changes. From literature it is known that baroreceptor firing decays progressively during maintained pressure elevations ${ }^{17}$. This phenomenon is known as adaptation and is thought to result from viscoelastic relaxation occurring within the wall of the arteries, which leads to progressive reduction of strain placed upon baroreceptors ${ }^{18}$. In case of a maintained pressure reduction, the phenomenon of adaptation may also occur. However, during carotid baroreceptor stimulation, baroreceptor firing is not induced by arterial wall stretch and baroreceptor strain, but it is induced by external electrical pulses onto the arterial wall. Since the electrical pulses activate the carotid baroreflex 
without expected changes in arterial wall stretch, it is not likely that baroreceptor adaptation may occur.

\section{Baroreceptor resetting}

Another phenomenon, extensively described in literature, is baroreceptor resetting. When pressure changes are maintained for longer periods, changes of baroreceptor responses are termed as resetting, but the precise time when adaptation becomes resetting is unclear. Baroreceptor resetting is presumably caused by mechanical changes within baroreceptive arteries ${ }^{18}$.

The present data shows no evidence for the occurrence of permanent baroreceptor resetting (Chapter 7). As shown in Figure 7.3, it seems that resetting has occurred during carotid baroreceptor stimulation, since the curve has shifted to the left. However, this shift is caused by the sustained fall in blood pressure, while there is no evidence that baroreceptor response has changed. In addition, we showed that blood pressure tends to rise toward pre-implant level when stimulation is discontinued, which also pleads against permanent baroreceptor resetting. As presented in Chapter 4, blood pressure does not immediately jump to pre-implant level, but is still decreased after a short period (in the majority of participants only five minutes) of discontinuing stimulation. After a longer period of 45 minutes of discontinuing stimulation, as presented in Chapter 7 and 8 , blood pressure has risen toward pre-implant level.

It seems that the continuous manner of electrical stimulation causes an uninterrupted activation of the carotid baroreflex which causes the fall in blood pressure. Whenever this continuous stimulation is stopped, the naturally present baroreflex may initially become activated attempting to prevent an increase in blood pressure, but finally the blood pressure will increase toward its original level.

\section{Baroreceptor sensitivity}

It may be questionable whether chronic carotid baroreceptor stimulation can impair baroreceptor sensitivity. Mechanisms responsible for impaired baroreflex control are not well understood, it may be due to abnormal baroreceptor transduction or disordered sympathetic outflow. In general, baroreflex control is impaired in hypertension and the degree of impairment seems proportional to the degree of blood pressure elevation ${ }^{18}$. In hypertensive subjects, the slope of the heart rate-blood pressure relation curve is not as steep as it is in normotensive ones. In practise, the same change in blood pressure results in a smaller change in heart rate, mediated by the baroreflex. 
Data presented in Chapter 7 show no evidence for decreased baroreceptor sensitivity during baroreflex activation therapy. The slope of the heart rate-blood pressure curve is unchanged (Figure 7.3), indicating that the relation between change in heart rate and change in blood pressure during head-up tilt is unchanged after one year of stimulation. The sequence method even showed a slight increase in sensitivity. Overall, baroreceptor sensitivity seems not impaired during carotid baroreceptor stimulation, but this does not automatically preclude any changes in carotid baroreceptor transduction, since a compensatory role by baroreceptors located elsewhere in the body is suggested.

\section{Functional and structural effects}

Changes in cardiovascular hemodynamics were studied during head-up tilt in 16 participants (Chapter 7). It showed that orthostatic hypotension did not occur during chronic carotid baroreceptor stimulation. The effects on renal hemodynamics were investigated in 15 participants (Chapter 8) and it presented an intact renal function during chronic stimulation. Both studies showed functional effects of chronic sympathetic suppression, but on the long-term also structural effects are to be expected.

Hypertension is associated with deterioration of target organ damage like urinary microalbuminuria excretion and left ventricular hypertrophy. From literature it is well-known that those adaptations are reversible and can be diminished when hypertension is successfully treated. Large randomized trials have shown significant changes already after one year of blood pressure control. First results on microalbuminuria measured in a small cohort of participants showed a slight but not significant reduction after one year of carotid baroreceptor stimulation (Chapter 8). A small cohort from the feasibility studies showed regression of left ventricular hypertrophy, and left ventricular mass index was decreased in 15/16 participants after one year of device therapy ${ }^{19}$. In addition, activation of the Rheos ${ }^{\circledR}$ System showed remodelling of the left atrium and ventricular chambers and improvement of systolic function after two years in 12 early-stage heart failure participants ${ }^{20}$. These findings merit larger controlled studies with long-term follow-up to assess the degree of improvement in target organ damage. Besides, the protective effects of left ventricular hypertrophy reduction and cardiac remodelling from the Rheos ${ }^{\circledR}$ System needs to be investigated. Further research on structural effects is emphasized. 


\section{Feasibility data}

Many procedure-related complications, like anesthesia-related sickness, pain, throat discomfort, skin numbness, and nerve injury have a temporary nature and have only mild to moderate effects on participants life. The more serious complications are infection, nerve damage, stroke, and angioneurotic edema. Decreasing surgical procedure time may reduce the rate of infection and also the rate of nerve damage often caused by post-operative swelling. But most of these serious complications may be directly related to the participants poor health condition, which makes the participants more vulnerable. Co-morbidities like hyperlipidemia, diabetes mellitus, heart failure, COPD, and renal deterioration, which are commonly seen in these patients decrease the likelihood of an event-free survival of this kind of surgical procedure. Therefore, the patients health condition and procedure-related risks should be taken into consideration before surgery.

The first efficacy results are promising, but it is important to keep in mind that these results are obtained in a feasibility study and the reproducibility of these findings need to be determined via a randomized controlled trial, which is currently underway.

\section{Suggestions of improvement}

Issues seen to date are typical of first clinical experience with active implantable medical device products and are naturally expected to resolve as surgical implant experience is gained and the technology evolves. The placement of the electrodes on the carotid sinus is an important part of the implant procedure and it mainly determines the procedure time. Furthermore, the accuracy of placement is the major factor that determines the effectiveness of this therapy. Placement is sometimes complicated by the carotid bifurcation anatomy that may influence lead usability on the artery. Improvement of the lead design and simplification of the lead handling and mapping procedure is desired to reduce the change of procedure-related complications. It may also diminish stimulation of extravascular tissue, which may be seen when high device settings are required to achieve the desired blood pressure reduction. The size of the implantable pulse generator could cause pain complaints and can sometimes limit arm movements. Besides, the current battery capacity is limited, especially when high device settings are required. Improvement of the implantable components, i.e. pulse generator and leads, will make the therapy more acceptable to a larger population.

For future implication, it is important to determine factors that may affect responsiveness and factors that may be responsible for no responsiveness to this therapy. Among the more common characteristics it may be worthwhile looking at the effects of Diabetes Mellitus, volume load, vessel condition, cardiac capacity, renal deterioration, and baroreflex function. Besides, the effects of chronic administration 
of different classes of antihypertensive agents in relation to device-responsiveness should be investigated. Recent data showed that prolonged baroreflex activation caused an additional decrease in arterial pressure during chronic adrenergic blockade ${ }^{3}$. Presumably, this device therapy can not substitute medication therapy in these patients, at least not completely, but it is important to determine which kind of agents co-operate and which kind of agents counteract this therapy with the Rheos ${ }^{\circledR}$ System.

\section{Clinical implication}

In the next years, experience with the Rheos ${ }^{\circledR}$ System to treat drug-resistant hypertensive patients will be increased and data will become available from the randomized controlled trial. This may lead to regulatory approval and market release of the Rheos ${ }^{\circledR}$ System in Europe and the USA. Patients with uncontrolled high blood pressure due to drug-resistance, but possibly also patients with uncontrolled high blood pressure due to drug-intolerability or unacceptable side-effects caused by drugs, may benefit from this therapy, resulting in a fall in blood pressure and a decrease in associated risks. Number of prescribed drugs, number of physician visits, amount of diagnostic testing and number and duration of hospitalizations may significantly decrease in this group of patients that are now exposed to high cardiovascular risks. Improvement of the device and increased experience with the Rheos ${ }^{\circledR}$ System will make the therapy acceptable to a larger population. 


\section{References}

1 Scheffers IJ, Kroon AA, Tordoir JH, de Leeuw PW. Rheos ${ }^{\circledR}$ Baroreflex Hypertension Therapy ${ }^{\mathrm{TM}}$ System to treat resistant hypertension. Expert Rev Med Devices 2008;5:33-39.

2 Tordoir JH, Scheffers I, Schmidli J, Savolainen H, Liebeskind U, Hansky B, Herold U, Irwin E, Kroon AA, de Leeuw P, Peters TK, Kieval R, Cody R. An implantable carotid sinus baroreflex activating system: surgical technique and short-term outcome from a multi-center feasibility trial for the treatment of resistant hypertension. Eur J Vasc Endovasc Surg 2007;33:414-421.

3 Lohmeier TE, Hildebrandt DA, Dwyer TM, Iliescu R, Irwin ED, Cates AW, Rossing MA. Prolonged activation of the baroreflex decreases arterial pressure even during chronic adrenergic blockade. Hypertension 2009;53:833-838.

4 Esler M, Kaye D. Sympathetic nervous system activation in essential hypertension, cardiac failure and psychosomatic heart disease. J Cardiovasc Pharmacol 2000;35(7 S4):S1-7.

5 Lohmeier TE. The sympathetic nervous system and long-term blood pressure regulation. Am J Hypertens 2001;14:147S-154S.

6 DiBona GF. The sympathetic nervous system and hypertension: recent developments. Hypertension 2004;43:147-150.

7 Barrett CJ, Ramchandra R, Guild SJ, Lala A, Budgett DM, Malpas SC. What sets the long-term level of renal sympathetic nerve activity: a role for angiotensin II and baroreflexes? Circ Res 2003;92: 1330-1336.

8 Guyenet PG. The sympathetic control of blood pressure. Nat Rev Neurosci 2006;7:335-346.

9 Thrasher TN. Arterial baroreceptor input contributes to long-term control of blood pressure. Curr Hypertens Rep 2006;8:249-254.

10 Lohmeier TE, Dwyer TM, Hildebrandt DA, Irwin ED, Rossing MA, Serdar DJ, Kieval RS. Influence of prolonged baroreflex activation on arterial pressure in angiotensin hypertension. Hypertension 2005;46:1194-1200.

11 Heusser K, Tank J, Diedrich A, Engeli S, Menne J, Eckert S, Sweep FC, Haller H, Luft FC, Jordan J. Electrical Carotid Sinus Stimulation reduces Sympathetic Activity and Blood Pressure in Patients with Refractory Hypertension. J Hypertens 2009;27(S4):S288.

12 Lohmeier TE. Interactions between angiotensin II and baroreflexes in long-term regulation of renal sympathetic nerve activity. Circ Res 2003;92:1282-1284.

13 Lohmeier TE, Hildebrandt DA, Warren S, May PJ, Cunningham JT. Recent insights into the interactions between the baroreflex and the kidneys in hypertension. Am J Physiol Regul Integr Comp Physiol 2005;288:R828-836.

14 Guyton AC, Coleman TG, Fourcade JC, Navar LG. Physiologic control of arterial pressure. Bull N Y Acad Med 1969;45:811-830.

15 Lohmeier TE, Hildebrandt DA, Dwyer TM, Barrett AM, Irwin ED, Rossing MA, Kieval RS. Renal denervation does not abolish sustained baroreflex-mediated reductions in arterial pressure. Hypertension 2007;49:373-379.

16 Lohmeier TE, Irwin ED, Rossing MA, Serdar DJ, Kieval RS. Prolonged activation of the baroreflex produces sustained hypotension. Hypertension 2004;43:306-311.

17 Landgren S. The baroreceptor activity in the carotid sinus nerve and the distensibility of the sinus wall. Acta Physiol Scand 1952;26:35-56.

18 Eckberg DL, Sleight P. Humans baroreflexes in health and disease. Oxford Medical Press, 1992.

19 Leeuw de P, Gangahar D, Bach D, Lovett E. Left ventricular reverse remodeling with chronic treatment of resistant hypertension using an implantable device: Results from European and United States trials of the Rheos Baroreflex Hypertension Therapy System. J Hypertens 2008;26(S1):S471.

20 Bisognano J, De Leeuw P, Bach D, Kaufman C, Lovette E. Improved cardiac structure and diastolic flow velocities in early-stage heart failure with chronic treatment using an implantable device: results from European and United States trials of the Rheos System. Journal of American College of Cardiology 2009;53:A188. 
Summary 



\section{Summary}

Drug-resistant hypertension is a major clinical problem. Definition and current therapeutic plan for hypertension, including lifestyle changes and pharmacological therapy, are described in Chapter 1 . Despite all the existing antihypertensive pharmacological agents, many patients show an insufficient response to treatment. In general practice, the incidence of resistant hypertension is $5 \%$. This high prevalence together with the associated high risks for cardiovascular events demand for a new and successful therapy.

In the past several attempts were made to investigate the value of electrical carotid baroreflex activation in the treatment of hypertension and also angina pectoris in both animals and humans. Chapter 2 gives an historical overview of all previous research in this area. In total, 64 cases of hypertension and 135 cases of angina pectoris were reported in the literature. Despite the positive and promising results, few questions remained unanswered: stimulation of the carotid nerve versus stimulation of the carotid artery, bilateral versus unilateral stimulation and open-loop versus closed-loop stimulation. Furthermore, the unknown long-term effects and the reported side effects were unresolved issues at that moment.

Chapter 3 profiles a novel device for carotid baroreflex activation with modern microelectronics and improved lead design that is under investigation for the treatment of drug-resistant hypertension. This implantable device (Rheos ${ }^{\circledR}$ Baroreflex Hypertension Therapy ${ }^{\mathrm{TM}}$ System; CVRx. Inc., Minneapolis, MN, USA) delivers electrical impulses to the baroreceptors in the wall of the carotid arteries in order to chronically activate the carotid baroreflex. As a result sympathetic outflow is reduced. It is expected that the introduction of this novel therapy may reduce the costs involved in treatment of drug-resistant hypertensive patients. When the device can effectively lower blood pressure, complications of uncontrolled hypertension may be avoided, and the need for more medical check-ups and diagnostic tests as well a the number of hospitalizations will probably decrease. Even the amount of prescribed antihypertensive drugs may fall. The results from feasibility studies and a randomized clinical trial may lead to further regulatory approvals and market release of the Rheos ${ }^{\circledR}$ System for the treatment of resistant hypertension.

The surgical technique and preliminary safety data from a cohort of 17 participants who underwent implantation of the Rheos ${ }^{\circledR}$ System in the European feasibility study are described in Chapter 4. For successful device implant, participant preparation and anaesthetic regimen are important factors. Agents which blunt the baroreflex should be avoided. After exposure of the carotid arteries, the baroreceptors are localized using the hemodynamic response to brief intraoperative electrical stimulation. Several locations on the carotid arteries are tested to assure that the position producing an optimal blood pressure decrease is properly identified. Then the electrodes are placed around the carotid sinus and the leads of the electrodes are tunnelled subcutaneously and connected to the pulse generator, which is placed on the breast. The implant 
procedure can be performed with reasonable safety, although a number of serious procedure-related complications were reported in a minority of participants. Among those, wound complication, infection, and tissue and nerve injury were reported in a single case.

In Chapter $\mathbf{5}$ the complete results from the European feasibility study on safety and efficacy of the Rheos ${ }^{\circledast}$ System are presented after three months of carotid baroreceptor stimulation. In addition, data from a cohort of 17 subjects who completed two years of chronic carotid baroreflex activation therapy is described. Implantation of the Rheos ${ }^{\circledR}$ System is feasible and the device is acceptable to the participants. The majority of related events were directly related to the incision or to the anesthetic procedure, but over $80 \%$ of subjects remained free from any procedure- or device-related serious adverse event. No orthostatic hypotension as measured by postural-related blood pressure readings, no renal function loss as measured by serum creatinine and no carotid artery stenosis as measured by ultrasound were seen after three and/ or 12 months of device therapy. Participants ability to perform exercise as measured by 6-minute hall walk test was increased after one year of device therapy. In addition, both sitting office and 24-hour ambulatory blood pressure measurement showed a clinically and statistically significant reduction in blood pressure that could be sustained for at least two years.

Analysis of 24-hour ECG registration after three months of chronic therapy with the Rheos ${ }^{\circledast}$ System in 21 subjects is presented in Chapter 6 . Together with office blood pressure and heart rate, also heart rate variability frequency-domain parameters assessed using fast Fourier transformation were significantly changed during stimulation of the carotid baroreceptor. The spectral power of the high frequency component was increased and the spectral power of the low frequency component was decreased. Furthermore, heart rate turbulence onset was significantly decreased. Those changes correlated with blood pressure reduction and are consistent with inhibition of sympathetic activity and increase of parasympathetic activity.

Chapter 7 presents beat-to-beat blood pressure and heart rate data at supine rest and during head-up tilt in 16 subjects that were on continuous therapy with the Rheos ${ }^{\circledR}$ System for one year. Variability in those parameters was analysed using power spectral analysis to estimate sympathetic and vagal activity. In supine rest, blood pressure was significantly reduced accompanied by a highly significant decrease in sympathetic activity compared with pre-implant. Vagal activity showed a slight increase. The suppressed sympathetic activity during carotid baroreceptor stimulation did not lead to orthostatic hypotension as measured during head-up tilt. Baroreceptor sensitivity as measured by the sequence method and by the ratio of change in heart rate and change in mean arterial pressure was not impaired, and even showed a slight increase. Temporary discontinuing carotid baroreceptor stimulation showed no evidence for permanent resetting of the baroreflex during continuous stimulation, since blood pressure increased toward the hypertensive level within 45 minutes. 
The effects of one year carotid baroreflex activation on renal hemodynamics in 15 participants is presented in Chapter 8. We measured glomerular filtration rate and effective renal plasma flow using the continuous infusion method with inulin and para-aminohippurate. The sustained reduction in blood pressure after one year of chronic carotid baroreceptor stimulation did not compromise effective renal plasma flow. Glomerular filtration rate was unchanged and no changes in neurohormonal profile were measured after one year. Temporary discontinuing device therapy caused a significant increase in blood pressure toward the pre-implant level accompanied by an increase in effective renal plasma flow, but glomerular filtration rate was again unchanged. This data shows neither evidence for impairment of renal function nor activation of the renin-angiotensin-system during chronic electrical carotid baroreceptor stimulation. Therefore, the Rheos ${ }^{\circledR}$ System is a treatment option for drug-resistant hypertension that may be expected to be safe for the kidneys.

Chapter 9 discusses the main findings presented in this thesis. Among other topics, we discuss the possible role of the kidney on the sustained decrease in blood pressure during chronic carotid baroreflex activation. It seems that the kidneys do not play a direct role in the fall of blood pressure, but that they do play an important role for enabling the sustained effect on blood pressure. 

Samenvatting 



\section{Samenvatting}

De definitie en huidige therapeutische aanpak voor hypertensie bevat leefstijlveranderingen en farmacologische therapie, zoals beschreven in Hoofdstuk 1. Ondanks verschillende soorten antihypertensieve geneesmiddelen tonen veel patiënten onvoldoende effect op behandeling. Daarmee is therapieresistente hypertensie een enorm klinisch probleem met een incidentie van $5 \%$. Over het algemeen is de incidentie van resistente hypertensie $5 \%$. Vanwege een hoge prevalentie en het geassocieerde hoge risico op cardiovasculaire aandoeningen is een succesvolle therapie gewenst.

In het verleden zijn enkele pogingen gedaan om de waarde van het elektrisch activeren van de carotis baroreflex te onderzoeken in de behandeling van hypertensie en ook angina pectoris, in zowel dieren alsook in mensen. Hoofdstuk 2 geeft een historisch overzicht van deze onderzoeken. In de literatuur zijn experimenten gerapporteerd met in totaal 64 patiënten met hypertensie en 135 patiënten met angina pectoris. Ondanks de positieve en veelbelovende resultaten bleven de volgende vragen onbeantwoord: elektrische stimulatie van de carotis arterie of de zenuw, stimulatie aan één of twee zijden en wel of geen gesloten feedback systeem. Daarnaast bleven de lange termijn effecten onbekend en er waren geen oplossingen beschikbaar voor de gerapporteerde bijwerkingen.

Hoofdstuk 3 beschrijft een nieuw apparaat voor het activeren van de carotis baroreflex met moderne micro-elektronica en een verbeterd design van de elektroden. De waarde van dit apparaat voor de behandeling van therapieresistente hypertensie wordt momenteel onderzocht in klinisch onderzoek. Het apparaat (Rheos ${ }^{\circledR}$ Baroreflex Hypertension Therapy ${ }^{\mathrm{TM}}$ System; CVRx. Inc., Minneapolis, MN, VS) levert elektrische impulsen af aan baroreceptoren in de wand van de arteriae carotis met als doel het chronisch activeren van de carotis baroreflex. Het gevolg is een daling van de sympathische activiteit met als resultaat een verlaging van de bloeddruk. De verwachting is dat het gebruik van deze nieuwe therapie de kosten voor de behandeling van resistente hypertensie zal verlagen. Wanneer de therapie effectief bloeddruk kan verlagen in deze patiëntengroep, dan kunnen complicaties van ongecontroleerde hypertensie voorkomen worden. Daarnaast zal het aantal medische controles, diagnostische tests, ziekenhuisopnamen en misschien zelfs het aantal voorgeschreven antihypertensieve middelen kunnen verminderen. De resultaten van twee uitvoerbaarheidonderzoeken en een gerandomiseerd klinisch onderzoek naar veiligheid en effectiviteit kunnen ertoe leiden dat het Rheos ${ }^{\circledR}$ Systeem wordt toegelaten tot de markt voor de behandeling van therapieresistente hypertensie.

De chirurgische techniek en eerste resultaten over veiligheid en effectiviteit van het Rheos ${ }^{\circledR}$ Systeem zijn beschreven in Hoofdstuk 4. Het betreft preliminaire resultaten in een cohort van 17 deelnemers uit het Europese uitvoerbaarheidonderzoek. Voor succesvolle implantatie is voorbereiding van de patiënt en de anesthesietechniek van groot belang. Middelen die de baroreflex stilleggen mogen niet gebruikt worden. $\mathrm{Na}$ 
het blootleggen van de arteriae carotis worden de baroreceptoren gelokaliseerd met behulp van kortdurende elektrische stimulatie op de carotis. Op verschillende plaatsen op de carotis wordt het hemodynamische effect op deze stimulatie gemeten, om zodoende de plaats die de grootste bloeddrukdaling bewerkstelligt te lokaliseren. Daarna wordt de elektrode op deze plaats rondom de carotis geplaatst en de draad van de elektrode wordt onder de huid door getrokken richting de pulsgenerator, die subcutaan op de borst wordt geplaatst. Deze implantatie kan met redelijke veiligheid worden uitgevoerd en de serieuze proceduregerelateerde complicaties, zoals wondcomplicatie, infectie, weefsel- en zenuwbeschadiging zijn slechts in een enkele deelnemer gerapporteerd.

In Hoofdstuk 5 wordt het resultaat van de Europese haalbaarheidsstudie na drie maanden van therapie met het Rheos ${ }^{\circledast}$ Systeem gepresenteerd. Daarnaast wordt data getoond van een cohort van 17 deelnemers die twee jaar therapie reeds voltooid hebben. Implantatie van het Rheos $^{\circledR}$ Systeem is haalbaar en het apparaat wordt geaccepteerd door de deelnemers. Een meerderheid van de gerelateerde bijwerkingen zijn direct gerelateerd aan de incisie of aan de anesthesie, en in $80 \%$ van de deelnemers werd geen gerelateerde bijwerking gerapporteerd. Na drie en/of 12 maanden van therapie werd geen orthostatische hypotensie waargenomen als gemeten met houdingsgerelateerde bloeddrukmetingen, er was geen sprake van nierfunctie verlies als gemeten met serum creatinine en er werd geen stenose in de arteriae carotis gezien met ultrageluidsgolven. De mogelijkheid tot inspanning werd gemeten met een 6-minuten looptest en was verbeterd na 12 maanden van therapie. Zowel zittende spreekkamermeting als 24-uurs ambulante meting van de bloeddruk toonden een klinisch en statistisch significante daling na drie maanden, die ten minste twee jaar gehandhaafd bleef.

Analyse van 24-uurs ECG registratie na drie maanden van chronische therapie met het Rheos $^{\circledast}$ Systeem in 21 deelnemers is gepresenteerd in Hoofdstuk 6. Naast spreekkamerbloeddruk toonde ook de variabiliteit in hartfrequentie, gemeten met fast Fourier transformatie een significante verandering tijdens elektrische stimulatie van de carotis baroreceptoren. De spectrale power van de hoogfrequentie component was toegenomen en de spectrale power van de laagfrequente component was afgenomen. Daarnaast was 'hartfrequentie turbulence onset' significant afgenomen. Deze veranderingen correleren met afname in bloeddruk en zijn consistent met remming van sympathische activiteit en toename van parasympathische activiteit.

Hoofdstuk 7 presenteert data van beat-to-beat bloeddruk en hartfrequentie in liggende positie en tijdens head-up tilt in 16 deelnemers die gedurende een jaar therapie ontvingen met het Rheos ${ }^{\circledR}$ Systeem. De variabiliteit in deze parameters is geanalyseerd met power spectraal analyse om de sympathische en vagale activiteit te schatten. Na een jaar was zowel bloeddruk alsook sympathische activiteit significant gedaald in liggende rust. Vagale activiteit toonde een kleine toename. De onderdrukte sympathische activiteit tijdens carotis baroreceptor stimulatie veroorzaakte geen orthostatische hypotensie gedurende head-up tilt metingen. Baroreceptor gevoelig- 
heid was niet verminderd, maar zelfs een beetje toegenomen, zoals gemeten met de sequentie analyse alsook met de ratio van de verandering in hartfrequentie en bloeddruk tijdens head-up tilt. Het tijdelijk stoppen van de stimulatie toonde geen bewijs voor permanente resetting van de baroreflex, omdat de bloeddruk binnen 45 minuten steeg naar het niveau van voor de implantatie.

De effecten op nier hemodynamica na een jaar van carotis baroreceptor stimulatie zijn gepresenteerd in Hoofdstuk 8. In 15 deelnemers hebben we glomerulaire filtratie rate (GFR) en effectieve renale plasma flow (ERPF) gemeten met behulp van continue infusie van inulin en para-aminohippurate. De aanhoudende daling in bloeddruk na een jaar van carotis baroreceptor stimulatie leidde niet tot een daling in ERPF. GFR was onveranderd en er werden geen veranderingen in het neurohormonale profiel gemeten na een jaar. Het tijdelijk stoppen van de stimulatie veroorzaakte een significante stijging in de bloeddruk samen met een toename in ERPF, maar GFR bleef onveranderd. Deze data toont geen bewijs voor verminderde nierfunctie of het activeren van het renin-angiotensine-systeem tijdens chronische carotis baroreceptor stimulatie. Daarom lijkt het Rheos ${ }^{\circledR}$ Systeem een behandeloptie voor therapieresistent hypertensie die veilig is voor de nieren.

Hoofdstuk 9 bediscussieert de belangrijkste bevindingen van dit proefschrift. Naast andere onderwerpen wordt de rol van de nieren op de blijvende bloeddrukdaling tijdens carotis baroreceptor stimulatie besproken. Het lijkt alsof de nieren geen directe rol spelen bij het verlagen van de bloeddruk, maar dat ze wel een belangrijke rol spelen bij de instandhouding van de bloeddrukverlaging. 
Dankwoord 



\section{Dankwoord}

De weg naar dit proefschrift was een lange reis. Gelukkig heb ik me vooraf niet kunnen realiseren in welke mate en grootte de bijkomende uitdagingen zouden zijn, want dan was ik misschien nooit aan deze reis begonnen, maar terugkijkend op de afgelegde weg ben ik zeer blij met de rijke ervaring. Zoals tijdens elke denkbare reis, zijn er altijd een heleboel mensen die je pad kruisen. Aan mij nu de taak om al deze mensen te noemen en te bedanken.

Ten eerste alle patiënten, zonder jullie deelname was dit proefschrift er nooit geweest. Jullie trouwe inzet is mijn drijfveer geweest. Zeer dankbaar voor de prettige samenwerking moet ik toegeven dat ik jullie wel een beetje mis. Ik wens jullie allen het allerallerbeste.

Mijn promotor prof. dr. P.W. de Leeuw. Beste Peter, ik werkte nog maar enkele maanden bij jouw onderzoeksgroep toen je me uitnodigde voor een Investigator Meeting in Parijs. Ik had destijds niet kunnen vermoeden wat de gevolgen van mijn bevestigend antwoord zouden zijn. Ik ben je ontzettend dankbaar dat je me de kans en het vertrouwen hebt gegeven om dit mooie project op te starten en te coördineren en dat je me daarnaast de mogelijkheid hebt gegeven om eigen onderzoek uit te voeren, waardoor uiteindelijk dit proefschrift is ontstaan.

Mijn copromotor dr. A.A. Kroon. Beste Bram, talloze patiëntenbesprekingen op jouw kamer en talloze patiëntenvisites op het lab. Vanaf het allereerste begin kon ik een beroep op je doen, vaak ook op de meest ongunstige momenten. Ik heb veel respect voor je en ben ervan overtuigd dat de patiënten het getroffen hebben met jou als dokter. Jouw bijdrage aan de totstandkoming van dit proefschrift is groot en daarvoor mijn hartelijke dank.

Mijn copromotor dr. J.H.M. Tordoir. Beste Jan, de deskundigheid en zeker ook het geduld waarmee jij de implantatie procedures heb uitgevoerd zijn bewonderenswaardig en hebben zeker bijgedragen aan de goede resultaten. Ik heb de samenwerking als zeer prettig ervaren en ben blij met jou als mijn copromotor.

Leden van de beoordelingscommissie, prof. dr. H.J. Crijns, prof. dr. R.S. Reneman en prof. dr. H.A. Struiker-Boudier, hartelijk dank voor het beoordelen van dit proefschrift. Members of the judging committee, prof. dr. J. Schmidli and prof. dr. P. Sleight, many thanks for judging this thesis.

Beste Tiny, bedankt voor alle hulp bij de lay-out van dit proefschrift. Beste Ron, hartelijk dank voor je grafische talenten bij het vormgeven van de omslag. 
Medewerkers van de centrale operatie afdeling, medewerkers van de afdeling anesthesie en medewerkers van het chirurgisch dagcentrum, hartelijk dank voor de vakkundige hulp en het geduld tijdens de implantatie procedures.

Erik, Evelien en Koen, hartelijk dank voor de prettige samenwerking, hopelijk vloeien er nog mooie resultaten uit voort en veel succes met het voortzetten van jullie wetenschappelijk carrière.

CVRx, thanks for the faith in me and for all the opportunities you have offered me, I have really appreciated the collaboration. Lisa and Myriah, thank you very much for answering all my e-mails. Chris, Peter, Ralf, Thomas, Tim and Tom, thanks for the numerous visits to Maastricht and for the assistance during many procedures.

Collega's en oud-collega's, Adriana, Amy, Barry, Boy, Claudia, Claudia, Danielle, Dorien, Ellen, Esther, Guy, Heidi, Jolanda, Kaz, Kim, Léon, Margriet, Marian, Marieke, Monique, Paula, Peggy, Rianne, Roger, Sander, Stella, Thomas en Willem. Ergens op de weg naar dit proefschrift hebben jullie een rol gespeeld, hiervoor mijn hartelijke dank. Tevens bedankt voor alle gezellige momenten: verjaardagen, (kerst)diners, (nieuwjaars)borrels en natuurlijk het beroemde jaarlijkse labuitje. Uiteraard ook dank voor alle hulp op de momenten dat ik met drie dingen tegelijkertijd bezig moest zijn. Kaz, bedankt voor je tomeloze inzet. Amy, Barry en Rianne, collega-promovendi en ook Marcella, ik wens jullie veel succes met het voortzetten en/of afronden van jullie promotiewerk.

Natuurlijk is er één collega die absoluut extra aandacht verdient in dit dankwoord. Vanaf het moment dat mijn werkplek verplaatst werd naar dezelfde ruimte als jouw werkplek, hebben we het goed met elkaar kunnen vinden. De melige vrijdagmiddag momenten dreigden steeds eerder in de week te beginnen. Maar ook de momenten dat het huilen ons nader stond dan het lachen hebben we samen gedeeld. Jij bent in alle opzichten een grote steun voor me geweest, nu ook weer als mijn paranimf, maar helemaal toen het afronden van mijn promotie door omstandigheden verder voor me uit werd geschoven. Heidi, jouw inzet en kundigheid zijn veel waard en ik hoop dat jij je nog lange tijd met veel plezier blijft inzetten voor dit werk. Ik weet zeker dat de studies en bovenal de patiënten bij jou, en ook bij Ellen, in goede handen zijn.

Flausmause, beste carnavalsvrienden, jullie hebben geen idee wat jullie voor me betekend hebben: het naaien van carnavalskostuums en het beplakken en schilderen van carnavalswagens, het was een welkome afleiding tijdens de drukte van promoveren. We hebben vorig jaar een fantastisch seizoen gehad, eindelijk die 'stinkvis' gewonnen en nu een mooi jubileumjaar. Ik hoop dat we samen nog veel plezier mogen beleven tijdens en buiten het carnavalsseizoen. Dames, bedankt voor de gezelligheid tijdens de naaiavonden en bedankt voor de mooie gesprekken met immer 
boeiende onderwerpen die met deze avonden gepaard gingen. Speciaal aan Anne, Eefje, Sabine en ook Danielle, bedankt voor alle leuke momenten, ook buiten de carnaval. Stappen, concerten bezoeken en niet te vergeten kamperen, daar moeten we vooral mee doorgaan.

Ellen, Sabine en Sindy, lieve meiden, met z'n vieren zijn we compleet, vier totaal verschillende karakters, dé vier elementen. Sindy, altijd heb je interesse getoond in mijn onbegrijpelijk werk. Sabine, ik voel me rijk dat mijn zus tot één van mijn beste vriendinnen mag behoren. Ellen, altijd sta je voor me klaar, nu ook weer als mijn paranimf, jij bent goud waard. Ik hoop van harte dat we samen nog heel veel leuke dingen mogen beleven.

Sander, grote kleine broer, bedankt voor alles en vooral voor het jezelf zijn. Met jouw nuchtere opmerkingen word ik telkens weer met beide voeten op de grond gezet. Samen met Josje en natuurlijk ook de rest van het gezin beleven we vele mooie momenten. Ik hoop dat we nog lang met z'n allen mogen blijven genieten.

Pap en Mam, mijn grote voorbeelden. Ik mag oprecht zeggen dat ik het getroffen heb met jullie als ouders. Het is veel waard om te weten dat er altijd een vertrouwde plek is waar je terecht kunt. Bedankt voor alles, ik hou ook van jullie.

Lieve Patrick, mijn vaste rots in de branding. Het was niet altijd gemakkelijk om in ons drukke leven tijd te vinden voor elkaar. Maar ook dit proefschrift hebben we overleefd, samen kunnen we de hele wereld aan. 
Curriculum vitae 



\section{Curriculum vitae}

Ingrid Scheffers werd geboren op 2 september 1981 in Budel, waar ze ook haar jeugd doormaakte. In 1999 behaalde ze het VWO diploma aan het Bisschoppelijk College in Weert. Aansluitend startte ze met de studie Gezondheidswetenschappen aan de Universiteit Maastricht, ze koos voor de studierichting Bewegingswetenschappen. Een gedeelte van het onderwijs volgde ze aan de Vrije Universiteit van Amsterdam. In 2003 behaalde ze het doctoraalexamen. Datzelfde jaar begon ze als onderzoeker bij de afdeling Interne Geneeskunde van de Universiteit Maastricht, waar ze later coördinator werd van de Device Based Therapy in Hypertension (DEBuT) studie en de Rheos Pivotal Trial. Daarnaast startte ze een promotietraject via het Cardiovascular Research Institute Maastricht (CARIM) onder leiding van prof. dr. P.W. de Leeuw en dr. A.A. Kroon, in samenwerking met dr. J.H.M. Tordoir van de afdeling Heelkunde. 
